\title{
THE IMPACT OF INTERGENERATIONAL TRANSMISSION OF \\ TRAUMA FROM THE HOLODOMOR GENOCIDE OF 1932-1933 \\ IN UKRAINE
}

by

Brent Bezo

\begin{abstract}
A thesis submitted to
the Faculty of Graduate and Postdoctoral Affairs

in partial fulfillment of the requirements for the degree of

Master of Arts

in

Psychology
\end{abstract}

Carleton University

Ottawa, Canada

(C)2011 Brent Bezo 
Library and Archives

Canada

Published Heritage

Branch

395 Wellington Street Ottawa ON K1A ON4 Canada
Bibliotheque et

Archives Canada

Direction du

Patrimoine de l'édition

395 , rue Wellington

Ottawa ON K1A ON4

Canada
Your file Votre référence

ISBN: 978-0-494-83148-9

Our file Notre référence

ISBN: 978-0-494-83148-9
NOTICE:

The author has granted a nonexclusive license allowing Library and Archives Canada to reproduce, publish, archive, preserve, conserve, communicate to the public by telecommunication or on the Internet, loan, distribute and sell theses worldwide, for commercial or noncommercial purposes, in microform, paper, electronic and/or any other formats.

The author retains copyright ownership and moral rights in this thesis. Neither the thesis nor substantial extracts from it may be printed or otherwise reproduced without the author's permission.

\begin{abstract}
AVIS:
L'auteur a accordé une licence non exclusive permettant à la Bibliothèque et Archives Canada de reproduire, publier, archiver, sauvegarder, conserver, transmettre au public par télécommunication ou par l'Internet, prêter, distribuer et vendre des thèses partout dans le monde, à des fins commerciales ou autres, sur support microforme, papier, électronique et/ou autres formats.
\end{abstract}

L'auteur conserve la propriété du droit d'auteur et des droits moraux qui protège cette thèse. $\mathrm{Ni}$ la thèse ni des extraits substantiels de celle-ci ne doivent être imprimés ou autrement reproduits sans son autorisation.
In compliance with the Canadian Privacy Act some supporting forms may have been removed from this thesis.

While these forms may be included in the document page count, their removal does not represent any loss of content from the thesis.
Conformément à la loi canadienne sur la protection de la vie privée, quelques formulaires secondaires ont été enlevés de cette thèse.

Bien que ces formulaires aient inclus dans la pagination, il n'y aura aucun contenu manquant. 


\begin{abstract}
Qualitative methodology was utilized to explore the perceptions and experiences of the Holodomor Genocide and its intergenerational impact on three generations in 15 Ukrainian families. Each family included a genocide survivor, an adult child, and adult grandchild of the same family line. Based on the thematic analysis of 45 semi-structured interviews, conducted in Ukraine, three super-ordinate themes were identified:

(i) emotions, behaviours and mental well-being; (ii) loss; and (iii) family functioning. Within the three super-ordinate themes, all generations spoke of the impact. Therefore, the data suggest that the impact of intergenerational trauma, stemming from the Holodomor Genocide of 1932-1933, still exerts substantial effects on adult children and grandchildren of survivors. The findings further suggest that intergenerational trauma is transmitted through the family and through the environment, external to the family unit.
\end{abstract}




\section{Acknowledgements}

To my thesis advisor, Dr. Stefania Maggi, thank you for agreeing to take on this research project. Your patient guidance, advice and your knowledge of qualitative methodology proved indispensable. It was a real honour to have worked with you.

To my committee member, Dr. Connie Kristiansen, thank you for your guidance regarding the qualitative method. Your advice strengthened my data collection and data analysis processes.

To my committee member, Dr. Frank Elgar, thank you for your advice on application of theory to the findings of this study.

To my committee member, Dr. Pauline Rankin, thank you for bringing an interdisciplinary perspective to the final defence.

To Larissa, my wife, no words can describe your support during the entire process - THANK YOU. 
$\begin{array}{lll}\text { ABSTRACT } & \text { ii }\end{array}$

ACKNOWLEDGEMENTS

LIST OF TABLES $\quad$ ix

LIST OF APPENDICES $\quad \mathrm{x}$

INTRODUCTION

INTERGENERATIONAL TRANSMISSION OF TRAUMA 4

HOLOCAUST SURVIVOR FAMILIES

SURVIVOR FAMILIES OF THE ARMENIAN

GENOCIDE AND MASSACRES OF ARMENIANS 8

CHILDREN OF JAPANESE-AMERICAN WWII INTERNEES 9

CHILDREN OF WAR VETERANS 11

MODELS, THEORIES AND MECHANISMS OF TRAUMA

$\begin{array}{ll}\text { TRANSMISSION } & 13\end{array}$

COGNITIVE SOCIAL LEARNING THEORY 13

THE ECOLOGY OF HUMAN DEVELOPMENT 14

SECONDARY TRAUMATIZATION 15

$\begin{array}{ll}\text { ATTACHMENT THEORY } & 17\end{array}$

SHATTERED ASSUMPTIONS COGNITIVE THEORY 17

$\begin{array}{ll}\text { SUMMARY OF INTRODUCTION } & 18\end{array}$

HISTORICAL BACKGROUND: THE HOLODOMOR (UKRAINIAN

$\begin{array}{ll}\text { FAMINE-GENOCIDE OF 1932-1933) } & 18\end{array}$

$\begin{array}{ll}\text { METHOD } & 24\end{array}$ 
$\begin{array}{ll}\text { PARTICIPANTS } & 25\end{array}$

$\begin{array}{ll}\text { PROCEDURE } & 27\end{array}$

$\begin{array}{ll}\text { THE INTERVIEW GUIDE } & 27\end{array}$

$\begin{array}{ll}\text { THE INTERVIEWS } & 27\end{array}$

DATA ANALYSIS

EVALUATING THE RESEARCH 34

$\begin{array}{ll}\text { CREDIBILITY } & 34\end{array}$

$\begin{array}{ll}\text { TRIANGULATION } & 37\end{array}$

QUALITATIVE AND QUANTITATIVE

METHODS TRIANGULATION 38

QUALITATIVE DATA SOURCES

TRIANGULATION 38

MULTIPLE INTERVIEWER/ANALYST

$\begin{array}{ll}\text { TRIANGULATION } & 38\end{array}$

DEPENDABILITY 39

$\begin{array}{ll}\text { TRANSFERABILITY } & 39\end{array}$

$\begin{array}{ll}\text { CONFIRMABILITY } & 40\end{array}$

$\begin{array}{ll}\text { RESULTS } & 42\end{array}$

EMOTIONS, BEHAVIOURS AND MENTAL WELL-BEING 42

$\begin{array}{ll}\text { EMOTIONS } & 42\end{array}$

$\begin{array}{ll}\text { FEAR } & 43\end{array}$

$\begin{array}{ll}\text { HORROR } & 48\end{array}$

$\begin{array}{ll}\text { SADNESS } & 50\end{array}$ 
INDIFFERENCE TOWARD OTHERS

SHAME

ANGER

BEHAVIOURS

STOCKPILING OF FOOD

INABILITY TO DISCARD

EXTREME REVERENCE FOR FOOD

OVEREATING AND EMPHASIS ON FOOD:

THE CULT OF FOOD

LIVING IN SURVIVAL MODE

MENTAL WELL-BEING

STRESS, ANXIETY AND SELF-ESTEEM

HOSTILITY

ALCOHOL, AIDS AND DRUGS

LOSS

LOSS OF MASS OF UKRAINIANS

LOSS OF FAMILY MEMBERS

LOSS OF TRADITIONAL WAY OF LIFE

LOSS OF UKRAINIAN CULTURE AND ETHNIC IDENTITY 89

LOSS OF MEN

FAMILY RELATIONS

TWO FAMILY TYPES: ADJUSTED AND MALADJUSTED 
FIXATION OF SECOND GENERATION ON

THEIR SURVIVOR PARENTS

INTERGENERATIONAL PATTERNS OF COMMUNICATION 108 OPEN COMMUNICATION BETWEEN

ALL GENERATIONS

GRANDPARENT AS THE CONVEYOR

OF INFORMATION

LIMITED OR NO DISCUSSION

IMPORTANCE OF FAMILY DISCUSSIONS

EXTRA-FAMILIAL DISCUSSION

IN-DEPTH DISCUSSION

LIMITED DISCUSSION

NO DISCUSSION

DISCUSSION

THEORIES, MODELS AND MECHANISMS

COGNITIVE SOCIAL LEARNING THEORY

ECOLOGICAL SYSTEMS THEORY OF THE FAMILY

SECONDARY TRAUMATIZATION

ATTACHMENT THEORY

SHATTERED ASSUMPTIONS COGNITIVE THEORY

EMOTIONS

LIMITATIONS 
CONCLUSIONS

REFERENCES 


\section{List of Tables}

Table 1: Summary of Reported Emotions for Families 1-10

Table 2: Summary of Reported Emotions for Families 10-15

Table 3: Summary of Reported Behaviours and Mental-Well Being for Families 1-10

Table 4: Summary of Reported Behaviours and Mental-Well Being for Families 11-15

Table 5: Summary of Reported Behaviours and Mental-Well Being for Families 1-10, continued

Table 6: Summary of Reported Behaviours and Mental-Well Being for Families 11-15, continued

Table 7: Summary of Reported Loss for Families 1-10

Table 8: Summary of Reported Loss for Families 11-15

Table 9: Summary of Reported Family Relations for Families 1-10

Table 10: Summary of Reported Family Relations for Families 11-15

Table 11: Summary of Reported Intra-Familial Communication Strategies for Families 1-10

Table 12: Summary of Reported Intra-Familial Communication Strategies for Families 11-15

Table 13: Summary of Reported Extra-Familial Communication Strategies for Families 1-10

Table 14: Summary of Reported Extra-Familial Communication Strategies for Families 11-15 


\section{List of Appendices}

Appendix: The Interview Guide 


\section{Introduction}

Current international data suggest that Ukraine is comparable to, or even surpasses, many of its neighbouring nations in terms of overall development. For example, regarding level of democratization, Ukraine is ranked fourth out of the 15 former Soviet Union nations (Freedom House, 2011). Prior to the onset of the world economic crisis of 2008 , the United Nations ranked Ukraine 85 th out of 182 nations, in terms of overall economy and equality. This ranking placed Ukraine on the cusp between "high human development" and "medium human development" (United Nations, 2009a, p. 196). Ukraine's gross domestic product grew 600 per cent between 2000 and 2008 . During this time, Ukraine held one of Europe's and one of the world's fastest growing economies (Nation Master, 2010; World Bank, 2009). Of 159 states and territories, Ukraine is ranked $58^{\text {th }}$ as having obtainable access to information and communications technologies (International Telecommunication Union, 2010). In addition, Ukraine has the fourth highest adult (ages 15 and up) literacy rate in the world (United Nations, 2009a), where literacy is defined as possessing the ability to both read and write a short, simple statement on her/his everyday life (UNESCO, 2008).

Despite these positive indicators of development, Ukraine is ranked first out of 41 (mostly Northern Hemisphere) nations for the highest percentage of 11-year olds, 13-year olds and 15-year olds who drink alcohol at least once a week. Ukraine tied for second (with Latvia, Wales and Russia) for 11-year old boys who had been intoxicated from alcohol at least twice. Ukraine also ranked first for the percentage of 11-year old boys who smoke at least once a week, and second for 13-year old and 15-year old boys who smoke at least once a week. Ukraine tied for second place (with Romania) for the 
percentage of 15-year old boys who had been involved in a physical fight at least three times in the last year (World Health Organization, 2008). Ukraine also has the lowest life expectancy in Europe. The average life expectancy in Ukraine is 61.9 years for males and 73.8 years for females (World Health Organization, 2009) whereas the European average is 73.3 years for males and 79.7 years for females (Population Reference Bureau, 2007). Ukraine also has one of the fastest declining populations (International Centre for Policy Studies, 2008), mainly due to the world's second lowest birth rate out of 230 countries in the years 2000-2005 (United Nations, 2009b). Further, the United Nations projects that Ukraine will experience the third highest decrease in population for the years $2007-2050$ (United Nations, 2007). Finally, with regards to perceptions and views, Ukrainian citizens consistently rank themselves as having one of the lowest levels of lifesatisfaction as compared with ninety-four other nations (Veenhoven, 2009).

An incongruence seems to exist between Ukraine's developmental trends and Ukrainians' perceptions and health behaviours. The literature supports the notion that similar perceptions and views, combined with risky health behaviours are often seen in survivors and descendent populations of survivors of genocide and other mass, collective trauma (Kupelian, 1993; Nagata, 1993; Rowland-Klein, \& Dunlop, 1997). For example, Canadian Aboriginals - who have experienced a long legacy of collective trauma, are often associated with higher rates of alcohol use (Health Canada, 2003). The death rate due to alcohol use in Canada's Aboriginal populations is twice as high as the general population (National Native Addictions Partnership Foundation, 2000). The life expectancy for Canada's Aboriginals is approximately 68.9 years for males and 76.6 years for females; in contrast, the Canadian population's life expectancies are higher at 
76.3 years and 81.8 years, respectively (Indian and Northern Affairs Canada, 2001). Furthermore, Nagata (1993) found that male Japanese-American civilians interned in American WWII (second world war) camps were twice as likely to die before the age of 60 and Israel (with a large population of Holocaust survivors and descendents) tied (with Bulgaria) for the highest percentage of 11-year old boys who were intoxicated from alcohol at least twice; Israel also was ranked second for the percentage of 11-year old boys who had consumed alcohol at least once a week (World Health Organization, 2008).

It is interesting to note that the Ukrainian people also suffered from a genocide in 1932-1933 (Conquest, 1986; Reid, 1999). Despite Ukraine's optimistic developmental trends, Ukrainians continue to exhibit health trends and perceptions that appear to be consistent with other descendents of survivors of historic, mass, collective trauma such as the Armenian Genocide (Kupelian, 1993), the internment of Japanese-Americans (Nagata, 1993), the Jewish Holocaust (Rowland-Klein, \& Dunlop, 1997) and the Canadian Aboriginal experience (Health Canada, 2003). Therefore, the question arises as to whether the impacts of the 1932-1933 genocide of Ukrainians, known as the Holodomor, may be responsible or at least partly responsible for Ukrainians' behaviours/perceptions and underperformance in health outcomes. In this context, the Holodomor may continue to have substantial social and psychological effects on the offspring and families of Ukrainian survivors comparable to that documented on descendents of genocide survivors and other mass, collective trauma - in terms of negative views of self and ethnic identity (Major, 1996; Nagata, 1993), pervasive feelings of mistrust, fear (Major, 1996), shame (Nagata, 1993), and risky health behaviours (World Health Organization, 2008). 
Because research on intergenerational trauma is relatively scarce in the literature and because no research from a social sciences perspective exists on the 1932-1933 genocide in Ukraine, exploratory research on this topic is proposed. To this end, a thematic analysis approach (Braun \& Clarke, 2006) will explore how Ukrainians perceive the Holodomor, and its potential impact on their own lives. In turn, the findings may inform as to the potential intergenerational transmission of trauma in Ukraine.

Precedence for this study (and the approach to this study) exists in that research has been conducted on descendents of survivors of the Jewish Holocaust, the Armenian Genocide of 1915, the World War II internment of Japanese-Americans, and on families with war veteran fathers. To this respect, this research will also contribute to the knowledge of impact of collective trauma - in the Ukrainian context.

\section{Intergenerational Transmission of Trauma}

Intergenerational transmission of trauma was first noted in 1966, when clinicians in Canada observed high numbers of children of Holocaust survivors, born after World War II (WWII), seeking treatment (Rakoff, Sigal, \& Epstein, 1966; Trossman, 1968). Their survivor parents were reported to exhibit impaired childrearing practices (Rosenberger, 1973; Russell, 1974) and separation-individuation problems that resulted in behavioural disturbances in their children (Barocas \& Barocas, 1980; de Graaf, 1975; Freyberg, 1980). In the 1980 's, research suggested that intrafamilial patterns of communication within survivor families affected the psychological well-being of the second generation (Krell, 1984; Steinberg, 1989). Adult children of World War II Holocaust survivors were also reported to display psychopathological symptomatology (Bar-On, 1989; Barocas \& Barocas, 1973; Bergman \& Jucovy, 1982; Epstein, 1979). In 
addition, clinical observations at this time associated families with Vietnam veteran fathers with difficult parent-child relationships. Specifically, when veteran fathers experienced difficulty in forming trusting relationships and held negative self-images, increased intra-familial violence and severe difficulty in forming father-child bonds were noted in their families (Haley, 1985).

Pertaining to Holocaust survivor families, Solkoff (1992) noted that much of the data pointing to psychopathological effects in the second generation were based on clinical and anecdotal findings. He, therefore, cautioned against overgeneralization from clinical studies and limited cases to non-clinical children of survivor families. Solkoff also pointed out potential methodological limitations in Holocaust survivor family research, such as no separate gender analyses, questionable validity of psychological instruments and biased sampling recruitment procedures. Solkoff's criticism of trauma transmission research methodology in Holocaust survivor families seemed to have affected subsequent research in the field, as subsequent studies with improved methodologies began to appear in the literature, thereafter.

In the 1990 's, a greater exploration of the long-term effects of collective trauma in survivor families of genocides and mass traumas, from a global perspective, appeared in the literature - and this trend continues into the present. However, even though publications in the field increased, this thesis emphasizes that: (1) studies examining the impact of trauma into the second generation are scarce, and (2) research on the third generation is even more scarce. Therefore, this thesis will contribute to a better understanding of the perceptions of the Holodomor and its potential impact. To date, the literature has focused on survivor families of the Holocaust (Sigal \& Weinfeld, 1989) and 
the Armenian Genocide (Kalayjian \& Weisberg, 2002). Additionally, offspring of WWII interned Japanese-Americans (Nagata, 1993) and war veterans (Rosenheck and Nathan, 1985) have also been studied. Although no specific studies have been conducted, the literature acknowledges that higher rates of alcoholism (Gagne, 1998), identity problems, social unrest, and even violence (Simpson, 1998) may be manifestations of trauma transmission in African-Americans (Cross, 1998) and in survivor families of: ethnic conflicts in Nigeria (Odejide, Sanda, \& Odejide, 1998); dictatorships in Argentina (Edelman, Kordon, \& Lagos, 1998) and Chile (Becker \& Diaz, 1998); wars in the Balkans (Klain, 1992); and apartheid in South Africa (Simpson, 1998). However, no qualitative or quantitative studies have been attempted to confirm these observations in any of these latter groups.

For this thesis, I have designated the term survivor family to refer to a single family line comprised of a trauma survivor and one of their adult children for the two generational studies - and a single family line comprised of a trauma survivor and one of their adult children and adult grandchildren for the three generational studies. In this context, I have borrowed the term "survivor" from the literature (Major, 1996, p, 358), to refer to the senior family member who remained alive after the collective trauma, such as genocide, internment, or war.

As previously mentioned, the intergenerational transmission of trauma literature has focused on Holocaust and Armenian Genocide survivor families, and offspring of WWII interned Japanese-Americans and war veterans. As such, these four latter groups will form the basis of the following review. 
Holocaust survivor families. With regard to family functioning in Holocaust survivor families, Lev-Wiesel (2007) noted strong family ties in descendents of Holocaust survivors. Further, Ganz (2002) found higher levels of parent-child enmeshment in American children and grandchildren of survivors. Rowland-Klein and Dunlop (1997) reported an over-protective parenting style, while Wiseman, Metzl and Barber (2006) noted that a "mutual overprotection" (p. 182) existed between survivor parents and children. American descendents of Holocaust survivors were twice as likely to report difficulties in their parents' childhoods (Ganz, 2002), while Australian children (Rowland-Klein and Dunlop, 1997) reported a heightened awareness of parents' Holocaust survivor status and over-identification with parents' experiences. Major (1996) found that Norwegian children of the survivors evaluated their fathers as being more introverted and their childhood home life to be less harmonious.

Major (1996) also found increased school-related behavioural problems in children of survivors and sub-clinical levels of depression and anxiety, while children and grandchildren (Rowland-Klein \& Dunlop, 1997) of Holocaust survivors tended to have a general fear and mistrust of other people and expressed a sense of loss of family and roots. In addition, offspring were less likely to endorse a Jewish identity, altogether (Major, 1996). In general, survivors' children (Ganz, 2002; Major, 1996) and grandchildren (Ganz, 2002) were more likely to seek psychological or psychiatric treatment. Third generation descendents of survivors also scored significantly higher in state and trait anger - and in state and trait irritability; they also perceived others to be more angry and irritable (Iliceto, Candilera, Funaro, Pompilo, \& Kaplan, 2011). 
Wiseman et al. (2006) found a lack of open communication regarding parental traumatic pasts, in the homes of survivors. Further, in comparing Holocaust survivor families (parents and offspring) with histories of imprisonment in concentration camps versus active resistance (ex-partisans) in WWII, Kav-Venaki, Nadler and Gershoni (1983) found different transgenerational patterns of communication between the two family types. Ex-partisan parents and their adult children reported significantly more direct communication on Holocaust-related themes compared to former camp internees and their children. Children of partisans knew significantly more about their parents' biographical information, as it pertained to the Holocaust, and about the Holocaust, in general. Major (1996) also found significantly less family discussion about the Holocaust in survivor families, and this in turn, was related to evaluations of less family harmony, more introverted mothers and more pessimistic fathers - in both groups.

Kav-Venaki et al. (1983) found that ex-partisans' children exhibited more positive attitudes toward Holocaust survivors. For example, ex-partisans' offspring were significantly more likely to agree with statements like "the Jews of the Holocaust were heroes" (p. 55). In contrast, offspring of ex-camp internees were significantly more likely to agree with statements like "the Jews were blind to reality" (p. 55).

\section{Survivor families of the Armenian Genocide and massacres of Armenians.}

Similar to Holocaust survivor families (Lev-Wiesel, 2007), Kalayjian, Shahinian, Gergerian and Saraydarian (1996) and Kassabian's (1998) findings suggested that high levels of family adhesion and adaptability - even after three generations of Armenian survivor families in America - are still in existence. Further, these family patterns are congruent with historical descriptions of Armenian families' coping strategies that 
developed over five centuries of Turkish oppression that culminated in a genocide of Armenians by Turks in 1915 - where one to one and a half million Armenians perished (Kalayjian \& Weisberg, 2002). As such, Armenian families tended to "close up" (p. 200) during and "open up" (p. 200) after a period of danger - followed by adaptation and the search for opportunities. Kassabian (1998) noted that Armenian ethnic identity has been transmitted intergenerationally based on old familial patterns developed under Turkish oppression, even after the collective trauma has long since passed and no imminent danger has presented itself for several decades.

Most Armenian survivors expressed anger and rage when asked about continued Turkish denial of the genocide (Kalayjian et al., 1996). However, unlike their parents and grandparents, the third generation also expressed their desire for redress from the Turkish government and exhibited greater participation in Armenian political organizations, as opposed to American organizations (Kassabian, 1998). In one study, the American-born third generation of survivors of $19^{\text {th }}$ century massacres of Armenians also exhibited more somatic complaints and more pathology than the American-born second generation on the Brief Symptom Inventory (BSI) (Kupelian, 1993).

Also similar to Holocaust survivor families (Kav-Venaki et al., 1983; Major, 1996; Wiseman et al., 2006), Kalayjian et al. (1996) found that Armenian participants had seldom spoken about their experiences; those who spoke about their experiences only did so with others of Armenian descent.

\section{Children of Japanese-American second world war internees. Former}

Japanese-American internees also exhibited the same reluctance to speak about their experiences (Nagata, 1993) as evidenced by Holocaust (Kav-Venaki et al., 1983; Major, 
1996; Wiseman et al., 2006) and Armenian Genocide survivor families (Kalayjian et al., 1996). More specifically, Japanese-American survey participants noted that fathers displayed greater reluctance to speak about their internee experiences and that twice as many formerly interned fathers died before the age of 60 as compared to non-interned fathers. The second generation, when interviewed, speculated that the camp internment trauma physiologically affected their fathers' health (Nagata, 1993). The research of Pennebaker, Barger and Tiebout (1989) supports their belief, in that, an unwillingness to openly speak about large-scale past trauma may lead to impaired physical health.

One 2003 study (Nagata, 2003) on former Japanese-American internees and their offspring found more open communication surrounding the trauma as compared to previous research conducted in 1993 (Nagata, 1993). The increased communication was attributed to implementation of redress during the years (i.e., 1993-2003) between the studies. As such, Nagata (2003) suggested that redress by the American government may have created an increased willingness in former internees to engage in discussion with their offspring. In the 2003 study, two-thirds of parents responded that internment had been a "central topic" (p. 274) of discussion with their children. In contrast, only onethird of offspring had reported that internment was a "central topic" (p. 274) of family discussion in 1993. This discrepancy may have reflected what the parents intended to communicate as opposed to what they actually did relate to their children. Even though an increase in intergenerational communication was seen in the second study, the conversations were of short duration, usually 15 minutes or less. Lengthy discussion still remained rare and mirrored earlier studies of transgenerational trauma communication in Japanese-American families with a history of WWII internment (Nagata, 1990; Nagata, 
1993; Nagata, Trierweiler, \& Talbot, 1999) and survivor families of genocide (Auerhahn \& Laub, 1998; Felsen, 1998; Kalayjian et al., 1996; Solomon, 1988).

Nagata (1993) reported that WWII internment of 110,000 Japanese-Americans facilitated a degeneration of Japanese cultural identity, since second generation participants perceived their survivor parents as having actively discouraged Japanese language and culture - in order to appear less ethnically Japanese. For some participants, this resulted in a sense of shame and inferiority regarding their Japanese heritage. Children of two formerly interned parents expressed a stronger desire to maintain interpersonal associations only with other Japanese-Americans. Many participants felt a strong parental pressure for high achievement or to achieve a higher education, based on the notion that others may take away their freedom, but not their ideas. In addition, children of former internees rated themselves as less confident in their civil rights. Overall, the second generation also wondered how their lives would have been different had the internment camps not existed.

Children of war veterans. Research has shown that children of war veteran fathers exhibited poor school performance, poor social adjustment (Harkness, 1993) and increased behavioural problems (Jordan et al., 1992; Rosenheck \& Fontana, 1998). Rosenheck and Fontana (1998) found twice as many behavioural problems in children of Vietnam veteran fathers who had participated in abusive violence (in combat) as compared to children whose veteran fathers had experienced high levels of war stress, but did not utilize abusive violence (i.e., killing a civilian or child). Moreover, the behavioural differences were seen in the veterans' children $15-20$ years after the fathers' experience with trauma. Further, previous parental mental illness, previous 
parental substance abuse, recent parental violence, current social support, the number of close friends, the father's own experience with child abuse (in his own childhood), family income, current marital status, veteran Post Traumatic Stress Disorder (PTSD) symptoms, or exposure to combat did not appear to be related to their children's behavioural problems.

Jordan et al. (1992) also found more behavioural problems in children; however, they found an association between offspring behavioural problems and PTSD in war veteran fathers. Specifically, 35\% of children with PTSD fathers yielded scores in the clinical range for behavioural problems. In contrast, 14\% of children with non-PTSD fathers yielded behavioural problem scores in the clinical range. Davidson and Mellor (2001) also found an association between PTSD in war veteran fathers and effects on offspring. Australian children of fathers with PTSD rated their families as dysfunctional. Children of non-PTSD fathers rated their families as borderline dysfunctional. Children in the matched control group rated their families as functional. Jordan et al. (1992) also found that fathers with PTSD were four times more likely to commit domestic violent acts, or threaten violence, while their spouses/partners were three times as likely to commit domestic violent acts, or threaten violence - as compared to families in which PTSD was not prevalent in the father.

Some research has reported that offspring of veteran fathers with PTSD displayed higher rates of aggression and anxiety than their peers with non-veteran fathers (Ahmadzadeh \& Malekian, 2004; Dansby \& Marinelli, 1999). However, these latter findings have not been replicated, as studies by Davidson and Mellor (2001) and Westerink and Giarratano (1999) reported no differences from controls. In addition, no 
association seems to exist between fathers' and children's self-esteem, or paternal PTSD symptomatology (Davidson \& Mellor, 2001).

In addition to describing the transgenerational effects of historical traumas such as the Jewish Holocaust, the Armenian Genocide, internment and war combat, the literature also provides models that may be applied to explain the transmission of trauma.

\section{Models, Theories and Mechanisms of Trauma Transmission}

Although the purpose of this study was not to test models or theories of transgenerational trauma transmission, the results may lend themselves to interpretation by existing models and theories. Further, the models and theories presented below were not necessarily developed to explain intergenerational trauma transmission.

Cognitive social learning theory. Bandura's (2000) social-cognitive theory of learning may be applied with its inter-related environment and cognition affecting learning and development. Potentially, survivors of mass collective trauma cognitively assess their environment of atrocity, in order to develop new strategies, thought processes and behaviours necessary for survival. Should these newly acquired thought processes and behaviours persist after the trauma, combined with the strength of reinforcement of these behaviours and perceived necessity of learning them, children of survivors may learn these behavioural strategies from their family units and from the outside world. Social-cognitive theory might help to explain, for example, the decreased likelihood in adult offspring of genocide survivors to endorse their ethnic identity. Hypothetically, their survivor parents may have incorporated the hiding of ethnic identity as a protective mechanism during a genocidal period and may have continued to hide or not endorse ethnic identity after the trauma due to shame. And although no longer serving any 
protective strategy for offspring, children of survivors may learn to not endorse or even be ashamed of their ethnic identity - as learned from their parents and social environment. In fact, evidence suggests that non-willingness to endorse ethnic identity (Major, 1996) and shame (Harkness, 1993; Kalayjian et al., 1996; Kupelian, 1993; LevWiesel, 2007; Major, 1996; Nagata, 1993; Rowland-Klein \& Dunlop, 1997) are, indeed, intergenerationally transmitted into children of survivor parents of collective trauma. Likewise, social-cognitive theory may help to explain research that suggests fear and mistrust are learned intergenerationally (Rowland-Klein \& Dunlop, 1997) and stem from the original impact of the genocidal trauma.

The ecology of human development. Bronfenbrenner $(1979,1986,1995)$ proposed that the developing child is set in five systems, operating in states of flux, that include: (i) the microsystem of the immediate family, daycare, school, etc.; (ii) the mesosytem that connects the various microsystem elements and allows for the elements to influence each other; (iii) the exosystem of secondary influences, such as parents' friends, media, extended family, etc.; (iv) the macrosystem or overall culture in which the micro, meso and exosystems are embedded; and (v) the ever-changing dimension (over time) of the chronosystem that houses all of the other systems. In Bronfenbrenner's model $(1979,1986,1995)$, children and parents influence each other, while at the same time parent-child relationships are influenced by other individuals, institutions, and community, which in turn are influenced by the culture to which they belong. Further, all systems are prone to influences and changes overtime, as dictated by the chronosystem.

Application of Bronfenbrenner's $(1979,1986,1995)$ chronosystem dimension may help explain how trauma is transmitted, intergenerationally. Mass, collective trauma 
affecting the temporal, dynamic chronosystem subsequently impacts and potentially changes elements in the micro, meso and macrosystems. Specifically, events of genocide (or any sudden changes in the chronosystem) may directly impact all other systems, including the family and more broadly, society. During a collective trauma, a critical mass of individuals may be influenced to adopt new survival strategies and behaviours, which in turn affects societal changes. In addition, changes in societal structures and community may act to reinforce the newly developed coping strategies and behaviours of the individual. In this context, newly developed coping strategies and behaviours (from the impact of trauma) may be incorporated into parent-child relationships and further, may be transmitted intergenerationally as learned behaviours. The prospect of transmission will be greater when reinforced by society. Lastly, depending on the severity of the traumatic impact, changes in society may be incorporated into the culture, which in turn might reinforce the impact and its implications on the individual and society.

Secondary traumatization. The literature supports the notion of secondary traumatization as being a real phenomenom. Secondary traumatization first appeared in the literature as "compassion fatigue" (Elwood, Mott, Lohr, \& Galovski, 2011, p. 26) or "vicarious trauma" (Vrklevski \& Franklin, 2008, p. 106) as trauma that was transferred to clinicians and other professionals as a result of having worked with survivors of trauma (McCann \& Pearlman, 1990; Salston \& Figley, 2003). Disclosure of traumatic experiences is the proposed mechanism for transmission of secondary trauma transmission from the client to treatment provider (Elwood et al., 2011) and may result in the development of PTSD-like symptoms (Figley, 1995) similar to those of the actual trauma survivors (Motta, Kefer, Hertz, \& Hafeez, 1999), including intrusive thoughts, 
avoidance behaviours, and arousal (Figley, 1995). Symptoms may also include job burnout (Birck, 2001; Kadambi \& Truscott, 2003; Killian, 2008) and newly acquired negative beliefs regarding personal safety, independence, esteem and intimacy (Pearlman \& Saakvitne, 1995). As such, clinicians who provide trauma-based counselling and treatment may be particularly vulnerable to secondary traumatization (Figley, 1995; Pearlman \& Saakvitne, 1995). Subsequent research suggested that secondary traumatization may also be prevalent in other helping "professional groups" (Vrklevski \& Franklin, 2008, p. 107) like social workers (Cornille \& Meyers, 1999).

Although to date, the vast majority of the literature has focused on professional relationships (Feldman \& Kaal, 2007), secondary traumatization (via exposure to details of experienced trauma) may also affect friends, family members and caregivers who play a significant role in the life of the trauma victim (Figley, 1995). For example, in the offspring of veterans, scores of standard measures of the after-effects of trauma (depression, PTSD-like symptomatology, state and trait anxiety) were often elevated, but still within normal limits (Suozzia \& Motta, 2004).

Despite the literature suggesting the existence of secondary trauma, the phenomenon has never received a universal definition (Suozzia \& Motta, 2004) because of low observed scores on standard measurements of traumatic expression (Carmel \& Friedlander, 2009; Levin \& Greisberg, 2003; McCann \& Pearlman, 1990; Vrklevski \& Franklin, 2008). Hence, the lack of sensitivity of measuring instruments (Suozzia \& Motta, 2004) and restrictive psychiatric classification systems (Karenian et al., 2010) in the American Psychiatric Association's (1994) fourth edition of the Diagnostics and 
Statistics Manual of Mental Disorders (DSM-IV) have both been cited for the lack of development of an accepted definition of secondary traumatization.

Attachment Theory. Bar-On et al. (1998) proposed attachment theory as a model for intergenerational transmission when genocide survivors are unwilling to talk about their traumatic experiences with offspring. When explicit reasons or overt causes for parental distress are unknown, children may develop disorganized attachment patterns. Further, when children view their parents as a source of fear and a source of safety, they use neither a consistent insecure or secure attachment strategy. Hence, unresolved parental loss or trauma is often associated with disorganized attachment in their children. The underlying mechanism in this association may be the frightened parent and/or frightening parental behaviours that the child cannot understand or interpret.

Shattered assumptions cognitive theory. Janoff-Bulman (1989) posited that the psychological impact of trauma in adults, with secure parent-child attachments (stemming from childhood), "shatters" (p. 51) their fundamental assumption that the world is benevolent and the self is worthy. Resulting from the broken trust associated with secure attachment, subsequent cognitive changes result in fear, anxiety, pessimism, preoccupation with self-preservation, new views of the world as malevolent and an unworthy self. Although Janoff-Bulman's (1989) theory does not account for intergenerational transmission of trauma, transmission of insecure attachments (as an impact of trauma) might account for the cognitive changes in the offspring of trauma survivors. Fundamental to Janoff-Bulman's (1989) theory is the notion that viewing the world as malevolent is an impact of trauma. 


\section{Summary of Introduction}

Substantial evidence exists that children and grandchildren of survivors of collective, mass trauma display: an unwillingness to speak about the traumatic experiences, increased anxiety and depression (usually sub-clinical levels), an increased sense of shame and inferiority, negative attitudes towards self-ethnic identity, a belief in the degeneration of one's ethnic culture, poor school performance, behavioural problems in childhood, close-knit family structures with possible parent-child enmeshment, and a great sense of loss (Harkness, 1993; Kalayjian et al., 1996; Kupelian, 1993; Lev-Wiesel, 2007; Major, 1996; Nagata, 1993; Rowland-Klein \& Dunlop, 1997). Anger and outrage also seem to appear if persistent denial of the genocide by the perpetrator exists (Kalayjian et al., 1996). In war veteran families, domestic violence is also evident (Jordan et al., 1992). Further, these characteristics appear to be universal and cross-cultural and appear with greater heterogeneity in survivor offspring when compared to non-survivor offspring (Davidson \& Mellor, 2001; Jordan et al., 1992; Major, 1996).

To sum, research suggests that a constellation of behaviours, perceptions and emotions resulting from the impact of trauma may traverse into the second and third generations. To contribute to this body of knowledge, I conducted a qualitative study in Ukraine, since Ukrainians were the target of a genocide that occurred in 1932-1933 (US Commission on the Ukraine Famine, 1988). Lastly, five models were presented as they may assist in explaining the results.

Historical Background: The Holodomor (Ukrainian Famine-Genocide of 1932-1933)

The Holodomor can be described as a genocide (Dutton, 2007; Naimark, 2011) that was orchestrated to kill and subdue ethnic Ukrainians and destroy Ukrainian 
statehood (Subtelny, 1994). Stalin's desire to destroy the Ukrainian nation was exacerbated by his well-known phobia of Ukrainians (Conquest, 1986; Courtois et al., 1999), as he openly acknowledged that Ukraine was a weak spot in the Soviet Union (Subtelny, 1994). In Stalin's paranoia of Ukrainians (Reid, 1999), he also viewed them as the imaginary enemy (Subtelny, 1994).

Beginning in 1929 and continuing into the 1930 's, Stalin unleashed a wave of terror (in mainly urban areas) in an attempt to crush Ukrainian nationhood that resulted in mass arrests and executions of Ukrainian political leaders, academics, lawyers, writers, linguists, artists, singers, students and clergy. (Dutton, 2007; Reid, 1999; Subtelny, 1994; Zinkewych \& Sorokowski, 1988).

More specifically, mass arrests and deportations of clergy and bishops of the Ukrainian Autocephalous Ukrainian Orthodox Church occurred. In addition, all Orthodox churches under various jurisdictions were closed or destroyed (Zinkewych \& Sorokowski, 1988). The Ukrainian language was banned and a program of Russianization commenced. Artists, writers and musicians considered to have Ukrainian themes in their works were shot, en masse (Subtelny, 1994). In one instance, several hundred celebrated musicians who played the bandura (a traditional Ukrainian string instrument) were invited to a conference; they were subsequently arrested and presumed shot - as they all disappeared (Reid, 1999; Subtelny, 1994). In the carnage, Stalin ordered all Ukrainian folk singers to be executed, in an attempt to annihilate Ukrainian culture (Dutton, 2007). To further promulgate destruction of culture, works of art and architecture considered to be inspired by Ukrainian themes were also destroyed, en masse (Conquest, 1986; Zinkewych \& Sorokowski, 1988). Across Ukraine, Ukrainians from entire university 
faculties, judicial boards, theatre groups and film studios were sent to their deaths (Reid, 1999; Subtelny, 1994). Ukrainians were, henceforth, excluded from senior positions in government, media, the judiciary, political leadership, the church and academia (Morozov \& Garnett, 2001).

In 1931, a Ukrainian backlash against the Russian regime began, but by this time much of the nation's intelligentsia and leadership had already been executed. Stalin knew that the essence of Ukrainian nationhood was articulated by the intelligentsia, but was sustained by the rural population over the centuries. Therefore, he first exterminated the Ukrainian intelligentsia in an attempt to destroy any potential leadership for an uprising (Conquest, 1986).

Stalin and his chief architect, Lazar Kaganovich (Marochko, 2007), then orchestrated a genocide (US Commission on the Ukraine Famine, 1988) and directed it against the Ukrainian people, with the aim to further crush Ukrainian nationhood (Conquest, 1986). In 1932-1933, Stalin directed confiscation of all harvests (food crops) in Ukraine. Stalin's goal was to starve Ukrainians (Reid, 1999) and use the expropriated grain to finance Soviet industrialization (Kordan, 2008). Watch towers were erected across the Ukrainian countryside to prevent the population from accessing food supplies. In addition, military-enforced travel restrictions prevented Ukrainians from searching for food. Those who did not starve were shot. The end result was the greatest genocide of the twentieth century (Dutton, 2007). Stalin after remarked that the Ukrainians had been "defeated but not completely exterminated" (Conquest, 1986). One of Stalin's lieutenants commented that the genocide of Ukrainians was necessary "to show them who is master here" (Subtelny, 1994). Dutton (2007, p. 31) also concluded that military confiscation of 
food and harvest from an unarmed population was a "much more efficient means of genocide than gas ovens, deportation, firing squads, or even nuclear weapons." In a speech in 1956, Krushchev remarked that Stalin's true intention was to eradicate every Ukrainian from the territory of Ukraine, however, "there were too many of them" (Reid, 1999, p. 183). In reaction to this speech, the Russian audience responded with laughter (Reid, 1999). The Ukrainian famine-genocide of 1932-1933 has since become known as the Holodomor - a word borrowed from the Ukrainian language meaning murder by starvation.

The Russian-Soviet government went to great lengths to keep the Holodomor a secret, though many Western intellectuals including H.G Wells, George Bernard Shaw and Pulitzer Prize winning journalist Walter Duranty of the New York Times knew about the extreme human carnage, but chose to deny the genocide because of their ideological sympathies to the Russian-Soviet regime. Recently, the British government declassified documents confirming the Holodomor. However, at the time of the Holodomor, the British government kept silent as it did not want to risk confrontation with Stalin (Dutton, 2007).

For most of the twentieth century, the Soviet regime denied that any genocide existed at all (Kulchytsky, 2008). This Soviet stance, supported by Western textbooks until recently, was that "collectivisation was a painful but necessary step towards modernising the rural economy, the famine something obdurate [Ukrainian] peasants brought upon themselves" (Reid, 1999, p. 117). Reid (1999) argues that this stance was and is counter-productive. As Ukraine's rural people were the most successful farmers in the Soviet Union, deporting and starving them was simply not a means to increase 
agricultural output. In fact, the opposite occurred - whereby, agricultural output drastically fell and never recovered during the Soviet era. Reid (1999) argues that the word, famine, implies a natural disaster and is hence the incorrect semantic to describe the events of 1932-1933. Instead, Reid (1999) concluded that the most convincing explanation was that the famine was a deliberate genocide orchestrated against the Ukrainians. In this context, Stalin feared that growing Ukrainian nationalism would have resulted in Ukrainian independence, which in turn, would have precipitated the downfall of the Soviet Union (Serbyn, 2008).

Soviet statistics from the period are unreliable. Stalin, displeased with the shocking death toll of the 1937 Ukrainian census had the lead census takers shot and, subsequently, fabricated statistics to hide the reality of the Holodomor (Subtelny, 1994). To calculate the death toll due to the genocide, the historian Robert Conquest, compared the 1926 Soviet census and the natural population growth rate following the 1926 census with a post 1932-1933 census. A conservative, minimum estimate of five million rural deaths due to the famine-genocide was established (Conquest, 1986). In addition, unknown millions more urban Ukrainians were shot or deported by long trains of cattle cars to northern Russia, and subsequently perished in the late 1920's and early 1930's. Over the twentieth century, mass graves were found with tens of thousands or even hundreds of thousands of bodies. Some of these mass graves hold bodies that were all shot in the back of the head (Reid, 1999). Although, the exact number of deaths that resulted from the Holodomor is unknown, estimates place the death toll at between six (Conquest, 1986) and ten million (Reid, 1999). Continued resistance of the Russian government to open files for investigation has not allowed for confirmation. A minimum 
of 18.8 percent of the total population of Ukraine was exterminated (approximately 25 percent of the rural population). In comparison, less than one percent of Ukrainians died in WWI (first world war) (Conquest, 1986). Some estimates suggest that the Holodomor killed twice as many people as the Holocaust (Reid, 1999). International journalist Anna Reid (1999) also noted that killing more people than the First World War, the Holodomor is one of the most under-reported atrocities of world history, and has resulted in a perpetual feeling of victimization amongst the Ukrainian people. 


\section{Method}

Qualitative research methodology was employed in this study as it helps to explore and understand the experiences and perceptions of others (Jackson, 2003). To this end an "interpretive constructionist" (Rubin \& Rubin, 2005, p.27) approach was assumed whereby researchers must take caution in not allowing their personal assumptions to hinder their ability to "hear" (Rubin \& Rubin, 2005, p. 1) the meaning of the narratives of the participants. In the broader context, the constructionist approach searches for shared meaning held by participants in a common community or participants with a common history, religion, and ethnicity. As such, this approach was particularly relevant to explore the thoughts and perceptions of Ukrainians regarding the Holodomor.

Having previously resided in Ukraine for five years, I developed a cultural sensitivity for the Ukrainian context and became fluent in Ukrainian. Through volunteering and work as an international election observer, I garnered greater insight into modern day Ukraine. Also, my travels to nine former communist countries of eastern and southern Europe provided me with a greater cultural sensitivity for the region. Specifically, as it relates to Ukraine, I was able to establish contacts within the Department for Foreign Cooperation at the National University of Kyiv Mohyla, nongovernmental organizations, non-profit organizations, the Canadian embassy and internationally sponsored development projects. Individuals within some of these abovelisted entities were helpful, directly or indirectly, by providing contact information for potential participants, via snowballing sampling (mentioned below). 


\section{Participants}

The participants were chosen from three successive generations of Ukrainians that included genocide survivors, children of genocide survivors and grandchildren of genocide survivors. Further, members of the three generations belonged to 15 families. As such, the participants were chosen from 15 family lines, with each line comprised of a survivor grandparent and one of their adult children. In turn, the grandchildren were offspring of the adult children participants. In keeping with qualitative methodology, purposeful sampling (Jackson, Gillis, \& Verberg, 1994; Patton, 2002), through a snowballing technique, was utilized to recruit participants who could provide in-depth descriptions of their experiences - in order to provide insight into their perceptions of the potential impact of the Holodomor. Therefore, no ads or posters were utilized to locate participants.

Participant families were chosen that consisted of the survivor generation being able to recall their experiences and perceptions of the 1932-1933 genocide. Further, participant families with adult children and grandchildren, over the age of 17 years, were selected. Families consisting of survivor parents, who had lived in areas known to have been affected by the Holodomor were selected.

Participant recruitment was also attempted to ensure gender balance. However, most of the survivor families comprised of females in the first generation. Given that the average life expectancy for men in Ukraine is only 61.9 years (World Health Organization, 2009), I had anticipated that participants from the survivor generation may have a higher female to male ratio. Of the combined second generation and third generation participants, $53 \%$ of participants were female and $47 \%$ were male. I also 
achieved inclusion of participants from both urban and rural settings, at the time of the interviews.

At the time of the interviews in 2010 , the average age of the first generation participant was 87 years. Hence, the average age of the survivors was 9-10 years of age during 1932-1933. Most of the first generation participants had lost family members and relatives to the Holodomor. Many of the first generation participants had not completed elementary or high school; however, some had finished high school or had a bachelorlevel post-secondary education. All of the first generation participants were retirees and many had worked as teachers or communal farm workers. Most of the first generation participants were widowers or widows. The average age of the second generation participant was 58 years at the time of the interview. The majority of the second generation obtained a minimum of a bachelor-level university degree. Most of the second generation were still in the workforce and their employment positions were more varied as compared to the first generation. For example, the second generation included a public servant, engineers, a writer, a mechanic, an agronomist, a professor, a seamstress, a veterinarian, a store clerk, a retired electrician, an actor and a teacher. The average age of the third generation was 30 years at the time of the interview. The majority of the third generation also had a minimum of a bachelor-level university degree and were in the workforce. The third generation included a business owner, a lawyer, an IT specialist, a teacher, a stay-at-home mother, a public policy analyst, a business manager, a property manager, advertising executives, and a sales representative. The third generation also included a few post-secondary students. In addition, many of the third generation were parents and had children under the age of 18 years. 
In the remainder of this thesis, the first generation participants are referred to as the survivors, the grandparents, the survivor generation, or the first generation. The second generation participants are referred to as the children, the children of survivors, or the second generation. The third generation participants are referred to as the grandchildren, the grandchildren of survivors, or the third generation. No differences in meaning are implied when describing a particular generation with different semantics. Lastly, to protect the identity of participants, real names were not used in their quotations; instead, pseudonyms were assigned.

\section{Procedure}

The interview guide. I used a thematic approach for this study, as guided by Braun and Clarke (2006). In principle, the thematic approach allows for organization and description of the data set, but can also accommodate interpretation of some aspects of the research topic. In this context, main interview questions were developed using guidelines from Patton (1990) and Rubin and Rubin (2005) to help elicit descriptions of experiences, opinions and feelings of the Holodomor and its potential impact on participants' lives and to gain insight into the processes of potential trauma transmission. Specifically, "experience/behaviour," "opinion/values" and "feeling questions" (Patton, 1990, p. 290-291) were incorporated into the interview guide. Additionally, one question regarding family discussion on the Holodomor was also incorporated into the script - as guided by the literature on trauma transmission (Nagata, 2003).

The interviews. The interviews commenced with an explanation of the study's purpose that included informing the participants of negative feelings that might arise out 
of the interview. All participants were provided with a list of community resources for counselling, after the interview. I also left my own contact information with participants. Instead of signing the consent and demographics forms (provided in Ukrainian) at the start of the interviews, I verbally informed participants as to the forms' contents and requested that they sign the forms after the interview. As such, I also obtained initial, verbal permission to audio record the interviews. After the interviews, conducted in Ukrainian, I again explained the rationale of the consent form to allow the interview contents to be used in this study. This technique of pre-interview verbal consent and postinterview written consent provided the participants with the additional option of allowing or not allowing their audio recorded interviews to be used for this study. In this way, after the interviews, participants who may have felt uncomfortable about releasing their recorded interviews to the study had the option to release or to not release their interviews. However, participants were also offered the choice to read and sign the forms prior to the commencement of the interview, but all participants chose to sign the consent forms after their interviews.

Participants were also assured of their anonymity and confidentiality and were given the option to withdraw from the interview at any time - as emphasis was placed on voluntary participation.

Regarding pre-interview explanation of consent forms and information about the study, some first generation participants began speaking to me about their perceptions of the Holodomor, literally, upon my immediate arrival through their front doors. In those situations, I gently found ways to intervene to obtain verbal consent and provide explanation of the study. 
The literature suggests that trauma created by deliberate human design can have greater psychological consequence as compared to those associated with accidents or natural disasters (Loos, 1993). As well, trauma seems to have its greatest impact during the first ten years of life (van der Kolk, Roth, Pelcovitz, Sunday, \& Spinazzola, 2006). Because both apply to the first generation survivors of this study, I had decided in advance of my departure for Ukraine, that in not knowing whether first generation participants had ever publicly spoken about their experiences, I would not ask explicit questions about their personal experiences with atrocity - in order to avoid creating participant distress.

With regard to potential duress in participants, I had taken precautionary measures, especially regarding the first generation (survivor) participants. First and foremost, I only chose participants who appeared to be "open" and "communicative" about sharing their thoughts, opinions and experiences. Prior to graduate school, I worked as a documentary/television filmmaker/writer and developed screening skills for potential interviewees/participants which I applied to this study. For example, during the initial telephone screening, I attempted to make "small talk." It has been my experience that if this level of communication can be achieved, potential participants will be likely to engage in later scheduled interviews with high levels of comfort. Conversely, if "small talk" cannot be successfully engaged and potential participants only respond with "yes, no or uh-huh" type answers, it has been my experience that these potential candidates are prone to be nervous and show distress during a later, scheduled interview. Hence, I did not select this latter type of participant in order to avoid potential participant distress. 
I later learned that all first generation participants had at least somewhat talked about their Holodomor experiences prior to this study. Many even reported to have relayed substantial Holodomor-related information to their family members. However, during the interviews, I adhered to my original plan and avoided direct questions that might elicit experiences related to atrocity. In helping to achieve this goal, I also began the interviews with a more neutral question, "What does it mean for you to be Ukrainian?" as per the tenet of Patton (1990, p. 294). As part of the first question, I used probes to help clarify participants' answers to develop trust with the participants that helped them to talk "descriptively" (Patton, 1990, p. 294). Early on in the interviews, all first generation participants chose to speak about their traumatic experiences. As such, I used some probes to learn more about their experiences and thoughts.

Included in my precautions with first generation participants, I followed up with phone calls 3 days and 2 weeks post-interviews to ensure that no delayed stress response resulted. One participant, in particular displayed potential distress during the interview. With that participant, I also followed up, via telephone, six weeks after the interview.

The interviews were "semi-standardized" (Berg, 2004, p. 80) in that all the questions in the guide were asked of each participant. However, based on participants' responses, the order of the questions was allowed to digress from the guide and probes were also used. This approach helped participants to answer questions in their own way and helped me to approach the subject matter from the perspective of the participants. This approach also allowed me to explore new ideas with the participants. For example, I incorporated a question regarding outside of family Holodomor-related discussion into the guide, as a result of this approach. 
To create an atmosphere of security and comfort for the participants, interviews were conducted in the participants' place of choice. Most participants chose to be interviewed in their homes. Because of the familial locations of the interviews, participants of the first and second generations, in particular, shared family photographs, family scrapbooks, personal historical documents, books on local-regional histories, newspaper articles and their own personal writings. This sharing, coupled with the indepth interviews, amplified my connection with the participants. Some of the participants, after the interviews, expressed an enthusiasm for my research and for having taken part in the study:

She [mother] wants her children and grandchildren to have broader opportunities and perspectives. Yes, therefore this [the Holodomor] did have an impact. Therefore it is imperative to write books about this. This is essential for our children and our grandchildren. You know more about this at the moment. We will read what you write and so will our children and they shall then pass this along to their children. (Oleksandra, Second Generation Participant)

In addition, interviews were conducted individually to ensure the privacy of all participants and allow for participants to communicate their perceptions and experiences in their own way. I had also accommodated any participant requests for family members to be present during the interview. There were two such requests; both were accommodated.

Very early on, I decided not to make notes during the interviews as this appeared to be too distracting for the participants. Moreover, participants preferred to make eye 
contact during the entire interviews which precluded detailed note taking. However, during the interviews, I still wrote down key words that helped me to formulate prompts. Therefore, I completed all notes after the interviews.

During the interviews, participants seemed to display a high comfort level in responding to my questions, despite the sensitive and difficult nature of the subject matter. The high degree of participant openness may have been due to the fact that they perceived me, the researcher, as both an "insider" (Dwyer \& Buckle, p. 57) and "outsider" (Dwyer \& Buckle, p. 57) at the same time. In terms of being an outsider, I was not born in Ukraine and do not possess a personal family history associated with the Holodomor. Hence, I was not part of the participant group under study. However in terms of being an insider, I previously resided in Ukraine for five years, became fluent in the Ukrainian language and possess an in-depth knowledge of Ukrainian history, politics, arts and culture. Relevant to participant trust in the researcher, the findings of this study suggest that Ukrainians developed a loss of trust in government and state structures, stemming from the impact of the Holodomor. By extension, I believe that my outsider researcher status of not being affiliated with any Ukrainian state structure, university or organization may have fostered increased participant trust in me, the researcher. I believe that being concurrently viewed as an insider and outsider combined to provide trust and comfort for the participants, which in turn, encouraged participants to speak openly and provide descriptive, personal and vivid narratives of their perceptions and experiences.

Regarding the number of participants and interviews in this study, my committee originally recommended that I interview five families. However, I actually interviewed 15 families. The increase in number was necessary to reach saturation (Rubin \& Rubin, 
2005 ), in order to explore the impact of the Holodomor on family functioning. The average length of each interview was 53.1 minutes; the median was 44.0 minutes.

Lastly, between July 1, 2010 and November 27, 2010, I travelled over 6000 kilometres, by bus, train and car in Ukraine, in order to meet participants and conduct interviews.

\section{Data Analysis}

All interviews were audio recorded and transcribed into text and then translated into English. Given the exploratory nature of the study, data collection and partial data analysis were conducted concurrently, in Ukraine. As such, field notes and partial, initial data analysis helped to identify "patterns of meaning" (Braun \& Clarke, 2006, p. 86) in the data that allowed for potential, additional topics and questions to be incorporated into the script. One additional question was incorporated regarding outside of family discussion. Concurrent, initial partial analysis and field notes also allowed for some follow-up interviews to explore additional information with participants.

The remainder of the data analysis was conducted in Canada where a more systematic, inductive, content analysis was employed. Analysis began with reading and re-reading the transcripts. The tenets of Rubin and Rubin (2005) also proved useful in looking for concepts and themes. Specifically, questions from the interview guide, issues raised by participants, indirectly revealed concepts, the comparison of concepts to each other and the comparison of concepts between interviews - all were used to code the data.

Guidelines by Jackson, Gillis and Verberg (1994) were used to break down the text of the interview transcripts into meaning units which were assigned Level 1 codes. Next, comparison of Level 1 codes to all other Level 1 codes, combined with further 
breakdown of Level 1 codes allowed for the formation of Level 2 codes (i.e., the categories or themes). These themes were compared and merged into the superordinate themes, or Level 3 codes. These superordinate themes formed the results of the study. Use of computer software, N Vivo (Denzin \& Lincoln, 2011; Patton, 2002), and manually created charts were enlisted to facilitate the coding process.

To assist in the creation of codes, I also created a paper filing system. This system proved particularly helpful in the creation of Level 2 codes. Essentially, I created a paper file for each theme that included: (i) a rationale as to why the theme was created; (ii) notes on potential generational or gender differences in the reporting of the theme; (iii) selected hardcopy quotes from the interviews to provide frame of reference and consistency in coding; (iv) tables that included the main theme and any of its sub-themes; and (v) any other notes pertaining to a particular theme. The paper filing system allowed for easier merging of the Level 2 codes into Level 3 codes (superordinate themes). In turn, the resultant superordinate themes helped to answer the original questions of the interview guide.

\section{Evaluating the Research}

To help legitimate the findings of this study, criteria relating to credibility, dependability, transferability and confirmability were employed. In particular, guidance of Patton (1990) helped to increase credibility. Guidance of Jackson (2003) assisted in increasing dependability, transferability and confirmability - with the writings of Jackson based on the tenets of Lincoln and Guba (1985).

Credibility. Patton (1990, p. 474) described how interviewers may be "absorbed into a local culture" and therefore change over time. Having previously lived in Ukraine 
for five years prior to my masters program, I may have been less prone to changes related to traversing cultures. As such, this helped to keep the measuring instrument (the interviewer) more consistent. Also, having previously resided in Ukraine helped me to better understand the environment to which the participants belonged. Aside from my pre-graduate school interviewing experience, I also brought my learned interviewing skills from graduate school at Carleton University, where I recently conducted interviews with teachers, principals and school board administrators in Eastern Ontario for a qualitative study. Familiarity with Ukraine and past interviewing experience helped to keep consistency in interviewing strategy.

According to Patton (1990, p. 462), "the qualitative researcher has to be methodological in reporting sufficient details of data collection and the processes of analysis to permit others to judge the quality of the resulting product." To this end, as part of the inductive analysis process, I attempted to explore open questions to sort the data into categories and potential relationships. As such, I avoided deductive analysis to look for relationships in the data. My motivation behind this process was to allow the voices of the participants to be heard. For example, the literature on intergenerational transmission of trauma tends to focus on the family as the vehicle for transmission. Therefore to counter potential, personal, preconceived notions - I purposefully searched the data to look for other contrasting influences. Hence, I found dimensions of family and outside of family influences.

Considering negative cases also helped to increase credibility. Additionally, part of this process involved searching for alternative patterns in the data to avoid rigid categorization. Therefore, during the data analysis, I looked for cases that contradicted 
observed relationships. In the search for negative cases, I found one second generation participant who spoke of the Holodomor as not changing his "reality" and not changing the "trajectory" of the Ukrainian people, overall. However, reviewing the overall interview actually showed it as similar to all the other interview transcripts regarding the impact of the Holodomor, in terms of the "destruction of the nation" and Ukrainians by genocide. The participant also revealed that he too, like many other participants, lamented the loss of members of the antecedent generation. However, these statements still did not address how the participant may have been personally affected by the Holodomor. Closer examination revealed that the participant spoke of the Holodomor's deleterious impact, in that members of his antecedent generation were severely "scattered" in terms of re-location and emigration to other parts of the Soviet Union, as part of their attempted recovery from the Holodomor. In turn, this resulted in a loss of "family connections" and a loss of intergenerational transmission of "culture, of values, the passing on of family values to the next generation." The participant described this as an "absolute tragedy" that he feels in his life and for his children. So, re-examination of this participant's narrative, originally coded as "no impact," revealed that he, in fact had, expressed an impact of the Holodomor on his life and on the life of his family. According to Rubin and Rubin (2005), this example might be more of a contradictory answer that could have been followed up with a confrontational follow-up question. However, I did not choose this route. This participant also shared the above-mentioned, additional information at the end of the interview. Perhaps, the participant felt more comfortable to express personal opinions, at this point in the interview, as better rapport may have developed. Another re-evaluation of the interview transcript supports this notion, as he 
mentioned that he prefers not to speak about the personal impact on himself or on his family, outside of his family unit. As written by Rubin and Rubin (2005, p. 1), I was not "hearing" the data, during the initial coding.

To increase credibility, I also provided extensive, vivid quotes to provide the reader with adequate information to assess the credibility of the findings, for as Rubin and Rubin (2005) wrote, the quotations are the "core evidence" (p. 261).

In addition, to assist the reader, I attempted to distinguish between the data and my interpretation of the data. I accomplished this by writing when the participants "reported, "stated," "spoke of," "emphasized," or "noted" an issue. For example, many participants reported a fear to take action. In this instance, I simply noted the participants' reported fear in the results section, with no additional interpretation. Conversely, regarding interpretation of the data, I also noted when I created semantics to describe and identify issues in the narratives. For example, I indicated (in the results) that I identified three types of Holodomor-related, intra-familial communication strategies: "open," "grandparent as conveyor," and "no/limited" discussion. Participants did not necessarily speak to being part of an "open" family and no participant expressed belonging to any particular family type regarding communication strategy. Therefore, I provided explanation for the identification and use of my terminology. Hence, the reader may note my interpretation of the data regarding family styles of communication strategies.

Lastly, in some instances, I applied the guidelines of Rubin and Rubin (2005) in utilizing elision dots (...) to shorten excerpts, yet, preserve their meanings.

Triangulation. In an attempt to decrease bias, methods triangulation, data triangulation, and interviewer-analyst triangulation may be employed to increase 
credibility. Each method of triangulation involves comparison of findings to other sources or perspectives to help ensure consistency of the results.

Qualitative and quantitative methods triangulation. This research study was not supplemented with quantitative methods. To compensate, I compared the qualitative results to available quantitative data in an attempt to triangulate. Although data regarding the impacts of trauma from the 1932-1933 genocide do not exist, some non-Holodomor related, international data corroborated and helped to increase the credibility of the results of this study. This comparison is presented in the conclusions section.

Qualitative data sources triangulation. The triangulation of data sources requires the comparison of information collected at different times, by different means, and from participants of different backgrounds and locations. To this end, I tried to incorporate: gender balance, variation in education levels, variations in geographical locations, and participants from urban and rural settings. Regarding locations and settings, I travelled more than $6000 \mathrm{~km}$ in Ukraine to include participants from various regions that were impacted by the Holodomor - as opposed to selecting all the participants from one small location.

Multiple interviewer-analyst triangulation. Despite only one analyst and one interviewer being attached to the study, triangulation of interviewers-analysts was attempted on a lesser scale. Regarding multiple interviewer triangulation, feedback from the thesis supervisor during data collection helped to increase credibility. Regarding multiple analyst triangulation, feedback from the thesis supervisor regarding coding, and the development of themes and superordinate themes assisted in enhancing credibility. 
Dependability. The extent to which two researchers independently achieve the same findings is reflective of dependability. To achieve this end, an audit trail was utilized to document the research process that included analysis decisions and issues pertaining to reflexivity. In principle, a researcher should be able to arrive at similar conclusions by examining the audit trail of another researcher. Ultimately, the audit trail should help to explain the stability and changes in data over time. My audit trail consisted of journals, paper files and electronic files. Among other things, my audit trail consisted of notes on interviews, observations surrounding the interviews, photocopies of articles from participants, personal thoughts and reflections, feedback from my thesis supervisor and committee members, notes on coding, contact information and issues pertaining to reflexivity. My electronic files also contained current event news articles from Ukraine that were collected over the duration of my data collection process.

During the data analysis process, memos consisting of ideas and decisions were kept to assist in the development of codes and themes. As previously mentioned, paper files were utilized to help assist in the coding and development of themes. As well, to increase dependability, collaboration took place with my thesis supervisor in terms of reviewing the transcripts and developing the themes. This approach brought in a second perspective to increase the dependability of the findings.

Transferability. The generalizability to other contexts, populations, settings, etc. is considered to be the transferability of the findings of a study. To achieve this end, descriptions of the participants and the settings are provided. These descriptions help the reader to assess the transferability to other settings, as the reader becomes better able to assess to what settings and to what individuals the findings of this study might apply. In 
addition, a detailed, historical description of the Holodomor was provided to allow for comparison to other participants with family histories of collective trauma. To help increase the transferability of the results, I purposefully tried to include a gender balance, a rural-urban balance and participants from various educational backgrounds.

Confirmability. This last issue can be described as the conclusions being dependent on the participants and the environment of the interviews, as opposed to being dependent on the researcher. As such, confirmability deals with neutrality. In this context, the researcher explores personal feelings and biases in an attempt to prevent them from influencing the findings of a study. Dealing with issues of reflexivity in my audit trail and questioning my motivation for conducting this study assisted me with confirmability.

In addition, my motivation was not to prove or disprove any theory. Instead, my motivation was to allow the voices of the participants to be heard. During the data analysis stage, to help allow the participants' voices to be heard, I periodically reviewed printed hard copies of selected participants excerpts as they provided motivation to code the data to, indeed, allow for the participants voices to be heard. One example is presented:

And it is clear that this is interesting to you and that you have this in your thoughts as do we. It seems to me that today, educated people from other countries, from developed countries have done a lot more, unfortunately, in unpacking this issue and providing greater understanding than that which has been done in Ukraine. Unfortunately, all of these challenges get in the way. Simply trying to live and survive day to day here often prevents us from fully immersing ourselves in this topic and promoting these issues on a general societal 
level... Thank you to you and all of the other people who are not complacent when it comes to this subject. I would like to thank you for your concern about this topic. And, that you are concerned about this like we are in Ukraine. (Tymofiy, Third Generation Participant) 


\section{Results}

Open-ended interview questions were devised to engage participants in discussing their perceptions of the Holodomor and its potential impact. To this end, patterns in the data regarding the Holodomor's impact were organized around three main subject areas, which in turn formed the three superordinate themes and the results of this study. The majority of the 45 participants from all generations spoke of: (1) associated emotions, behaviours and mental well-being as the impact of Holodomor; (2) a sense of loss associated with the Holodomor; and (3) the impact of the Holodomor on family relations. The three superordinate themes are presented below.

\section{Emotions, Behaviours and Mental Well-Being}

Emotions, behaviours and mental well-being were organized into one superordinate theme, as many of the issues raised in this theme were reported to affect the lives of Ukrainians as stemming from the impact of the Holodomor.

Emotions. Fear, horror, sadness, indifference to others, shame, and anger were the emotions participants associated with the Holodomor. Reporting of emotions sometimes varied between the generations. For example, all generations spoke about fear, shame and indifference. However, sadness was more frequently reported by the third generation as compared to the first and second. As such, a small gradient emerged. Conversely, horror and anger were more frequently reported by the first relative to the second generation. In turn, these two emotions were less frequently reported in the third generation as compared to the second. As such, the gradients for horror and anger decreased, in terms of frequency of reports, when moving from the first to second and then to the third generation. 
Fear. All generations reported three fears: a fear that Ukrainians could once again be targeted for genocide, a fear to take action, and a fear and mistrust of others. Regarding the fear of another genocide, at least one member in each of the 15 families raised this issue. Many members of all generations similarly noted that if the genocide happened once, then it could happen again:

How frightening this was. Let the Lord never let this be repeated for people. That people would once again be compelled to eat children...let us never allow ourselves to experience this reality again. (Marianna, First Generation Participant)

And the most important thing is to teach those that come after us so that we never allow something like this to happen again. We must past things along to the next generation. Because, there is always a risk that things could be repeated as they were back then. (Nazar, Second Generation Participant)

We do not want something like this to happen to us... Perhaps someone will come into power. Lord never let this happen, who will cause us to live through a similar Holodomor. We, at a minimum, need to be aware of these things. We need to know and be aware of what we should be prepared for. What life can lead to. I think that a person should be aware of this. (Yaroslava, Third Generation Participant)

In the Ukrainian context, the fear to take action was described as a fear to oppose, challenge, openly question, speak out against or strive to change the status quo of daily life, governance, public policy, legislation - even when these policies, governance and 
legislation are considered to be detrimental, suppressive or destructive in the lives of individual Ukrainians or to Ukrainian society as a whole. Participants also reported that this fear is responsible for the appearance of passivity related to taking action to effect change. Regarding the emergence of this fear, first generation participants explained how resistance to the Soviet regime during and immediately after the Holodomor was seen as a potential source for targeted death, imprisonment and victimization. Conversely, submission was viewed as a means to potentially secure safety and survival and resulted in a fear to take action. As such, first generation participants explained that this fear to resist translated into an overall, life-long fear to take action - within themselves and among Ukrainians, in general:

It really had an impact. You do not know what the NKVD [People's Commissariat for Internal Affairs] was. Or, what the KGB [Committee for State Security] was and what this signified. How over those years they specially targeted people. If you did not go into the collective farms, they would call you to the village council and there would be military/police persons sitting there. They would begin to question you. They put immense fear into you. Utter fear among our people and this fear persists among our people up until this very day. Yes, from the Holodomor. If you did not want what Russia wanted, they forced the genocide upon us. (Onysym, First Generation Participant)

The second generation directly attributed their parents' fear to take action as an impact of surviving the Holodomor. They reported that they learned and "inherited" this fear as they were taught by their parents not to oppose, challenge, or attempt to change 
the status quo of daily life, governance, public policy, or they would be met with "negative consequences," even death:

This fear was ingrained in people at the time of the Holodomor by the Soviet state. And, to fight that which has been internalized is extremely difficult. Each of us has a mechanism in our heads which censures us. This fear. This fear does not allow us to be free on the inside. We obtained independence, however, our inheritance, not that which we personally lived through, but rather our parents and grandparents. However, this fear is passed along from generation to generation. You learn that you should be silent. If you say something, there will be a negative consequence. (Svyatoslav, Second Generation Participant)

This same second generation participant further spoke of this fear to take action as "a slave mentality:"

I can simply say that the Holodomor changed peoples' psychological outlook, their mentality, the slave mentality of people....People are afraid to share their thoughts or perspectives. People are afraid of their bosses. They are afraid of state structures such as the Ministry of Internal Affairs or the military/militia. People are afraid. (Svyatoslav, Second Generation Participant)

In accounts very similar to the second generation, the third generation also reported learning this fear from their parents. Hence, like the survivor (first) generation, the second and third generations spoke of how this fear to take action currently prevents them from opposing government, public policy and taking action in their own personal 
lives to effect change. One third generation participant described the effect of the intergenerationally transmitted fear to take action on effecting political change:

All of us are afraid to take action. The experience of the Holodomor...And all of us wish to be alive. Only alive...About France. They disagree with something and they are on the streets. All of them because they are interested. We are sitting in our houses... And at this adult age one can start to protest when something is wrong. But I cannot. (Sofia, Third Generation Participant)

Intergenerational fear and mistrust of others, as an impact of the Holodomor, was also reported by many of the participants. Participants spoke of how the targeting of Ukrainians during the Holodomor producing a long-term fear and mistrust in others even in fellow Ukrainians. Unlike the fear to take action, the fear and mistrust of others was not necessarily directly attributed to being learned from parents. Instead, second and third generations reported that family oral histories of Holodomor-related atrocities, coupled with the knowledge that Ukrainians were betrayed, contributed to a fear and mistrust of others. This fear was reported to be responsible for isolation from, and a general suspicion and wariness of, others. For example, one second generation participant noted that communication of Holodomor-related information from his grandmother had prompted him to identify others as being either "traitors" or those who are "caring." Specifically, the following narrative speaks of a spy from the NKVD (pre-cursor to the KGB) who, posing as a priest in the community, turned over Ukrainians to the secret police (NKVD): 
She [grandmother] said that her son came to her and said that the priest is taking confessions. One man went to confession and shared things with the priest. That very night, they came and took this man away. No one knew what happened to him or where he was taken away or why. They took him away. The son went by where the man had visited the priest and he could see that the priest was there. The priest turned around and the son noticed that the priest had a gun tucked under his priest's garments. Well, a priest does not have the right to bear arms. A priest should be focused upon healing the soul/spirit of an individual. But, clearly he had different motivations. Then, he looked around the area and made the connection that this person and that person are missing and that they are all people who would go to the priest to take confession. These people would go to the priest during the Holodomor to confess that they had stolen a grain of wheat to eat or that item. It turned out that this priest was part of the NKVD and he was specially placed there to find people out. After a confession in the day, that person would disappear and be taken away in the night. Because they had taken this or that piece of wheat. They should not have been stealing because they were supposed to die from starvation. But, for some reason, these people were still surviving. The son returned home to his mother after supposedly going to confession. He told his mother that he now understands where our neighbours are disappearing to. He said, 'I saw the gun on the priest and now I understand everything.' Who this priest is as a person? Had he gone for confession, he too would have been gone....Ukrainians were a very friendly nation prior to the Holodomor. The Holodomor really shed light on who the traitors were and who the caring ones 
who shared were, who would share their last piece of bread. If to consider this, I think that overall the Holodomor had a negative impact. (Nazar, Second Generation Participant)

One third generation participant reported the fear and mistrust in others affecting relations between she and her neighbours:

If earlier, there were times when people did not lock their doors. Or, experienced genuine friendship among one another and helped one another. Huge barricades between homes did not exist at that time. Now, it seems to me, that people, this traces back to that time.... I think the impact from the Holodomor was solely negative....People do not have trust in each other. (Yaroslava, Third Generation Participant)

Horror. Most participants noted a feeling of horror with the Holodomor. As a result of having survived genocidal atrocities, every survivor emphatically associated the emotion of horror with the Holodomor. Although, I decided against asking first generation participants direct questions about their experiences with atrocity during $1932-$ 1933, every survivor raised this issue, in relation to horror. The following first generation narratives are reproduced:

There were instances when, I know $M^{* * * * *}$. Her mother went over somewhere and managed to dig up some onion. She was still a little stronger than most. They took bread away from us. She pulled up this onion and they killed her for 
this. They took the onion she had dug up and pushed it into the mouth of her dead body. It was horrific. (Petrusia, First Generation Participant)

The mother of a neighbour died and they buried her. There were two sons at the time. The following morning I woke up to discover that these sons had dug up their buried mother, cut her into pieces and stored her in the cellar in order to have food to eat. They salted the cut up body and stored it for future food. In the home, the walls and floors were covered in blood from the body that they had cut up. (Hafia, First Generation Participant)

People were dying all over. There was nothing with which to transport the dead bodies to the cemetery. People did whatever they were able. Not far from where we lived, there were two boys. One older teenager and the other one. My age. And their father and mother. I looked over. $\mathrm{D}^{* * * * *}$ is standing there and is not able to make it into the cemetery. He simply did not have the strength. He needed to dig up a hole. What did he do? He took his mother by the hair and dragged her along the ground. He kept walking dragging her until he approached a wide dugout of water. He struggled and struggled until he managed to drag her body across this space. Then, there was a road. Near the road, there was a hole of sorts... There was a hole and from this hole, people would take clay. I watched as he dragged his mother to this hole. He threw the body into this hole. He did not have a shovel. He had nothing. This was one such incident. (Onysym, First Generation Participant) 
Having been born after the Holodomor, however, horror was associated with oral histories of family survival or with general knowledge of the atrocities of the Holodomor in the second and third generation participants:

Horrific. Just as my mother would share... a young mother with child during the Holodomor would feed her child as she was dying. The child is feeding at the breast but there is no milk available for the child. The mother's body was already dead at this time. This is horrific. (Nazar, Second Generation Participant)

Grandmother was a little older than grandfather, four years older than him. She witnessed a lot of the horror. She shared that there were incidences of cannibalism, where people ate one another in order to survive. Famine is very terrifying. We lived in times where our family managed to survive such famine. Let God never allow people in the present day to live through such horrific times. This is, in principle, what I wanted to add in brief. The stories which my grandfather and grandmother shared with me were very horrific. They lived in the oblast at the time. From what we know of the Holodomor, it spread all across Kyiv oblast. The central region of Ukraine was the epicentre of the Holodomor. The Soviet administration/state did everything it could to intentionally take away all of peoples' food and surplus. They took things away from people. This is very horrific. (Petro, Third Generation Participant)

Sadness. As noted earlier, sadness was reported on a small gradient through the generations. As such, the third generation reported more sadness than the first and second generations. Sadness was reported to be associated with: (i) the fact that Ukrainians were 
targeted for genocide; (ii) Ukrainians who perished and/or experienced the Holodomor; (iii) painful memories; and (iv) death of family members. Moving from generation one to three, participants reported less sadness related to loss of family members and more sadness related to Ukrainians, in general, who survived or perished and to the fact that Ukrainians were targeted for genocide:

Of course this is all very sad. It is all saddening. It is unpleasant. This is difficult. Unpleasant. As a Ukrainian, it is unpleasant for me that this happened to our people. (Danylo, Second Generation Participant)

"So many emotions are sorrowful ones, only sorrowful ones" and "from time to time, one wants to cry when they remember this" were typical first generation explanations of sadness related to painful memories. Some participants, from all generations, reported feelings of sadness for their parents, siblings, and other relatives who perished. Second and third generations reported a sense of sadness for the death of family members and for never having had the opportunity to know antecedent family members:

My mom had a big family. But only some of them survived. And the same with my dad's family. Only some survived. I never met my grandma who passed away because of a lack of food. And I just know from my dad how wonderful she was, how educated she was. (Orianna, Second Generation Participant)

Sadness for all those who perished and/or for those who lived through the Holodomor was reported by all generations: 
I have no other emotions other than sadness. I feel nothing but sadness as it relates to the Holodomor. I really feel sorry for those people who died during those times....One wants to pray for those people so that things would be better for them where they are now. They suffered through very difficult times and then died. (Petro, Third Generation Participant)

Indifference toward others. Most participants reported that, as a result of the strong need to secure personal and family survival during the genocide, an indifference toward others developed. Participants elaborated that the extreme conditions during the Holodomor forced individuals to focus greater emphasis on the struggle for personal survival as opposed to the survival, suffering or plight of other individuals. Because the focus was placed onto the self (and one's family) and not onto others, an indifference toward the well-being of others was reported to have emerged during the Holodomor. This indifference was not reported to be part of an intrinsic selfishness, but rather as the result of the perceived need for self-preservation during the Holodomor, as the following first generation account illustrates:

People were pushed to the brink where there was nowhere else to turn and nothing else to do.... She [childhood friend] jumped out into the street and said my mother died. And, they responded, "we may die along this roadway. And, so what if she died." You see this is what it did to people. They were not even able to grasp the situation of a young child left without family because all of her family members have just died. (Olena, First Generation Participant) 
One second generation participant described this indifference toward others, stemming from self-preservation during the Holodomor, as having caused Ukrainians to become non-"human" in their conduct with each other.

The laws of nature are leading in this way. If someone only thinks about their own survival and is focused solely on these considerations within which he presently lives, he will still die. Amongst us not everyone is human, Ukrainians do not have a complete understanding as to what kind of tragedy this really was for us. (Pylyp, Second Generation Participant)

Most of the third generation also raised this indifference to others in relation to persons around them and how this indifference pertains to Ukrainians, in general. This indifference to others stemming from the need for self-preservation was reported to have carried through the generations via socialization, outside of the family unit. Further, indifference was reported to be unfavourable, yet prevalent and manifested into Ukrainians showing less compassion toward each other, as a long-term impact of the Holodomor:

This traces back to that time [the time of the Holodomor]. The attitude now is that if I have something, then I am lucky. But, the fact that my neighbour does not have, this is not my problem. I think that people have become less generous and caring with one another. (Yaroslava, Third Generation Participant)

Shame. Many of the participants reported "humiliation," "shame," "degradation," "embarrassment," "an inferior sense of being" and "being made fools of," as a result of 
the Holodomor being inflicted on Ukrainians. Participants also expressed Holodomorrelated shame as being connected to Ukrainian ethnic identity, itself. Reports of this ethnic shame increased with each younger generation. Therefore, especially third generation participants noted this issue. One participant expressed being ashamed of the Holodomor as being a Ukrainian legacy and that the outside world might relate to Ukrainians in this way:

I never want the English-speaking world to know my country in this way. I want there to be an educated understanding of what has happened here. And, at a minimum, for there to be support and compassion toward our people. Compassion is a difficult emotion, but we require compassion and an attempt to understand why we as a country are constantly asking for our country's independence not to be destroyed. Because of this, well, this is painful.... The degradation that was never really eliminated but is still present. Because it is very hard to live with such a past and to be normal, now in the present. (Sofia, Third Generation Participant)

Men, in particular, reported shame stemming from the notion that the Holodomor was utilized as a mechanism to turn Ukrainians into "slaves." These participants emphasized that the Soviets destroyed the participants' independent way of life during the Holodomor and turned them into slaves of the Soviet regime:

Everyone was humiliated. They saw themselves as slaves because this was not done out of free will. (Mykhailo, Second Generation Participant) 
Anger. Six reasons for Holodomor-related anger were reported by some of the participants of all generations: (i) anger towards "those" who orchestrated the genocide. For example, one second generation participant expressed an "anger, such a rage that they could dare" orchestrate the Holodomor; (ii) anger related to the fact that the genocide occurred; (iii) anger around the inhumanity resulting in genocide. For example, one first generation participant noted, "Sometimes, it leads me to hysteria when I think about how people were judged as being so terrible. Humans did this to other humans;" (iv) anger over the denial of the Holodomor; (v) anger related to the genocide's destruction of identity and way of life; and (vi) anger that there has been no justice for the perpetrators. Also, a trend emerged, whereby, anger diminished through the generations (i.e., moving from generation one to three). Overall, anger was the least reported of all the emotions.

Behaviours. Most participants also described lifestyle behaviours and mental well-being related issues as stemming from the impact of the Holodomor. Moreover, resulting from the traumatic impact of large-scale death by forced starvation, perceptions of, and behaviours surrounding, food formed three out of the five reported behavioural and mental well-being sub-themes. These included: (i) the irrational stockpiling/hoarding of excessive food supplies; (ii) an inability to discard unwanted and unneeded items; (iii) an extreme reverence for food; (iv) overeating and emphasis on food; and, (v) a permanent state of survival. Participants did not directly address these concerns as mental health issues, although the permanent survival state was reported to affect mental wellbeing. 
Stockpiling of food. Participants reported the stockpiling/hoarding of food as a safety mechanism to protect against future potential threats, like another Holodomor. One first generation participant provided illustration:

The Holodomor had such an impact upon people, they feared starving. Death by starvation. This is horrific death. You know if a person is ill, that is one thing. But, if a person is healthy and they are dying because of hunger, this is horrific.... You need to have your own. You need to prepare for any unforeseen situation. The Holodomor scared people so badly that they even began saving their dry bread....We may purchase a second sack of sugar to store for when we need it. What else do we store? Flour. (Olena, First Generation Participant)

In terms of intergenerational transmission, the second and third generations noted how their practice of creating stockpiles of surplus foods was learned from antecedent generations as a protective mechanism. Although the second and third generations reported that their stockpiling tendencies are not necessarily rational, they still continue to create surpluses of food:

I will tell you that the need to conserve is ever present. The need to always have a surplus. This is present in each family. I remember my grandmother. There was a particular time when we travelled with my father to dismantle her house in $\mathrm{H}^{* * * * *}$. In the attic, there were at least two sacks of salt at thirty kilograms each. Matches. This was all about having a surplus. All of these supplies were available in the store, however, for them, it was critical to have a surplus. This mentality persisted, they would say "You never know what life will bring next." You 
understand, this mentality is already in one's blood....Similarly I cannot allow myself to live without a surplus. Today, it may be in the store, but tomorrow, may be a different story. Similarly, I suspect that it is like this with each of us, people do not live in the present. And bread, everyday they bring bread to the store. Everyday there is fresh bread. And when I go to the store, I think to myself, I have to take two. And, then I think why two? Tomorrow they will bring fresh bread again, but then I tell myself no, you take two today. (Mykhailo, Second Generation Participant)

The need to always have a surplus, regardless of what it is. You are always either preparing more or purchasing more to ensure that you will always have. Salt. Sugar. Basic foods. They are in stock always. It does not matter if these items are required in the present or immediate future. We laughed, recently when we were in the process of moving from one apartment to another apartment. We once purchased a lot of salt. We have not managed to consume this salt over a period of ten years living in our original apartment. We still transported this salt to our new apartment. Plain rock salt. Similarly, I remember a surplus of sugar and flour in sacks in her [great-grandmother's] attic. This surplus was prepared and stored at regular intervals of frequency. This is yet another example of the consequences. This is what my grandmother did. This is what my mother did. (Myroslava, Third Generation Participant)

Inability to discard. A few of the third generation participants attributed their inability to discard and excessive build-up of unwanted and unneeded items in their 
living spaces to the impact of the Holodomor. These third generation participants reported that, as a response to their grandparents having lost everything during the Holodomor, their grandparents excessively saved items with the belief that these items will have future value should another massive calamity take place. Further, these grandchildren reported that their parents (second generation) learned this behaviour from their parents (first generation). The grandchildren, in turn, learned these behaviours intergenerationally as being passed down from generation to generation:

If you were to look at her house, she [grandmother] has a lot of different stuff that she will never need but she still has it just in case. Because she did not have before, so just in case. It is her life motto now. In our attic, it is overwhelmed with, sometimes, with strange things. Because she is collecting everything. She cannot force herself to throw something away. She is collecting stuff. So, it is very hard and I think it is not only for my granny. It is for a lot of people her age and even the next generation, they cannot force themselves to throw things away. Because just in case they should have a, this just in case concept. It is even true for my parents' generation. I can see it. We were comparing my friends' families. It is so common....I notice that, for me it is not always easy to get rid of old stuff....To give it to my granny to store it, or to my mother to store it, or to somebody. I will find 100 ways to not throw it away. (Ruslana, Third Generation Participant)

Extreme reverence for food. Participants reported that the impact of the Holodomor produced an extreme reverence for food that was responsible for instilling a 
sense of guilt related to discarding food stuffs, even bread crumbs. All generations raised the issue of reverence and associated guilt (In this sub-theme, I coded reported feelings of not being able to bring oneself to discard food as guilt). Stemming from the safeguarding and confiscation of food and the fear of genocidal, forced starvation, the first generation participants reported a life-long reverence for food, characterized by an inability to discard food items. In turn, the second generation reported that they were directly taught, by their parents, about the extreme reverence for and value of food. Specifically, food was communicated to be lifesaving during forced starvation-genocide and, hence considered extremely valuable. The second generation reported that these lessons created a reverence for, and a guilt-induced inability to discard, food in themselves:

If we were out running in the fields and happened to drop a piece of bread we would get a swap across the ears. Mother, father or grandfather would say, "you have not looked a starved wolf in the eyes. You have never experienced the hunger that we experienced. If only we had the good fortune of finding a piece of bread in the field. And, you on the other hand are scattering your bread about. You cannot throw bread away." I remember this well from my childhood....We were taught that every crumb was precious. We were told, "you have to understand that for every little bit of crumb a person could live for another week." They told us what things were like. They taught us to never waste bread or to throw it away, rather to safeguard it. (Nazar, Second Generation Participant) 
Similar to the second generation accounts, third generation participants reported that they too learned from their parents (i.e., second generation) that food is sacred and should not be discarded:

Even if you eat a piece, and there is a little morsel leftover you cannot throw it away. You have to eat every last crumb. If the bread dries out, then you can steam it to make it fresh again. I am so used to this. I never paid much attention to this detail. But, later realized that this is a pattern that is present in many other families as well. Bread. It is sacred for Ukrainians. I think that it was sacred in the early centuries, but the topic of the Holodomor made this valuing of bread even more extreme. A piece of bread can save a person from hunger if you eat just a little bit. Then, when I travelled outside of Ukraine, I realized that this is only prevalent in Ukraine. This safeguarding and sacredness of bread. Beyond our borders, people can throw bread away. For me, this was a genuine shock. Then, later I understood that people, who have not experienced such a thing or whose ancestors did not survive such an experience, have a completely different frame of reference. (Orysia, Third Generation Participant)

Overeating and emphasis on food: The "cult of food." Overeating and an emphasis on food were reported by a small group of participants as a means to compensate for the fear of restricted access to food that was prevalent during the Holodomor. One first generation narrative illustrates overeating:

If I pinch but one bite I know that I will not be able to control myself and I will eat the entire loaf. (Vira, First Generation Participant) 
Additionally, some participants reported being overweight due to a Holodomorinstilled, fear-based, parental pressure for overeating in childhood, as explained by the following second generation narrative:

I feel that my generation, those children who are born to those people who survived the Holodomor, they are physically larger and overfed. This fear that there will be nothing to eat. My mother would literally stuff me. I would say, "I do not want to eat." She would force me, "eat, eat, eat." This is not psychologically correct. We were never hungry. I never knew starvation. My sister and I, we never knew, thank the Lord, what starvation was about. We would, of course, strive for something tasty to eat. But, never knew the reality of not having anything to eat. Our parents, fearful of this reality would stuff our refrigerators and freezers with food. They would force their children to eat. They would ask, "the sandwich we sent to school with you, did you eat it? Eat it. Eat it. Eat it." This fear, it is not normal. For instance, this is a violation of the natural function of the human body, because to overfeed an individual is not proper. Perhaps not everyone behaved this way. But, I am speaking from my own experience. I remember that I was never thin. Despite my not being thin/average weight, I was always being forced to eat. This obviously stems from that reality. (Mykola, Second Generation Participant)

Noting the strong emphasis on food as being a learned intra-familial behaviour, one third generation participant spoke of how food takes primary precedent at family gatherings: 
The entire cult of food. It remains as a primary factor...I also remember that my grandmother's number one rule was, "first we need to feed." All other needs are not seen as important. I believe today that this approach was detrimental to discussion and interaction between family members, as there are times when you just want to sit and share/speak and my mother is constantly busy either preparing food or with other household activities. As a result, we do not enjoy the kind of interaction/contact that should be present in these relationships....In principle, I think that this is a consequence of the shock and horror that was experienced at that time. Something could happen and we could be left without food. Therefore, I would say that this is a consequence and it is something that is passed down. From time to time, I catch myself when I am preparing something in anticipation of my parents coming to visit as guests. I also catch myself deeply consumed with what to feed them with. Not even considering other aspects of the visit. Perhaps a cultural program or other activities. But the primary consideration is...am I providing enough to eat? You understand this reality, but realize that this is not rational thinking... or a rational approach. There is clearly some kind of impact here...that I described with this cult of food in our family. (Myroslava, Third Generation Participant)

Living in survival mode. Several participants summarized the above-mentioned stockpiling, inability to discard, emphasis on food, etc, in their daily lives as being part of a permanent state of survival, stemming from the long-term, intergenerational impact of living in "a post-genocidal society." In addition, fear and a constant need for self- 
preservation were also addressed as being part of this survival state. Life was reported to involve a "survival approach" that precluded the ability to "live in the present," "relax" and "enjoy life." I have called this sub-theme "living in survival mode" as participants described this state as existing and surviving, but not living. Two third generation narratives provide illustration for living in survival mode:

Constant need for survival which is also, you cannot enjoy your life. You are running. All of your life you are running, running, running to something. Something better. And when you stop running, you look back and say, "but when I lived, I was running all my life." (Ruslana, Third Generation Participant) Something that is passed along from one's parents. That you constantly find yourself in a situation, in your mind that you are always in survivor mode. That one cannot simply let go and relax. That there are never moments when one can fully enjoy life. (Myroslava, Third Generation Participant)

Mental well-being. Interestingly, only women raised issues of mental well-being affecting their own lives. Only one male participant spoke of mental health concerns, and did so only in relation to his survivor parents. As well, generational differences were observed in the narratives; only first and third generation females raised mental wellbeing issues as stemming from the impact of the Holodomor. Female participants talked about general stress, anxiety and decreased self-esteem.

Stress, anxiety and self-esteem. A few of the first generation women spoke of always being "nervous and worrisome" as a result of surviving the Holodomor. None of the second generation and some of the third generation participants raised the issue of 
stress and anxiety. However, differing from their grandparents' reports of stress and anxiety, the third generation females attributed their stress and anxiety as stemming from a Holodomor-induced, transgenerational and continual struggle for "survival" (related to the "living in survival mode" theme). The constant need for "survival" was reported to include maintaining food and other "surpluses" and the need to always strive to do more. Third generation participants reported observing their parents' and grandparents' constant motion in a "survival state" to direct their own "constant regimen of work and activity." The stress and anxiety stemming from "this constant need for survival" was reported to prevent third generation participants from "enjoying life," in terms of making time for personal development and forging stronger interpersonal relationships with friends and family. One third generation participant reported the impact of her grandmother's continuous motion in a "survival state" to influence the participant's own perceptions of the necessity for a "constant regimen of work and activity:"

But, if to take my life example, this provides us with opportunities to strive for more and to try harder. Because when I see that when my grandmother can barely stand and move and she continues to do more and more, then I realize that if I have a pain I simply have to think, well if my grandmother can do ten times more then you somehow manage to force yourself to do more despite the moaning.... One cannot simply let go and relax. That there are never moments when one can fully enjoy life.... This is something that was lacking for me as a child with my parents because they were constantly busy with something. (Myroslava, Third Generation Participant) 
All female, third generation participants that noted stress and anxiety also commented on its negative impact on self-esteem. Specifically, the stress and anxiety of the "survival mode" were noted to cause feelings of regret associated with perceptions of lack of achievement in stockpiling and the need to do "more." Further, a spill-over effect was reported, whereby participants also extended this lack of achievement to other areas in their lives. Hence, being in "survival mode" was reported to have, periodically, caused feelings of never having achieved or ever being able to achieve enough in the realms of employment, personal development, general everyday tasks, etc., which in turn, invoked negative thoughts about the self and resulted in decreased self-esteem. In addition, participants also reported having reflected on past perceived lack of achievements as not having done enough in the "past" and "lost opportunities," which lowered self-esteem to the point where most third generation participants who reported self-esteem issues referred to themselves as "stupid" or "losers:"

But I would feel sorry for doing something or not doing something. Although, I cannot change it. So, it is not logical. But I would think about it for a long time. Like still returning to my memory to those times that why, for example, I think it is a stupid example, but I was taking piano lessons when I was in school, but then I decided to quit. It was my decision, although my parents tried to convince me not to. And for several years, I was thinking how stupid it was to do it. Why did I do it? If I would not have done it, I would play now, or something. So, it was like stupid, stupid me. And for several years I accused myself of doing this. Of quitting. Although, it is. I cannot change it. And for example, I can think that I could take lessons again, but I was thinking how stupid I was. And why were my 
parents not hard enough and firm enough to not allow me to do this. Yes, sometimes it is some ridiculous thing, but still, thinking about it and imagining how it would be if you did not do this.... This is a simple example I think. I have a lot of such stuff in my life. But just how to formulate this. It is when you had some failures in your life....Like everything is bad. I am a loser. And nothing will change. (Ruslana, Third Generation Participant)

Hostility. A few third generation participants reported that increased, transgenerational hostility emerged as a by-product of the perceived need for selfpreservation and "survival" during the Holodomor. In other words, hostility is used as part of securing self-survival and placing emphasis on the self. These third generation participants noted that, stemming from the self-preservation aspect of the impact of the Holodomor, "people became more harsh with one another and would take advantage of one another" and that "no one is concerned with helping one another." This breakdown in amiable, inter-personal relationships was reported to result in increased hostility in interpersonal relationships outside of the family unit. In this context, participants reported behaving more "abruptly" and curtly with others. These interpersonal relationships were considered harsher, primitive and "more biological:"

When you travel outside of Ukraine, there are many things that you begin to notice. As you walk the streets in a different country, you do not have the same feeling of survival mode that you feel in Ukraine. In Ukraine, this survival mode is felt and exists. And, regardless of where you travel, it is always felt among people. I think that one of the consequences is that people are more abrupt as if 
you are surviving in a jungle. More biological relationships. You find yourself responding more abruptly to certain things, circumstances that would usually require you to be softer and more respectful. Simply more abrupt. (Myroslava, Third Generation Participant)

Further, hostility was reported to have manifested into witnessed bullying and physical fighting among Ukrainian children, in general:

I think the impact from the Holodomor was solely negative. People became more harsh with one another and would take advantage of one another. No one is concerned with helping one another. People do not have trust in each other. In particular, the young. In particular, the young. There are so many instances where young people are fighting with one another [physically] about absolutely nothing. They pick on one another. Out on the street this happens very often. So many fights. (Yaroslava, Third Generation Participant)

Alcohol, AIDS and drugs. A few first and second generation participants reported that alcohol abuse developed as a coping mechanism to lessen the stress of struggling in the aftermath of the Holodomor. None of the participants reported alcohol abuse problems in their own lives, but felt the issue warranted raising in the context of the impact of the Holodomor on Ukraine and Ukrainians. Additionally, this was the only behavioural theme raised primarily by men. When women raised the issue of alcohol use, they described it as a concern related to men. As such, of all the behavioural sub-themes, alcohol was portrayed as a men's issue. Men were reported to begin using alcohol, after the Holodomor, in an attempt to counter the likelihood of appearing independent and 
anti-Soviet. In this context, any appearance of independence, strength, or anti-Soviet sentiment was used by the Soviet regime as a pretext to execute men. Therefore, as a survival strategy and coping mechanism, the appearance of isolation and weakness was more advantageous. This weakness was then learned and reinforced by each successive generation of men and "still we have this approach," at current, to diminish stress because "it is easy to be weak" and "just abuse alcohol:"

Just to be hungry. This is good. To be sick. This is good. This is also the issue....Just do not touch me. I am sick and weak. It was dangerous to have good health and to be strong. And the consequences, we have lots of people who abuse alcohol. Abuse alcohol. With poor health. And no one touch me. Yes. Especially, I think the men. (Orianna, Second Generation Participant)

Also reported, by a few participants, was that people became "very passive" (connected to the "fear of taking action theme") as an impact of the Holodomor. In turn, this passivity became learned intergenerationally and was posited to be the root cause of ambivalence toward risky health behaviours that potentially leads to the contraction of AIDS and drug abuse in the younger generation. Like alcohol use, AIDS was discussed in terms of a population context, where "the young generation still keeps the impact of the past [Holodomor]. Maybe because of that there is lots of drugs and HIV."

\section{Loss}

Five related sub-themes were merged into one superordinate theme, entitled loss. As previously mentioned, participants were not directly asked about loss, yet the majority chose to raise and emphasize this issue as an impact of the Holodomor. Although loss 
occurred in the 1930's, participants stressed the enormity of historical loss as still negatively affecting them into the present day. Participants reported the loss of: (i) a mass of Ukrainians; (ii) family members; (iii) the traditional way of life; (iv) Ukrainian culture and ethnic identity; and (v) men.

Loss of mass of Ukrainians. The majority of participants reported a sense of loss for the large mass of Ukrainians that perished during the genocide. This theme was consistently stated across generations, as illustrated in the following accounts:

Ukrainians died. This is not just some suffering in a village. All of Ukraine was starving. So many people died. This is a very massive tragedy. (Lev, First Generation Participant)

This was not a victorious moment. This was not the capture of some kind of fortress. This was loss. This was loss of everything. A lot of human loss....The Holodomor was a war. (Mykola, Second Generation Participant)

It was difficult when she [grandmother] would share. There were certain moments when it was almost unbearable and difficult to comprehend the sheer volume of death at that time. (Tymofiy, Third Generation Participant)

In addition to the loss of masses of Ukrainians, the second and third generations expressed a sense of loss for the children who were never born to those who died during the genocide. No first generation participant reported this loss. Second generation participants expressed this loss in terms of unborn family members. These participants noted that had this loss not occurred, they would enjoy larger, stronger family units and a 
stronger sense of family heritage. Only second generation participants communicated that this loss of the unborn also resulted in a loss of potential artists, writers, intellectuals, the independent-minded and nation-builders. As such, this loss of human potential was reported to have impeded Ukraine's development in terms of culture, technology, independence and nation-building, which in turn, was reported to have decreased the "richness" of life. Unlike the second generation who reported the loss of unborn as affecting their family units and Ukraine`s development, third generation participants expressed a sense of loss for the unborn as only impacting Ukraine's development - in terms of technology, culture, independence and nation-building. One third generation participant noted the need for over-achievement to compensate for the lost potential of the unborn:

You know that it likely impacted as it was one more sinful act committed against Ukrainians. This effectively thwarted Ukrainians ability for selfdevelopment....With such growth, Ukraine could have become a strong nation. Therefore, I believe that this was the stop of the water faucet. The loss of a generation. The loss of unborn children. Unrealized dreams and possibilities. Pure and simple. It is such a loss. It is a collapse. Our generation, today's generation must deal with this collapse. Somehow to catch up. Do everything twice as well. You understand. For those that were never born. (Orysia, Third Generation Participant) 
Loss of family members. Feelings of loss for family members that perished during the Holodomor were expressed by the majority of all generations, as illustrated by the following first generation account:

I was thirteen years old....My parents died before my eyes begging for food. What could I give them to eat? I had nothing. It had all been taken away. They begged and begged for food and ultimately died. They said, "today we are not going to be able to eat, simply let us die." Ohhhh. (Hafia, First Generation Participant)

The second and third generation participants also expressed their loss in terms of lost relationships, as they were deprived of the opportunity to know grandparents and other antecedent family members who perished:

Of course in my life I never met relatives who passed away. I never met them. I just know from my mom about her cousins. About her uncles. And I just know the place where they lived. (Orianna, Second Generation Participant)

Members of all generations also expressed a sense of loss of childhood and opportunities for the countless children who lost parents to the Holodomor. In this context of loss, participants spoke of the "orphaned" children in their own family (or themselves). Some participants also spoke of friends and acquaintances who were orphaned or about "all the children that survived but became orphans."

In addition, some first and second generation participants noted that lone, survivor children from their families were placed into state orphanages. Further, these participants spoke negatively of the neglect and poor living standards of the Soviet orphanages that 
housed orphans of the Holodomor. As such, some of the housed children died of neglect; those that survived were "brainwashed" with a pro-Soviet, pro-Russian and antiUkrainian mentality. In addition, the orphanages changed the names of the orphaned children to further break their Ukrainian identity and identification with their deceased families.

Loss of traditional way of life. Most participants reported that, in addition to inflicting collective death, the Holodomor destroyed their way of life in terms of Ukrainian traditional independence and self-sufficiency. Participants reported that the confiscation of food, personal property and homes rendered them "bare" and resulted in the complete loss of traditional means to independently support, look after, and maintain themselves and their families. This loss was reported as a "destruction" of independent self-sufficiency that was a "deliberate act to break the will of the Ukrainian people" and "to show people" "that they would not become independent Ukrainian people." In this context of loss of way of life, most participants reported a sense of loss for their family's personal property and material possessions that were confiscated during the Holodomor. Participants reported the loss of foodstuffs, houses, land, livestock, clothing, household furniture and items, and even personal handicrafts:

Mother hid her money. She made money at the train station from tobacco sales. She climbed onto the roof made of straw and hid her money. At one point, she instructed me to climb onto the roof to find this money. Her feet were already swollen and she could not do it. Water was already seeping from her legs. I was thirteen at the time. I climbed up and looked for the money but could not find it. I searched but could not find it. She said be quiet so that the communist does not 
hear you. He came and took our horses away...our cattle... he climbed on top of the house and tore the roof of straw off. The little satchel that mother had hidden fell to the ground. He emptied the contents of the satchel into his own container and threw the empty satchel back at me. (Hafia, First Generation Participant)

Then along came the brigade consisting of Russians. These husky, burly men. They came with a cart and loaded everything up on this cart. We had a wooden chest at that time. They took it. They tied our cow up to the back of the cart. (Marianna, First Generation Participant)

Similar to first generation accounts, the second and third generations also emphatically stated the large scope of confiscation of personal property and possessions. The following second and third generation narratives illustrate the perceived enormity of the loss as some of these participants did not speak of the loss of their parents' and grandparents' personal possessions and property. Instead these participants, born decades after the Holodomor, spoke of the loss of "our" possessions:

The Holodomor hit our family very deeply. Grandmother told me that they took everything away from our home. She had prepared soup on the oven and they even took this cooked soup away. They took away everything. Whatever raw food products we had. Wheat. Grain. Everything. They took away our sewing machine. They took away our bedding. We had a set for a large bed and they took this away. The communist ideology at the time was that they would squeeze out the Ukrainian people. (Liudmila, Second Generation Participant) 
I remember very well that they took away our stable. Here there was a very big house. It still stands. And there was also a space for all of our animals. It was a very large construction. I cannot even picture in my mind how one would dismantle a stable and to transfer it to another location. When they showed me the territory covered by this stable, to the extent that grandmother's parents were considered independent owners. I do not think that independent owners are something bad. They were independent land/property owners. They had a bit of land, they kept bees and had honey. I do not think that they lived excessively. They had what they needed to live comfortably. They worked very hard and did not have any hired help at all. But, when they took the wife of my great grandfather with her young children and threw her out of the house into the snow and did not allow her to enter into her own home. And, when the grandmother against all orders snuck back into this house to get pillows for the children so that they could stay warm in the cold. This shocked me. From what my father told me about the Holodomor, when they would even go so far as to take the last of what was hidden underneath a young sitting child. The last piece of bread. They searched out everything. Even a little bean or crumb that had been hidden under one's foot. Whatever they were able to find and take away. In the first place, for me this is pure wildness. (Sofia, Third Generation Participant)

In addition to the loss of personal property through confiscation, many first and some second generation participants spoke of the loss of small, personal gold and silver valuables and mementos like pendant-crosses and rings. Specifically, participants 
explained how the Soviet regime had set up trading centres across Ukraine where starving Ukrainians could trade small gold and silver items for miniscule amounts of food:

I will tell you about one particular episode. My father participated in the First World War against the Germans. He served in the Russian army. Father was an honest person. He fought honestly. He earned a medal...St. George's Cross. St. George's cross was gold. His was silver. This was for his service as a soldier. During the war, he was responsible for phone communications....The trading store was opened up within the train station. I went and showed them the cross. They took it and said, "what do you want?" I said, "give me a sack full of flour." They said, "no." They gave me a little bag of flour. I brought this flour home. My sister and I immediately cooked food for ourselves. We boiled water and added the flour. It boiled and we ate it. We immediately ate it. We were hungry. There was enough left for another meal. We hid what we had left. On the following day, we heard people knocking on our door. We remained silent sitting there. It was still light outside as the sun had not yet set. They came running up to our home. We lived and slept in the house, while in the little adjacent house/building we had our kitchen. We lived in the kitchen with my sister. We would heat the stove in there. It was warm in there. They ran up to the window of our little house and started to yell, "open up!" Once they spotted us, then I ran up and opened the door. They entered our home and the first question they asked was "where is the flour?" We replied that we had already eaten it. They said, "Do not lie. Where is the flour?" They started shaking their arms. They ran around the entire house looking for this 
flour and could not find this flour. They ran around the house searching and searching. In the house. In the attic. They could not find it. They finally left. We immediately cooked what was left because we knew that otherwise they could come back and find it. We cooked it and ate it immediately. (Onysym, First Generation Participant)

As part of the impact of the Holodomor, the overall loss of familial property and possessions with its associated loss of independence were reported by most participants to have quickly been replaced with forced dependence on the state. Previous selfsufficiency guaranteed all items necessary for sustenance, whereas the new, forced dependency on the state resulted in a complete reliance on the state for employment, food and all items of sustenance. The following first generation excerpt illustrates the dependency that ensued:

People had their own personal property and land and they worked their own land and knew what was needed to live and thrive, whether it be potato or beans. But, at this time you were forced into the collective farm. Everything that you produced had to be given away to the collective farm. Land, horses, poultry/birds, sheep, everything had to be given to the collective farm. And, on the collective farm, things simply began to disappear. Everything was essentially taken away. Sucked away. What did this mean? In the collective farm, everyone had to go into the field and work. You had to spade the beets, gather the produce. And for this they forced people into daily labour. You did not receive any compensation for your labour. How can one possible live in this situation? How can you live in this 
situation? Do you have a chicken in your possession? If yes, then hand over your eggs. Do you have a pig in your possession? If yes, then hand over the meat. Do you have any money, change? If yes, then sign this document and turn your money over. This is what it was like. A totalitarian system. We very much understood what was happening at the time. Mother, even more so because we lived half-orphaned, we absolutely understood what was going on. A single woman was obliged to tend to 7 hectares of beets. First, you had to prepare the land, then you had to get rid of the weeds, then you had to sow and harvest the beets, carrying them to the gathering site because at those times you did not have combines, then you had to clean the beet heads from leaves and to carry the beets to the processing machine. Mother worked 7 hectares of beets. 7 hectares. This is not labour. This is slavery. The world has not known this kind of slavery. Mother worked four rows of beets and we [my brother and I] maintained two rows behind mother. And, all we had all day long for this work was water. There was not even a piece of onion to eat. We were hungry. This is what the system was like. (Roksolana, First Generation Participant)

The second generation also stated that the organized destruction of independence and self-sufficiency during the Holodomor was replaced with dependency on the state for all essential items required for sustenance. This dependence on the state was reported in negative terms as the second generation spoke of struggling for survival just to secure basic, essential goods required for sustenance. Former independence and self-sufficiency were replaced with long line-ups, food stamps/cards, rationing and a lack of essential 
goods. One detailed account describes the impact on the participant's life, whereby state dependency took the form of waiting in long queues for essential items:

I was raised in lineups, you know that people had to line up for [food] cards if you lived in the city. Mother lost her cards, my sister stayed an orphan, half the village came to $\mathrm{O}^{* * * * *}$ to get something, whether salt or something else, but that salt, or that flour, for flour people stood in lineups. I even have a poem about this, about how people stood in lineups, quite simply, in lineups the length of four kilometers beginning to lineup the night before, they stood all night in this lineup.... lived in a communal housing apartment, there were six neighbours who lived together, one apartment consisting of 43 square meters, a giant kitchen where stood five separate stove tops, in other words there was no place to wash/bathe, most went to the Hotel $\mathrm{V}^{* * * * * *}$, a hotel across from the KGB headquarters, people took talons/tokens to enter the bathing area...and gossip and speculation at this time was passed along from one individual to another, all of this was discussed in those lineups across the country, lineups where stood the children as their parents were busy dealing with household matters and preparing things for their families...and young children stood in those lineups. Someone had to be in the lineup at all times because otherwise accusations would be hurled that you were not in line, that someone should have been in line, and therefore we stood. I stood as a five-year old child in those lineups and was essentially raised in those lineups. (Lesia, Second Generation Participant) 
Unlike the first and second generations, the third generation had lived the majority of their years after the collapse of the Soviet Union. As a result, they spoke of the dependency on the state as affecting their families and Ukrainian traditions, in general. Nonetheless, the third generation still noted that the destroyed Ukrainian traditions of independence and self-sufficiency were replaced by dependency on the Soviet state. Resulting from the forced dependency, the third generation spoke of the intergenerational impact of lost knowledge of private ownership, entrepreneurship and free markets:

People used to work on the yards, on the grounds. They were planting seeds for themselves. They were feeding their livestock as we said. While everything is taken, what to do? They were pushed to go to the collective farms to work together. And even there a lot of products were taken away. But still, so all incentives were made so that people could not have their own farm/business as we say...family enterprises, not family enterprises but the private enterprises were killed, the way of life ruined. (Halyna, Third Generation Participant)

Regarding the loss of way of life, the majority of all participants reported that the substitution of traditional means and resources of basic sustenance for state dependency resulted in immediate poverty. In comparison with pre-Holodomor levels, poverty was defined as being "poor" with decreased means for subsistence such as food, shelter and clothing. Further, poverty was said to have been sustained through the generations:

They made us poor. Before that, we were not considered that poor. We considered ourselves normal people, as did all others. The state turned us into unfortunate 
and poor people. Without homes. Without bread. (Onysym, First Generation Participant)

If prior to the Holodomor I had great-grandparents and they lived relatively well. Had there not been a Holodomor there would not have been poverty in my family and we would have continued to thrive and prosper. I think Ukraine, overall, all people would be living better. We would not know the poverty or struggle that we do now. (Nazar, Second Generation Participant)

But when I was thinking about this huge farm that they, that my father's family had. Maybe now we would have our own farms and plants and factories, so something like that. We would be a very big business family, family business or something like that. But now actually, we have nothing but my granny's house and that is it. (Ruslana, Third Generation Participant)

All generations further reported that the loss of traditional Ukrainian ways of independent living also resulted in a degeneration of sense of ownership. In this context, personal responsibility associated with private ownership was replaced with forced communal employment and living, which in turn, resulted in the degeneration and loss of traditional Ukrainian values associated with ownership. Specifically, the proper care and due diligence required in maintaining and improving property, and pride in ownership, were reported to have been lost as a result of the Holodomor. This lost sense of ownership was consistently reported among all generations: 
Back then, if you were to drive around and to spy the fields, everything would be orderly and crops would be sown [pre-Holodomor]. Whereas now, the land is left to its own devices. There are wild grasses and weeds growing in the fields now with nothing being attended to. Our soil would give birth to golden bread. And, no one is doing anything. I do not know where our bread comes from that we eat. You drive around and spy the fields and you can see so much unattended land. Everyday, I see fields that are littered with garbage bags and empty bottles. How much land and possibility there exists. Now we speak about the environmental impact of this garbage and these empty bottles on our land. Why can something not be done to address this garbage? Do something constructive. Why should we have to look out onto this garbage and not know what to do with the land? I spy one field littered and then another. What can be done about this? No one is concerned about this. (Marianna, First Generation Participant)

During the Soviet Union, I jumped to work, I jumped onto the bus. I am standing attempting to look through the filthy glass windows [on the bus], it was so dreary and unpleasant, and [the city] $\mathrm{O}^{* * * * *}$ through this filthy glass is too unpleasant....I am thinking to myself as we travel along, dear Lord, passing five bus stops, I am thinking, what would it be like if this was a private bus and the bus had an owner. In the morning, this owner would come an hour earlier to work, or perhaps hire someone, to make the bus shiny and pleasant for those customers entering into it....I was twenty back then, and this is how I would dream, if only this bus was a private one...and now they are private, and even under these circumstances, they still do not get it...an appreciation of the esthetic must be 
learned, this needs to happen from childhood, from a very young age. (Lesia, Second Generation Participant)

For me, this [the Holodomor] also represented a break in our traditions. One of the things that is lacking is that we have not renewed is our traditional and our institutions....Ownership. Even farming and agricultural production as it relates to land ownership.... This was halted with the death of our elites in the 1930 s.... This tradition disappeared in essence. There was nothing to return to. There was some kind of psychological barrier and that was it. This is quite complicated. (Andrusia, Third Generation Participant)

Regarding the reported lost traditions surrounding property ownership, some participants of all generations also emphasized a specific disrespect of communal/stateowned property that stemmed from the Holodomor. Specifically, confiscation of private property was used to establish state ownership of all assets. And since all property became state-owned and Ukrainians disrespected the state - by extension, participants also reported a disrespect of public/communal/state-owned property. This disrespect, being an impact of the Holodomor, was reported to have been transmitted through the generations. "Lack of respect" and "disrespect" were held responsible for irresponsible littering in public places, lack of interest in beautifying public areas and lack of cleanliness in public places. One second generation participant expressed her frustration with this "lack of respect," which she considered to be a non-traditional, Ukrainian attitude: 
And despite my efforts, no one will even bother carrying out a bottle of water for the flowers. Nor will they bother to sow a seed for a flower. And, each one of them will come to me and say " $\mathrm{L}^{* * * * *}$, if not for you, then nothing would grow here. "Oh you are such a woman." I reply to them, "I am not a woman, I am a Ukrainian. You are not Ukrainian, you are anti-Ukrainian. You are more interested in looking at dog feces and metal scrap in the courtyard. You do not see or notice anything. You do not see where you live and what it really looks like." (Lesia, Second Generation Participant)

As independence and self-sufficiency were replaced by dependence, participants further reported that an "erosion" of "morality" occurred during the Holodomor as Ukrainians began to steal from the state as a necessary means for survival - even though stealing from the state was reported to risk jail terms or even death. Stealing was reported as justifiable as it entailed taking back foodstuffs from the newly formed, confiscated state-owned property and farms that had previously belonged to the participants, themselves. Some participants of all generations raised the issue of stealing commencing during the Holodomor as the only perceived means to combat the newly, established poverty levels. In essence, stealing emerged as a survival technique to combat hunger and malnutrition:

No one gave us anything for our property. Nothing for our inventory. Nothing. Then they would charge you for stealing a piece of grain. If you stole some piece of grain when the combine worked past you, there was a risk that you would get 8 
to10 years in jail. People were imprisoned for this. (Olena, First Generation Participant)

Security stood watch over those fields and would charge and put people in jail for two years for stealing two potatoes. For some grain, there would be a five year penalty. These were not thieves, these were people who were searching for food so that their children would not die, or that their wife would not die. Or, perhaps a mother went out in search of food because she did not have a husband. And, for this she was severely charged and punished. (Mykola, Second Generation Participant)

Before the Holodomor happened, they [grandparents] did not ask for anything from the government, or from the local government or from anybody. Then she [grandmother] told me all these stories that in those times they actually survived by, everything was taken away from them. Everything. Just with no explanation why. It was done. They came. They took everything. They left. And they were punishing people for, not even for stealing of something from the local, it was some kind of unit called the communal work place. Everything belonged to the Soviet power in this unit. So, it was not even stealing of something. It was picking up of little grains from the ground near some farm. And people were punished and killed even for that. (Halyna, Third Generation Participant)

Further, all generations reported that stealing continued after the Holodomor as a means to survive the post-Holodomor, forced dependence on the state. Participants noted that "if you do not steal, you will not survive." Second and third generation participants 
reported that after hearing oral family histories of how the "state" committed the genocide and the destruction of the Ukrainian way of life, they also considered theft (for survival) from the state as justifiable, since it was directed at the oppressors. As one participant stated:

Because they understand that the state after experiences like the Holodomor did not treat them as their home and native land. A state that cares and should care about its citizens. By extension, these people felt that they had a moral right to take the same attitude towards the state. (Danylo, Second Generation Participant)

In addition to the new tolerance of stealing from the state, some members of all generations spoke of the erosion of morality that also created an environment in which other forms of corruption arose. These new forms of corruption, stemming from the impact of the Holodomor, emerged as part of a perceived need for self-preservation against an oppressive state and were reported to include bribery, lack of transparent and good governance, disrespect, and nonadherence to the rule of law. Corruption, transmitted through the generations, was reported to have spread into the spheres of the legislative, executive and judicial branches of government, the electoral process, privatization, education and health care delivery. The following narrative addresses corruption at the governmental level:

There was an impact. Because, it is people who form government and the state. We, ourselves, are building our state/country. And, those people that are intensely nervous, they are the ones that are going into positions within the state administration. And, are trying to steal a piece for themselves, without any regard 
for other people. Just as it was during the Holodomor, people tried to bring something into their family and not concern themselves with their neighbours. Now the same thing is happening perhaps three, four, ten, one hundred times more intensely. People are trying to meet their own needs. And the more they garner for themselves, the better. (Yaroslava, Third Generation Participant)

Also related to state and government, some members of all generations reported a loss of trust in the state/government stemming from the impact of the Holodomor. Specifically, first generation survivors reported that the genocidal actions of the Soviet regime during the Holodomor broke their trust in the state/government:

I will tell you about how they forced us out of our home. They made us leave everything behind. What kind of response and understanding could there be? If you have nothing to eat and are allowed to keep nothing, how else can one look upon the Soviet state. People were dying of hunger. How could one possibly like them? (Onysym, First Generation Participant)

Second and third generation participants also spoke of this loss of trust and how it traversed through the generations. In the following narrative, one third generation participant describes how her Holodomor-related loss of trust in state (and its leadership) prevents her from being able to trust the state in protecting her family's interests:

We remember that this event [the Holodomor] took place. That one should be focused upon living and protecting that which you have created with your own hand. That which you have earned with your own efforts and energy. We have to 
protect and preserve this. Your entire life very much depends upon your work and the efforts which you put into life. This is how we see it. Our leadership in the country, nothing will come of it. We cannot rely on them. Everything depends upon our own efforts and determination. For example, in the present moment, my life very much depends upon my own self-sufficiency and my own efforts and energy. I am responsible for determining how my life will unfold into the future. I am responsible for raising my daughter. (Vasylyna, Third Generation Participant)

Some members of all generations further reported that this loss of trust translated into an apathy toward state-building and working toward trying to effect change at a state/government level. Instead of working toward strengthening the state and good governance, participants reported a greater concern for self-preservation stemming from the Holodomor. Also, in the context of state-building, all generations - but in particular the second and third generations - emphatically stated that the Holodomor "destroyed" Ukrainians' earlier ambitions to form an independent state, as Ukrainians were on the verge of breaking away from the Soviet Union and forming an independent state by the early 1930's:

Where the concept and understanding of the meaning of people was broken. The idea that Ukraine could be independent and self-sufficient, it seems to me that in this context there was an impact. 1932-33 marked the ten year anniversary of the Soviet Union. If earlier, there were notions that Ukraine could become an independent nation-state that could be built, following this, it was understood that it would not be possible to build an independent and separate Ukraine. Because 
the Soviet Union was in existence. And, it seems to me in this vain that this [the Holodomor] took place as a deliberate act to break the will of the Ukrainian people. And, I think that the Ukrainian people understood this. To show people that in their independence as landowners/property owners, they would not become independent Ukrainian people. I think this was the plan, it seems to me. It was in this way that Ukrainians were targeted. (Liza, Third Generation Participant)

Therefore, as a result of the Holodomor, Ukraine remained part of the Soviet Union and was ruled by Moscow until 1991. Even though having achieved independence in 1991, the impact of the Holodomor was noted to still impede Ukraine's current status as an independent nation-state. In this context, participants reported that had the Holodomor not occurred, Ukraine today would be an "incredible" and more "independent" nation, in terms of being stronger, more united, more independent, and a more democratic nation-state. One third generation participant noted that, if not for the impact of the Holodomor, Ukraine would be a member of the European Union.

Related to the development of the state and independence, all generations also expressed a sense of loss for the leading Ukrainians who were defined as independent, self-sufficient, dissidents, entrepreneurs and members of the intelligentsia (intellectuals, writers and those with higher education). Participants reported that had these leading people not perished, Ukraine today would have more entrepreneurs, more individuals with higher education, more community leaders, and better political leadership:

Ukrainians as a unique nation were dealt a huge blow with the Holodomor. The fact that we lost a very significant part of our Ukrainian intelligentsia at this time, 
this very definitely has had an impact in terms of our development and evolution as a nation. Ukraine would likely be very different if we had not lost these people at that time. I suspect that life would be better now for us. If the nation-builders had not been destroyed during the Holodomor in massive quantities, then perhaps our country would have a leader who would be capable of leading our country forward. Even more so, we would likely have a group of potential high-quality leaders who could lead our country. (Mytsyslav, Third Generation Participant)

Loss of Ukrainian culture and ethnic identity. All generations reported a loss of Ukrainian ethnic identity as part of the long-term impact of the Holodomor. This loss of ethnic identity was emphasized as being the "destruction of cultural heritage in Ukraine" and as "a prophylactic, the Holodomor was used to address the issue of ethnicity/identity." Loss of ethnic identity was identified as loss of the Ukrainian language, loss of Ukrainian arts and literature, and loss of Ukrainian religious traditions. The resulting deficiency of ethnic identity was noted to have been passed down through the generations. In addition, participants who raised the issue of lost ethnic identity also spoke of the Holodomor as a mechanism of forced "Russianization." In this context, some participants of all generations (with particular emphasis by the third generation) noted that immediately after the Holodomor, Russians were brought in to re-populate Ukraine:

They even went so far as to try to bring in Russians here. They took away peoples' homes and even went so far as to place their own people [Russians] to live in these homes....They [Russians] were not even capable of maintaining the 
homesteads which they took. Grapevines grew wild. (Kalyna, First Generation Participant)

To revive the Donbass [eastern Ukraine] and south-eastern Ukraine, they moved entire groups of people from Russia. This was the policy. This was the process. I believe that these were policies that were conceived in detail for the ultimate assimilation of the Ukrainian people. (Pylyp, Second Generation Participant)

People were brought in from Russia to inhabit the homes and territory of people who had died. Entire villages were populated. Perhaps we would not have the problems which we presently have with language, the current cries for bilingualism [equal, official status for the Russian language in Ukraine]. We would be a more homogeneous society. (Myroslava, Third Generation Participant)

Re-population with Russians was reported to have sustained and exacerbated the loss of Ukrainian identity brought on by the Holodomor as part of a planned mechanism to further Russianize "our people and things Ukrainian" so that "there would be no ethnic heart." Hence, Russianization was further used to destroy Ukrainian culture (language, etc.) and the Ukrainian way of life to create the "ultimate assimilation of the Ukrainian people" into Russian traditions of dependency on the state, poor sense of ownership, and the Russian language. Further, some of the second and third generation participants noted that re-inhabitation had a particularly deleterious effect on Ukrainian culture in eastern Ukraine. 
In terms of lost ethnic and cultural identity, all generations reported the loss of the Ukrainian language as having stemmed from the impact of the Holodomor. However, this loss was not evenly noted by all generations. Loss of the Ukrainian language was reported by more third generation participants than second generation participants. In turn, more second generation participants reported the loss than first generation participants. In the aftermath of the Holodomor, pressure for Russianization was great as, "Ukrainians were additionally limited because they did not know Russian and as such were precluded from these leadership positions in cities." In addition, "because they did not know the language, it was difficult for them to break into these positions as they could not pass the necessary exams in institutions of higher education."

In the context of language and ethnic identity, the Ukrainian language was emphasized to be essential in providing: ethnic identity, association with Ukrainian culture and history, and kinship with Ukrainians - as an ethnic group. Conversely, loss of Ukrainian language (supplanted by Russian) was reported to break Ukrainians' connections to Ukrainian history, culture, traditions and each other. For, "if there is no language, there is no Ukrainian people. Genocide." In the following quote, a third generation participant addressed the loss of the Ukrainian language in her family that stemmed from the Holodomor:

Because language is the first issue of culture. And I think that anyone without any kind of specific and additional effort should keep your culture. Even speaking Ukrainian is very important to understand what is Ukrainian. Ukrainian was not my first language. Because my grandmother spoke Russian. Grandfather spoke Russian. Although, when they were very young, they spoke Ukrainian. But 
because of all the policies and politics and repression from the Holodomor, they turned more towards Russian. They were fluent in Ukrainian, but they did not use it....Because it is a cultural issue. Language helps you to understand which identity you belong to. Again, it is feeling of nature. It is a feeling of your identity and group. It is a feeling of your past, also. And also not just about the past, but about the future. (Halyna, Third Generation Participant)

A few participants from every generation further noted that the Ukrainian language and culture has come to be viewed as inferior as a result of the ethnocidal nature of the Holodomor. Accompanying the loss and decline of the Ukrainian language and culture was the rise of the Russian language, with the latter being viewed as more prestigious:

The fact that this is a tragedy for Ukraine what happened. It is very difficult for us to comprehend that we need to build our ethnic identity to Ukraine. We have lived to the point where it is embarrassing to speak one's mother tongue. This is a fact. Who thinks that this is a fabrication? I grew up in the city of $\mathrm{D}^{* * * * *}, \mathrm{I}$ completed the $* * * * *$ middle school in the center of $\mathrm{D}^{* * * * *}$ on $\mathrm{M}^{* * * * *}$ Street near the $* * * * *$ Theatre. All of my classmates lived there and it was not considered prestigious to speak in the Ukrainian language. Now there are many who say that it was not like that. Yes, it was like that! The process [of the Holodomor] was created to lead precisely to this. (Pylyp, Second Generation Participant) 
Also reported to be part of the cultural loss, members of all generations spoke of the loss of Ukrainian arts (visual arts, folk art, dance, music) and literature as stemming from the Holodomor's impact. Participants reported that Ukrainian arts were lost with the loss of large-scale deaths of leading Ukrainian artists, writers and musicians. In addition, Soviet-based censorship was implemented, during the Holodomor, to prohibit any rebuilding of Ukrainian artistic traditions and Ukrainian writing styles and perspectives. To fill the void of lost Ukrainian arts and traditions, the Soviet regime swiftly forced an implementation of Russian traditions in the arts and writing onto Ukrainians, as explained by one second generation participant:

The $\mathrm{M}^{* * * *}$ Journal is a sort of elite artistic journal, but it was established in 1933 and at that time had a certain ideological slant. This slant meant that at those times there were those authors who would be published, those that would not be published. That which could be said, that which could not be said. There was censorship. There were many times when we had to cut out sections of the book or to paste stickers atop a particular work. $\mathrm{K}^{* * * *} \mathrm{~s}$ young son assisted us at the printing house in tearing out particular pages from publications. If something undesirable appeared in a particular publication it would be returned to us....In order for people to survive they were forced to accept certain compromises and at our publishing house, they printed everything using Russianization as our new Ukrainian, ethnic identity. (Lesia, Second Generation Participant) Participants reported that this Russianization of Ukrainian identity was easy to achieve as Ukrainians were consumed with basic survival. Participants noted that the arts 
and artistic traditions would be "vibrant" today had the Holodomor not occurred and lamented that Ukrainian arts, artistic traditions, writings, and music have never been reestablished:

I really want to cry because I look at our contemporary writers in Ukraine and there isn't a single writer among them to whom a Nobel prize for writing could be given. We do not have Salman Rushdie, nor Orhana Pamucha nor Maria Vargaselios. No one remains. The situation is that Ukraine was so seriously drained of its blood resources, resulting from what happened. (Sofia, Third Generation Participant)

Some participants of all generations also placed "blame on the Holodomor" for the intergenerational loss of distinctly Ukrainian religious traditions, such as the knowledge/singing of Christmas carols, and the preparation of Easter baskets. Stemming from a Holodomor-related fear, participants reported an acquiescence in giving up Ukrainian customs and accepting Russian ones. The following third generation account illustrates the loss of religious traditions in eastern Ukraine, but not in western Ukraine (since the western region was independent of the Soviet Union during 1932-1933, the Holodomor did not extend to western Ukraine):

If in the west of Ukraine, people continue to sing Christmas carols into the present and there are Christian traditions for Christmas, Easter, etc. In the east of Ukraine this disappeared. Even my grandmother $\mathrm{T}^{* * * * *}$, she sees this [tradition] as something that has been artificially transplanted from the west. Yet the people themselves were genuinely religious, Orthodox, a peaceful, traditional people. A 
psychological barrier emerged. One can place blame on the Holodomor. (Andrusia, Third Generation Participant)

Loss of men. Participants of all generations reported a sense of loss for the men that perished during the genocidal period. Both genders, in the first and second generations, reported this loss. However, only females in the third generation raised this issue. All generations reported that independent and "anti-Soviet" men were specifically targeted and executed during the genocide and for a period of three to five years following the Holodomor. This first generation account provides illustration:

They took away 170 men. They said that they were all green. They claimed all of them were green. He really was green, but in any case, no fool! They took him away and after quite some time, they tried to get the truth out of all of them. And then I cannot imagine how this happened, a notification came back informing us that all 170 men that had been taken away had died. They offered the explanation that there were two illnesses that had taken them away: tuberculosis and some other illness. 170 people cannot simply die from two illnesses. Perhaps some from one and others from the other illness. And this is how my father supposedly died. They likely took them away to force them into labour outside of Kyiv, but he was most likely shot. They took him away April 28, 1938 and then in the month of May they shot him. We received notification and then sorted out what really happened. We drove to the site. You will recall that a few years ago, President Yushchenko held a memorial at the site outside of Kyiv where there was mass killing. It was an anniversary of some sorts...The news came to us that he was 
shot and killed because of his participation in the anti-Soviet revolution. AntiSoviet insurgent revolution. (Luba, First Generation Participant)

Similarly, the following second generation account also illustrates this loss of men:

You understand that after the Holodomor you still had 1937. My grandfather was shot in $\mathrm{T}^{* * * * *}$ and prior to that they sent him to lands in $\mathrm{B}^{* * * * *}$ and told $\mathrm{my}$ grandmother that they formed rows of people for defence which led nowhere. They understood that they were not being sent away to build a railway or whatever else, but rather they were simply sent away to be destroyed. And people who fell, they would be picked up and tied to spruce trees to be eaten to death by mosquitoes. This is how it was, this is a fact. I believe my grandmother. Because I heard this not only from her but from other people. (Pylyp, Second Generation Participant)

As a result of the loss of men, some participants reported a lack of male role models in their lives as an impact of the Holodomor. Every generation raised this issue and reported that they would have more male guidance and support had men not been specifically targeted during the Holodomor:

If my great-grandfather had not died from the Holodomor, I would have been wiser because he would have passed along to me the history of his experience when he fought in the war. He would have passed along his sabre to me when he served in the tsarist army. He would have shared these experiences with me and I could have been wiser. One can speak about these things. That a grandfather 
would have taught his grandson about life. But I did not have single grandfather in my life. I had one single grandmother who was alive, who lost her husband in 1938. He was shot by the NKVD [precursor to the KGB]. Stalin... Had there not been a Holodomor, I would be much more spiritually knowledgeable. I would know more stories from my grandfather. (Mykola, Second Generation Participant)

In addition to the lack of male role models, the loss of men placed extra burdens on female survivors and on their female descendents. Specifically, only female participants noted that, due to the loss of male counterparts and male supports, women were forced to assume additional responsibilities, duties and burdens within the family unit. Further, this assumption of extra burdens was reported to have carried into the second and third generations:

It was predominantly women who struggled and survived the Holodomor. Somehow, they were extremely poor, but still managed to survive. It was extremely difficult. This is truly a fantastic thing. In 1932, my grandmother was about twelve years old during the Holodomor and she managed to survive these atrocities and later gave birth to three sons.... That is why I have such a strange job because in this family, who is the man in this family? Me. Me. Not my mother, not my father. Me. The young man in this family is me. It is rather hard. Because it means hard work. It means duties. And sometimes it is rather hard to feel, not like this normal woman, but a woman with two hard backs. With two hard, heavy backs. It is very hard to find a normal boyfriend. You understand why? Because I 
cannot have high heels, I have two heavy backs. (Sofia, Third Generation Participant)

Also, only reported by female participants, the events surrounding the Holodomor "undermined" men and rendered them more "weak." Some female participants of every generation raised this issue. Since strength was seen as a dangerous liability during and immediately after the Holodomor, this "weakness" in men became reinforced as it was protective. In other words, "strong" men were targeted for death more than "weak" men. Therefore, men quickly assumed such positions of "weakness." "Weakness" was defined as inability to provide leadership, complacency in assuming responsibility and waiting for others to complete required tasks. This "weakness" was not reported to be limited to traditional male and female roles and responsibilities in maintaining traditional malefemale marriages/relationships. Instead, "weakness" was noted to pertain to a broader sphere that also included employment, home, and relationships. One third generation participant explains:

Genocidal policy and its impact on a physiological level and on a spiritual level, it undermines men/the male gender. From men who have been degraded and psychologically impacted...In principle, the man has to be generally in good form. I recognize this problem. It is evident in my generation. We do not have strong, active, creative, responsible men. Everything rests on the shoulders of women. Just as the Holodomor burdened women, just as the collectivization process placed a burden upon women in leading industrial development, just as in the present. But what is worst is the overall attitude towards women. If you ask 
whether I am a feminist, I will tell you that this is something that is not possible here. I am for basic, decent respect. In Ukraine, the reality is that the strong gender is the female one. From the beginning, this is how we are raised. The words "I do not want to" do not exist. Rather, there is the underlying requirement and understanding that you simply must. And, then there are men. He even sneezes and immediately the response is "you poor thing." We are raising a substandard male who is unable to properly adapt to life and to take responsibility for oneself as a leader. (Sofia, Third Generation Participant)

\section{Family Relations}

Included in the family relations theme are participant reports that the Holodomor produced a maladjusted and dysfunctional family type in a minority of the families. Also included in the family relations theme are participant reports of intra-familial and extrafamilial communication strategies regarding the Holodomor.

Two family types: adjusted and maladjusted. The Holodomor was reported to have created maladjustment, disharmony and dysfunctional family functioning in a minority of families. Conversely, the majority of families did not report an impact of the Holodomor on family functioning. For sake of clarity, family Types One and Two are used to denote the families with no reports and with reports of maladjusted family functioning, respectively. Interestingly, only third generation participants raised the issue of dysfunctional family functioning in the Type Two families. These grandchildren spoke about the impact of the Holodomor, commencing with their grandparents and further, how this impact was transmitted through the family lines. The narratives of third generation grandchildren of the Type Two, maladjusted families were remarkably 
similar, in that they attributed the following to the long-term, intergenerational impact of the Holodomor: (i) extremely, strict-controlling parenting styles; (ii) hostility in second generation parents; (iii) fixation of second generation parents on the needs of their survivor, first generation parents; (iv) third generation lack of trust in their parents; and (v) third generation estrangement from their second generation parents. Regarding these latter five points, there were no differences in the third generation reports in describing their male and female parents in Type Two families.

Strict-controlling families. First and foremost, grandchildren (third generation participants) of the Type Two families emphatically reported that the Holodomor directly created a strict, controlling and severe parenting style in their grandparents. Moreover, most of these grandchildren attributed the controlling behaviour to the necessity of survival that was thrust upon their grandparents at a young age. Grandchildren noted that traits of decisiveness, independence, demandingness and taking charge were quickly learned by their grandparents during the 1932-33 genocide as being essential for survival. However, grandchildren reported that, because these traits were acquired under extreme, pervasive and extraordinary life-threatening circumstances, decisiveness, independence, demandingness and taking charge also developed and were incorporated to extreme levels in the personalities of their grandparents. Although these traits proved adaptive and successful for surviving a genocide, the grandchildren reported that these extreme traits were later maladaptive in the personal lives of their grandparents, post-Holodomor - in particular with regard to family functioning and child-rearing. The following third generation account illustrates how the strict and controlling behaviour arose out of the impact of the Holodomor: 
She [grandmother] was forced to grow up very early. And, I think it influenced her character a lot. As well of the character of her sister and brother. And I think a lot of people who survived the Holodomor, they are now different in character. And the next generations, that they could be, if not for those hard times, because she was working since she was 9,10 years old. And now she still, sometimes she behaves strictly and she does not like when anyone tries to argue with her or discuss an issue. She is like, she is used to being very decisive and very strong, because she had to. She had no choice. And sometimes, it seems to me that it is not her. It is her life circumstances that forced her to become such a person. And sometimes it is not easy to deal with her and it does not ease her life as well to be such a strong and strict person. I think it actually influences her relationships with people and everything. So yes, it influenced people a lot, I think. Because they had to be as strict and strong as they could. And they were forced to think about how to survive and not other things that they would like to think about, or something. I think that only a few people had a chance to develop themselves in a way that they would have liked to develop themselves. The others had to do just what they needed to. To survive. I think that personal development was the last, last, last, last stage. (Ruslana, Third Generation Participant)

The grandchildren also spoke of their grandparents' strict-controlling behaviour as a constant attempt to impose their "will" onto other family members, combined with an inability to relate to the views of others. Because of the strict-controlling behaviours in the first generation, the third generation further noted that they often find visits and 
communication with grandparents frustrating, or even avoid such visits altogether. The following third generation narrative provides illustration regarding family relations with the Type Two grandparents:

Yes, because if my grandmother were to decide to do something, it is very hard to convince her not to do it. Or to do it later. Or to do it in another way. So, she is very firm and strict in this way. And sometimes it is a very simple issue like, I do not know, to do some reconstruction in one of the [her] rooms. In other cases, it is something that is more complicated and it is about how she would see her sons or her grandchildren. How she would like them to behave. Or to become somebody or something. So, sometimes it is hard and you have to actually know her very well to explain actually what you mean that you have another opinion. So you have to wait some time to address this issue later. Or just not bother her or something. So, you have to play games with my grandmother very often. And even some issues are very important for her, even if I found them ridiculous, I follow her rules, because I know that it will calm her down and she will feel safe and comfortable if I will do this. And I do this. Every time. (Ruslana, Third Generation Participant)

Further, the grandchildren of the Type Two family also reported that their parents (i.e., the second generation) incorporated the strict and controlling "character" into their personalities and parenting styles, as learned from their own parents (i.e., the survivor, first generation). As such, the third generation participants reported that their parents (i.e., the second generation) also employed the same, excessively strict and controlling 
parenting style with them (i.e., the third generation). The strict controlling behaviours (exhibited by the second generation) were described as attempts to "dominate" and impose parental "will" onto their children, combined with an inability to relate to the views of others. Noting the immense and constant attempts of such domination, one granddaughter found it difficult to believe that her father and grandmother ever thought of this third generation participant (granddaughter) as more than "their pawn" and "little figurine on a chessboard." Another third generation reported that visits and discussions (with their second generation parent) also frequently devolved into arguments:

And my views started to transform, because my father influenced me a lot, when I was living with him and my mother in $\mathrm{T}^{* * * * *}$. And after that when I was introducing some new opinions or something, so we decided to discuss it with my father because before that, it did not even occur to me that I have my own opinion on such issues. Not on everyday life, but on such huge issues, because I was

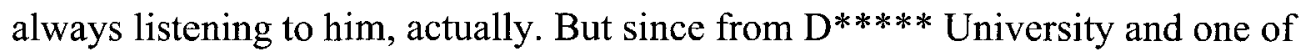
the brightest examples were the 2004 events [rallies] in Ukraine. My father, he was against me participating in all this. He was shouting at me over the phone that I could not do this and that he forbids me. (Ruslana, Third Generation Participant)

The third generation, of the Type Two family, expressed concern that they, too, may have already incorporated the strict-controlling behaviours of their parents and grandparents into themselves. However, the third generation also reported a selfawareness in their attempt to not become like their strict-controlling parents and 
grandparents. The following third generation account illustrates this self-awareness. The magnitude of the strict-controlling behaviour is evident as it is compared to murder:

Sometimes I notice such features in me too. But I am trying to fight them. Because it is not good for me or for people around me. And I try to think about them. Not to harm them. In such a situation, it is a mixture of catharsis and affection. In such a situation it is very simple to kill somebody. Not in physical terms, but in psychological terms. Yes, it is very easy. And it is not good. It is a way for breaking connections between relatives, friends and so on. (Sofia, Third Generation Participant)

Lastly, the third generation of the Type Two family reported that their attempts at voicing their own opinions or challenging their strict, controlling parents were often met with hostility. Hostility was described as "shouting" and shunning. For example, one third generation participant noted that her father and grandmother, when hostile, cease referring to the participant as their daughter or granddaughter, respectively. Instead the participant is shunned by contemptuously being referred to as "the daughter of your mother."

Fixation of second generation on their survivor parents. The grandchildren (third generation) reported that their parents (second generation) placed "first priority" on their survivor (first generation) parents and second priority on their own (third generation) children. Further, the grandchildren of the Type Two family reported that their parents (second generation) placed greater emphasis on meeting the needs of their survivor parents (first generation) than on meeting the needs of their own spouses and 
children (third generation). Consequently, the grandchildren reported having felt ignored and disrespected by their parents in their childhoods and adult lives. Specifically, the grandchildren reported that: (i) their parents (second generation) actively choose to spend more time with their parents (first generation) over spending time with their own children (third generation); (ii) their parents always respected and supported the views and opinions of their survivor parents, but not the views and opinions of their own children especially when conflict between the first and third generations arose; and (iii) their parents (second generation) are more interested in pleasing their survivor parent (first generation) than any other family member.

The following third generation narrative describes how her (second generation) parent spends more time with his (first generation) parent than with his own child (third generation):

$\mathrm{He}$ [father] spends his time with his mother and with his car... He is 64 and on one hand it is normal to spend time with his mother, my grandmother, under proper conditions. But on the other hand, for me it would also be very good to spend time with one's children and wife, together... He is not a tyrant. No. I do not know about the relationship between my mother and father. You know, intimacy. But, he never spent his time with us. He was always with his mother here. We did not spend our weekends together. Even until now. It is rather hard. (Sofia, Third Generation Participant) 
In addition, the grandchildren (third generation) perceived their parents' (second generation) fixation on the survivor grandparents (first generation) to be a source of family tension and quarrels:

Her [grandmother's] decision and her words should be final. For him [father], it is not acceptable to argue with her. And we had a recent discussion on that in the spring. And I was trying to convince him not to agree with something that my granny was proposing. And just to negotiate with her on some issue. It was not like a critical issue. It was a very simple issue when to plant our garden, when to plant it. So, and she wanted to do it three days before. And I said to do it three days after, due to some family circumstances we had. And my father was screaming that, "it is not acceptable. If granny said that she wants to do it on Wednesday, we should do it on Wednesday." And my facts and my logic were that on Saturday we would be all there, so there was no need to be in a rush. Two days or three days would not make any difference. He just could not listen. He did not listen to me. (Ruslana, Third Generation Participant)

With their parents (second generation) not placing primary emphasis on their own children, the third generation (of the Type Two family) expressed that they could not always (or could never) rely on their parents for emotional or other support. This lack of parental support was, in turn, reported to be responsible for causing a lack of trust that the third generation felt towards their (second generation) parents. In other words, the third generation expressed that they could not trust their (second generation) parents, as the (second generation) parents could not provide a "normal" supportive, parental role: 
We have never been close. I have observed this with my friends. Their relationships that they have with their families. With their moms. Once, several times I have tried. But not very successful. So I decided that we are all different and that is OK. Little trust because I know that I cannot trust. Nevertheless, I love her, she's my mom. What to do....Usually I do not tell my mom anything. I only tell her some things about $\mathrm{M}^{* * * * *}$ [daughter]. Not about myself. I can listen to what is going on with my mom and say something. She might ask what I think. I could say. But still it does not really matter for her. She has no interest in talking and listening to the reaction... you know, the majority of what I am doing I am just doing for $\mathrm{M}^{* * * * *}$ [daughter] to make her life better. And my grandmother understands this. For my mother, it is different. And for my mom, she is afraid and more interested in pleasing my grandmother. It was always like this. So, like when I tell my mom that, for me, my first priority is $\mathrm{M}^{* * * * *}$ [daughter], then myself and others. For my mom the first place is her, her mom and then me. (Halyna, Third Generation Participant)

The third generation, of the Type Two family, also reported an emotional estrangement and estrangement through physical alienation. Firstly, the third generation reported an estrangement from their parents, in terms of lack of emotional closeness. The grandchildren described the combination of strict parenting styles, hostility, lack of trust and quarrels as prohibitive obstacles to being "close" or "friends" with their parents. Although having strived to create a sense of closeness with their parents, the grandchildren reported that all attempts had been futile, as the above-mentioned obstacles 
proved too strong to overcome. Because of this emotional estrangement, one third generation participant viewed her parent as "not a father at all," but a "step-father."

Secondly, in an attempt to cope with the exasperation of dealing with their controlling and hostile parents, the grandchildren of Type Two families reported that they sometimes restrict communication and visitation with their parents. Regarding this dynamic of physical estrangement, the grandchildren also reported that their parents sometimes severed communication with their (third generation) children as a response to their children challenging the imposition of parental will. In turn, the grandchildren reported matching this severed communication by also dissolving communication with and imposing alienation from their parents - thus creating a cycle of estrangement:

This silent treatment endures when we are all together. And I have another rebuttal for this. I severely ignore them as well. And I tend to all my affairs here, but I do not keep an active association with them. (Sofia, Third Generation Participant)

Intergenerational patterns of communication. With regards to intergenerational patterns of communication, most of the first generation and some of the second and third generation participants noted that, during the Soviet era (pre-1991), the Holodomor was a "closed subject," "closed topic" or "closed theme." At least one member from most families spoke of this prior "closed subject," "topic" or "theme" status. As such, any public or private Holodomor-related discussion was strictly forbidden. Further, participants reported that execution, deportation to concentration camps in Siberia, loss of employment, and imprisonment were used to deter any Holodomor-related discussion 
during the Soviet-era:

We were forbidden to speak about it at the time. It was not possible to even speak about it. What are you thinking?....Because someone would turn you in for speaking about it and then you risked being taken away to God knows where....We could not speak about it....Many people were taken away. Many men were taken away. And, no one knows what happened to them. (Irka, First Generation Participant)

Under the Soviet Union, this was definitely a closed subject. I will tell you openly, had I raised this topic at the factory...I think that I would have destroyed my career and ended up in a camp, without a doubt. This was forbidden. Everyone had to provide their signature. During the times of the Soviet Union, this was not debated. No one spoke about this. This [the Holodomor] was considered taboo. (Pylyp, Second Generation Participant)

He [father] had a colleague who began to inquire about the situation. He [father's colleague] began to ask, "how are things really." The response he [father] gave was that people in the village were eating frogs. "There is nothing, they are eating frogs." And, when those around him realized that he [father] was speaking about the Holodomor, he [father] was assigned three years in prison for even discussing the subject....He [father] was given three years, then following these three years, they gave him another three years....He served in Siberia in $\mathrm{L}^{* * * * *}$. He spoke and said that the evenings were so bitterly cold that one could die from freezing. (Volodymyr, Second Generation Participant) 
Therefore prior to 1991, Holodomor-related conversation took place in this reported backdrop of reprisal. While considering the "closed topic" status of the Holodomor, three types of intergenerational patterns of communication regarding familial history of the Holodomor were observed in the narratives: (i) Most families reported open communication between all generations. (ii) Some families reported that the grandparent was the conveyor of information to the second and third generations. (iii) Few families reported limited or no conversation between any generations.

Open communication between all generations. In families with what I have called an "open" style of communication, each generation reported having had open conversations about the Holodomor, as it related to their family, with every other generation in their family. First generation participants reported sharing their experiences with subsequent generations and, moreover, second and third generation participants were able to communicate descriptive details about the ordeals of their first generation, survivor family members. Lastly, members in these families reported to have had discussions, prior to 1991, despite the repressive Soviet-era. The following, multigenerational narratives of the "open" family explain how each participant had Holodomor-related conversation with every other generation in their family:

I would tell them [children] about the life that I had. [For example,] my mother was in $\mathrm{K}^{* * * * *}$, things got a little easier when she came home. Then, I was taken from the orphanage to work in the collective farm when I was twelve or thirteen. I told them what it was like....I told them [grandchildren] about how difficult it was. 
How could they possibly guess what I lived through? (Lev, First Generation Participant)

And, practically speaking, that is what each child from a young age should know about. And, when I think of my father, these are the things that I hold in my heart. Every Ukrainian should hold this in their memory. It is this knowledge and reality which should unite the entire Ukrainian nation.... Of course, we are going to make sure that our children know about this. Our children know about this. We have a grandson. When he begins to understand things, we will tell him about this. We'll show you a picture of our children... Yes, this is the history of our family. The history of Ukraine is taught through the history of our family. (Svyatoslav, Second Generation)

He [father] explained to me what had happened. He [father] was very interested in this topic and he shared a lot of this information with me. And, now thanks to this, I have a certain level of understanding and knowledge about what happened.... Of course, she [grandmother] shared a lot of information about what she lived through. For me it was quite interesting and I feel that all educated adult persons should know about this information and make use of it in their day to day lives. (Ivan, Third Generation Participant)

Grandparent as the conveyor of information. Families which reported the grandparents as the conveyors of information noted that conversations occurred between the first and second generations and between the first and third generations. No conversations were reported to have occurred between the second and third generations. 
As such, the second and third generations obtained all of their Holodomor-related family history directly from the survivor first generation. Therefore, I have called this communication the "grandparent conveyor" style of intra-familial communication. Like the "open" family type of communication, the second and third generation participants were able to communicate descriptive details about the experiences of their first generation, survivor family members. The "closed theme" status did not appear to be a deterrent against intra-familial conversation, as most of the "grandparent conveyor" type also had conversations during the Soviet era. Regarding reasons for not having conversations with their children (third generation): many of the second generation participants reported that the survivor parents (first generation) were a better source of information; many reported that their children learned about the topic in school; and some simply reported not having set aside time for Holodomor-related conversations with their children. The following second generation account illustrates:

She [mother] told me about how they took things away. They took their bread away. At time the harvest was not a bad one. They did not allow people to live on the food and things that they had. They forcefully took things away from people. Hunger set in. The NKVD or the KGB, however it was called, did not allow people to leave Ukraine at the time...My children know about this topic from their school textbooks. Their textbooks provided limited information about this. Grandmother certainly shared a lot. (Bohdana, Second Generation Participant)

The following third generation narrative illustrates the communication between the first and third generations, with no communication between the second and third 
generations, in the "grandparent conveyor" family:

She [grandmother] shared about how difficult it was to find food. She told me about what they had to do to survive during these times. She told me about their struggles and how desperate the situation was back then. How painful it all was at the time... [With mother] No. There were no such discussions. (Pavlo, Third Generation Participant)

Limited or no family conversation. The third type of intergenerational style of communication occurred in families where little or no conversation took place between any of the generations. Hence, I called this the "limited or no" conversation family. Interestingly, the few families that reported limited or no intergenerational communication regarding the Holodomor were also families that belonged to the Type Two (maladjusted) family type. Conversely, no members of the Type One (well-adjusted) families reported limited or no intra-familial, Holodomor-related discussion.

In the families that reported little or no conversation, at least one family member pointed to the fear of Soviet-era deterrents against discussion as the determining factor for limiting conversation prior to and sometimes even after 1991. Primarily, first and second generation participants reported speaking more openly, within their families, about their familial experiences with the Holodomor after the fall of the Soviet Union and subsequent Ukrainian independence. However even after 1991, conversation was noted to still be limited or non-existent between all the generations. Specifically, first generation participants noted little or no conversation with their descendents. In one of the "limited or no conversation" families, the survivor grandparent kept her survivor status a secret 
(from her family) for sixty years. Overall, second and third generation participants did not provide descriptive narratives of the first generation survivor experiences in their families. The following two excerpts illustrate the contrast between the "open" and "limited or no discussion" styles of intra-familial communication, respectively:

How could there not be [discussions]? When our family gathers. If to gather just our immediate family in this outdoor gazebo there are twenty to twenty-four of us, depending upon who is able to gather. And from various generations. Mother's oldest sister has been present, and mother's older brother, but he is no longer alive. Everyone together and all the kids and everyone begins to share. And the grandchildren begin to inquire, what was it like? What happened? And, the greatgrandmother would share stories of their experiences with her family. We do not have a situation where this information is not passed along. It gets passed along from generation to generation. This is like an inheritance that is passed along. (Mykhailo, Second Generation Participant on "Open" Communication)

I would say this. On purpose to discuss this topic. No. I do not believe that this topic can be raised deliberately for discussion [with my children]. (Anton, Second Generation Participant on "Limited/No" Communication)

No participant in the study denied that the Holodomor occurred or that the Holodomor was genocide. However, in all of the "limited or no" conversation families, participants reported that one member of an earlier generation had previously denied the Holodomor. Specifically, in one instance, the third generation (grandchild) and the second generation (parent) reported that the survivor-grandparent "is changing her 
position, from time to time" by sometimes speaking of the Holodomor as genocide while at other times, speaking of the Holodomor as a naturally occurring famine. In another "limited or no" conversation family, the third generation grandchild reported that her father, at times, spoke of the Holodomor in non-genocidal terms.

In the "limited or no" conversation families, participants noted that any sort of denial or quasi-denial in antecedent generations probably resulted from the influence of twentieth century, Soviet-denial propaganda. As an example, the following second generation participant addressed the denial of the Holodomor by her survivor mother. The participant further reported that her mother viewed the Holodomor as punishment for acts of "sabotage" against the Soviet regime:

People who were formed at the time of Stalin, were like. She [mother] cannot, when she cries, she wants to believe in the rhetoric that existed earlier. Sabotage. This in turns means enemies. She wants to believe because otherwise, if she will not believe this, that which they forced her to believe, then one has to essentially discount one's entire life. One has to agree with the fact that they were deceived. This essentially means that they used you and by extension tricked you and tricked you the entire time and you did not understand this or know. (Lesia, Second Generation Participant)

Interestingly however, in my interviews with the above-mentioned participants who were reported to have some sort of Holodomor-denial sentiment by their family members, all spoke of the Holodomor as a genocide. Additionally, all of the families with reports of denial or quasi-denial belonged to the Type Two (maladjusted) family type. No 
denial of the Holodomor was reported in any of the "open" or "grandparent as conveyor" families.

Importance of family discussion. In total, few of the first, some of the second, and many of the third generation participants raised the issue of the importance of family discussion regarding the Holodomor. Moreover, all of the participants who stressed the importance of intra-familial conversation belonged to the previously mentioned "open" style of communication. Overall, at least one member from each "open" style of communication family reported this issue. Four underlying reasons for the importance of family discussion were raised: (i) to promote a deeper, personalized understanding of the Holodomor; (ii) to understand the "truth" of the Holodomor; (iii) to help bring closure to the trauma of the Holodomor; and (iv) to prevent another genocide against Ukrainians.

Participants noted that family discussions promoted a deeper understanding of the Holodomor by creating personal connections to family history. Overall, at least one member from every "open" communication family expressed the importance of deeper understanding via personal connection through family history, as explained by the following third generation participant:

Because I did not understand this fully when I first came across this. Against the backdrop, when you turn on the television and they are showing Hollywood blockbusters when people are dying or children, it is difficult to really comprehend. Then, when your beloved family begins to tell you that your grandmother experienced such horror and that it was her close family that died, you immediately begin to relate personally and think, what if this happened to my own brother? This is horrific. (Orysia, 


\section{Third Generation Participant)}

This personal connection to family history, and hence to the events of the Holodomor, was reported to augment understanding and ability to "relate" to the Holodomor "and make it real" in a way that "books" or "school" could not:

So, yes, we definitely discussed this topic. Because to tell you the truth, at school you cannot discuss this topic as you would at home. Here they would tell you what it was really like. (Savelia, Third Generation Participant)

In many of the families with the "open" style of communication, participants spoke of family discussions as being important to realize the "truth" of the Holodomor meaning that the genocide really occurred. In this context, the "truth" also helped to counter former Soviet and current Russian denial of the Holodomor. The following first generation participant describes the importance of imparting the "truth" onto her descendents:

They have to know everything. It is imperative that they know everything. My children, grandchildren and great-grandchildren, we tell them everything. About how everything was taken away from people and about the Holodomor. We tell them everything, everything. Our children know, as do our grandchildren and great-grandchildren. I also speak like this with other people. They believe me. They recognize that this is the truth. (Stephania, First Generation Participant)

The following second generation account explains the importance of sharing the "truth" to combat denial of the Holodomor. 
You know, the historical situation was such that for many years this issue was kept silent. However, in our family I was still a young child five or six years old, within our family this issue was brought to light. I was very fortunate in this light because my grandmother was a very smart woman. She had little formal education. She survived this historical event, this tragedy and thanks to her and my parents, I was fortunate enough to her for very many details from those times. Last year, I travelled to the homeland [specific region in Ukraine] of my parents $\mathrm{D}^{* * * * *}$ region. They took me to the cemetery where people are buried without crosses. Simply mounds of earth where lie people from the Holodomor. I can tell you with a complete sense of responsibility and accountability that the Holodomor, regardless of what others have said or whatever version of what happened is being put forward, this was genocide of the Ukrainian people. Period. And, for me this is fundamental to what happened. It was genocide regardless of what the United Nations, Russia, Ukraine, or state officials may or may not say. A tragedy of the Ukrainian people. (Pylyp, Second Generation Participant)

Some of first and third generation participants in families with "open" communication spoke of facilitating understanding via discussion to "free" themselves of a familial traumatic past, and thereby being able to move forward with their lives. These participants noted that "history is connected to our future" and coming to terms with "where their family line has come from" helps to move ahead.

Of the "open" communication families, a few second and some third generation participants reported the importance of intra-familial discussion for raising awareness in 
order to prevent another genocide against Ukrainians. The following third generation account provides illustration:

Over and over, we [the family] return to our thoughts about the fact that each individual has to have their own understanding of this....I think that if you do not understand the history of the past, both the positive stories as well as the sad ones, then you are not able to avoid future mistakes which potentially stand before you. And this history could repeat itself. That simple. (Tymofiy, Third Generation Participant)

Extra-familial discussion. The majority of all generations reported having had some Holodomor-related discussion outside of the confines of the family; however, many participants reported having no conversation outside of the family. Of the participants who reported extra-familial conversation, many reported having at least some in-depth conversation, while some reported having had very limited, non-detailed conversation. Overall, however, those who reported outside of family conversation noted that such conversation tended to be infrequent. Interestingly, the majority of participants who reported some in-depth, extra-familial discussion belonged to the "open" style of intrafamilial communication. Conversely, the majority of participants who reported no outside of family discussion belonged to families of the "limited/no" or "grandparent as conveyor of information" styles of intra-familial communication.

In-depth conversation. Some first and second and many third generation participants reported having at least some in-depth conversation outside the family. First generation participants noted the importance of outside of family conversation to: help 
promote awareness, combat denial, and function as an outlet to share personal recollections and experiences:

Yes, beyond our family. People around us lived the same reality that we did. We shared this experience and spoke about it. We would inquire about things from one another. Friends know such details about one another especially about those that are no longer around. We shared in this experience of suffering and it continues to reach into the present. (Marianna, First Generation Participant)

Second generation participants noted the importance of outside family discussion to: raise Holodomor awareness, combat denial, prevent another genocide against Ukrainians, and help to better understand the Holodomor:

I would like to add that we discuss this topic with our friends and colleagues.

Earlier, there simply was no desire for this. It turns out that there were independent Ukrainian land owners everywhere. In every family, it turns out that land and property was taken away. In Ukraine, we never had people who were genuinely poverty stricken [prior to the Holodomor]. This process essentially impacted and touched our entire population. (Svyatoslav, Second Generation Participant)

Third generation participants stressed the importance of extra-familial discussion to: help better understand the Holodomor, raise awareness, prevent another genocide, share family information, prevent denial, and understand the long-term impact of the Holodomor: 
[As as result of the Holodomor], there is this self-preservation mode. Selfpreservation is something that is quite prevalent and visible among Ukrainians. This is something that we discussed with friends and also observed that we are always living in a survival mode and this is constant. (Myroslava, Third Generation Participant)

Limited outside of family discussion. Some first and second and a few third generation participants reported having little conversation outside of the family unit. Unlike the participants who reported to have had some extra-familial, in-depth conversation - no participant who reported having had limited extra-familial conversation noted the importance of such discussion. Even though no longer relevant, a few of the first and second generation participants cited the former Soviet-enforced, "closed-topic" aspect of the genocide in limiting Holodomor-related, extra-familial discussion. One first generation participant also noted that "earlier people were not that interested in this topic." A few from all generations, who reported little extra-familial conversation, provided no explanation as to their limited discussion outside of the family unit.

No outside of family conversation. Some of all generations reported having no Holodomor-related discussion outside of the family. Many of these participants provided no explanation for not having extra-familial discussion. However, one first generation participant reported fear of reprisal for holding outside of family conversation. One second generation participant noted the former, Soviet-enforced, "closed-theme" aspect of the Holodomor as the rationale for not having discussion outside of the family unit. Lastly, one third generation participant noted that to "recall this horror" of the 
Holodomor precluded extra-familial discussion:

We do not want to recall this horror....I cannot say that I have in-depth discussions with my friends on this topic. We do not interact about this subject. Nor do I have discussions with my work colleagues about this subject. (Yaroslava, Third Generation Participant) 


\section{Discussion}

Overall, the families' narratives offered a multigenerational perspective on their perceptions of the Holodomor and its long-term, intergenerational impact. Within the three superordinate themes, all generations spoke of the impact in terms of emotions, behaviours, well-being, family relations and communication strategies. These reports were consistent with the results of other studies on the intergenerational impact of collective trauma. For example, fear and mistrust (Rowland-Klein \& Dunlop, 1997), anger (Iliceto et al., 2009; Kalayjian et al., 1996), shame, loss, anxiety, and family disharmony (Harkness, 1993; Rowland-Klein \& Dunlop, 1997) have all been reported to be prevalent in survivor families of collective traumas and were also noted by the participants of this study. With regard to the Holodomor's effect on family functioning, the strict-controlling, hostile parenting styles in some Ukrainian families are analogous to the literature's reports of lack of boundaries and dysfunction in survivor families (Rowland-Klein \& Dunlop, 1997). The third generation participants reports of their parents placing a "first priority" on their survivor (first generation) parents and second priority on their own (third generation) children are also supported by findings in the literature of enmeshing, symbiotic relationships between survivors and their children in survivor families of collective trauma (Rowland-Klein \& Dunlop, 1997).

However, unlike the majority of research on survivor families in the literature, most of the participants in this study reported some in-depth intra-familial conversation. But consistent with the literature, most of the participants in this study reported infrequent, extra-familial discussion. Further unique to this study, the participants also reported a fear to take action, emphasis on and reverence for food, loss of traditional 
ways of life, loss of trust in the state, an indifference to the needs of others, and the perpetual need for survival that included stockpiling/hoarding of food and the inability to discard unnecessary/unwanted items.

The reported impacts of trauma, stemming from the Holodomor, such as stockpiling, inability to discard, hostility, indifference toward others and a fear to take action also seemed to be related to a perpetual, continual state of perceived need for survival. Further, self-preservation was reported just as frequently, or even more frequently, by the second and third generations than the survivor, first generation. This continual need for self-preservation and safety seems to lend itself to Maslow's (1970) hierarchy of motivation for needs that includes a progressive achievement from (i) biology to (ii) safety to (iii) attachment to (iv) esteem and lastly to (v) self-actualization. In the latter (highest) level, an individual is able to realize their highest potential. Based on first generation reports, the Holodomor forced survivor participants into the lowest levels where the needs for food and safety served as the primary motivators. The second stage in Maslow's hierarchy addresses the need for self-preservation. To this end, the majority of the participants spoke of the perceived, perpetual need for self-preservation as a transgenerational impact of the Holodomor. With regard to the impact of trauma, the literature suggests that trauma victims (including children) may become preoccupied with self-preservation (Terr, 1979). However, the second and third generations of this study also emphasized their continual need for survival as stemming from the transgenerational impact of trauma inflicted by the Holodomor.

Also unique to this study on intergenerational transmission of trauma was the effect of the continual need for preservation on mental well-being. The cyclical process 
of stress and anxiety from the Holodomor-induced "survival mode" and its resultant unattainable need for achievement, learning, stockpiling, saving, and striving was reported to lead to decreased self-esteem. When self-esteem was reported to decrease with associated feelings of regret and disdain for the self, participants reported comparing themselves to others (who were thought to be achieving or have more, like parents, grandparents) as an impetus to achieve more and, thereby, increase self-esteem. As part of the cycle, the comparison would reportedly again provide motivation and inspiration for more unattainable striving that would ultimately lead to more negative self-thoughts and decreased self-esteem. This approach was reported to be irrational and illogical, but was still noted to be utilized by some third generation participants. Overall, the timeconsuming and exhaustive nature of the constant need to achieve safety and selfpreservation was reported to be related to poorer well-being. Lazarus (1984) found an analogous relationship in that, as daily chronic stressors increased in frequency and intensity, similar mental health concerns also increased.

Regarding loss, second and third generation narratives suggest that the impact of trauma has never been negated - because the impacts of traumatic loss have never been restored. In this context, the second and third generations may be struggling with the same after-affects of trauma as the survivors. As a result, the second and third generations seem to be coping with the same impacts of trauma and trauma-related stresses originally experienced by the Holodomor survivors, such as loss of way of life, loss of identity and increased poverty. Further, these trauma-related stresses in the second and third generations may have manifested into risky behaviours in an attempt to diminish the effects of trauma. Hence, participant reports of increased alcohol use, hostility, and risky 
behaviours that increase contraction of HIV/AIDS, as stemming from the intergenerational impacts of the Holodomor, are plausible as the literature suggests that such coping processes are used to attenuate the impact of trauma. The literature further suggests that to attenuate the effects of trauma, individuals are more likely to engage in risky health behaviours such as unprotected sexual intercourse, drug use (Vetter, Rossegger, Rossler, Bisson, \& Endrass, 2008; Wagner et al., 2009), smoking (Nandi, Galea, Ahern, \& Vlahov, 2005; Parslow \& Jorm, 2006), and alcohol use and abuse (Vlahov et al., 2004). Moreover, substance use may potentiate future anxiety, depression, general distress and decreased quality of life (Adams, Boscarino, \& Galea, 2006). Therefore in Ukraine, substance use and trauma-related stress may be inter-related in a cycle of sorts and may be passed down, intergenerationally.

The second and third generations never experienced the genocide of 1932-1933, yet they reported to still be experiencing the same impacts of the Holodomor on emotions, behaviours and well-being, and on sense of loss as did the first generation. The second and third generations cited two reasons for the intergenerational transmission of trauma into their own lives. First, the behaviours, fears, etc., stemming from the Holodomor, were learned from their parents and continue to be passed down from generation to generation as learned behaviours. For example, the stockpiling of food items was reported to be learned in the family unit. Second, behaviours like hostility were reported to occur outside of the family unit, at a community-societal level and were also reported to be transmitted intergenerationally through exposure to the societal environment. With regards to the influence of the societal environment, the fact that hostility was reported to be increasing with every generation removed from the 
Holodomor might explain why only third generation participants chose to raise this issue. Further, the hostility was reported to manifest itself as bullying and physical fighting among Ukrainian children, in general. The literature also suggests that exposure to trauma may also elucidate aggressive behaviour (Field, Claassen, \& O'Keefe, 2001).

Overall, the intergenerational findings of this study are analogous to the literature's constellation of perceptions, emotions, behaviours and family functioning related to transgenerational trauma (Harkness, 1993; Kalayjian et al., 1996; Kupelian, 1993; Lev-Wiesel, 2007; Major, 1996; Nagata, 1993; Rowland-Klein \& Dunlop, 1997). As such, participants' narratives of this study, combined with corroborating findings in the literature, strongly suggest that the impact of the trauma from the Holodomor has been intergenerationally transmitted in survivor families in Ukraine. Since most of the same fears, losses, behaviours, and effects on well-being reported by the first generation were also reported by the second and third generations, the impacts of the trauma of the Holodomor appear to still be exerting their effects on the second and third generations.

Perhaps, the most convincing evidence for Holodomor-related trauma still impacting descendents of survivors were the second and third generation reports of engaging in food stockpiling as a coping strategy. Nowhere in the literature could I find evidence of food stockpiling as a universal coping strategy to ameliorate the impact of trauma. I posit that if food stockpiling was a very specific coping strategy used to attenuate fear and trauma of death by forced genocidal-starvation in the first generation, then the impact of the Holodomor is still affecting second and third generation Ukrainians - as they are using the same, survival, coping strategies of their grandparents 
to ameliorate the effects of trauma, in 2010 , stemming from a genocide that occurred in 1932-1933. As such, the impact of trauma is very likely traversing the generations.

\section{Theories, Models and Mechanisms}

Although the purpose of this study was not to test models or theories of transgenerational trauma transmission, the results may lend themselves to interpretation by existing models and theories. Further, the models and theories presented below were not necessarily developed to explain intergenerational trauma transmission.

Cognitive social learning theory. Bandura's social-cognitive model (Bandura, 2000) may be applied with its interaction of environment, the individual and behaviour affecting learning and development. Behaviour may be influenced by prior beliefs, history and the environment. During the genocide of 1932-1933, survivors may have assessed and been influenced by the environment of atrocity (i.e, the need to survive) surrounding the Holodomor and formulated survival behaviours, such as the concealment of food, extreme reverence toward food, and the stealing of food items. According to the tenets of Bandura (2000), these behaviours would have been reinforced from the environment - with the reinforcement being survival during genocide. Further, the participants of this study reported that, during the Holodomor, behaviours such as taking action and speaking out were often punished with execution and imprisonment. Applying the tenets of Bandura - through observation of punishment, the first generation learned not to take action, not to speak out and not to trust others. In this context, survivor reports of the need to "keep quiet" were reinforced. In addition, because men were additionally targeted for execution, the punishments, reinforcements and social learning were greater for males than females. In turn, this process created the "weak" male reported by females. 
Alternatively plausible is that, prior to the Holodomor, women were already socialized to be more inactive. Therefore, the effects of the Holodomor appeared to more significantly affect men, when in actuality, both genders were impacted and socialized by the Holodomor to "keep quiet."

First generation participants reported the futile attempts at resistance during the genocide. This sense of futility may have influenced the first generation's self-efficacy (Bandura, 1997) to the point where participants no longer wanted to take chances as they expected any attempt to take action to be ineffectual. Further, because the Holodomor (or the change in the environment) occurred on a massive and collective scale, the observational learning, punishments and reinforcements most likely also occurred on a severe and massive-collective scale. This latter learning, combined with decreased selfefficacy, may have resulted in significant and permanent changes in the first generation's beliefs, attitudes and behaviours. Again, because a critical mass of Ukrainians were affected, the changes also collectively influenced the environment, reciprocally and were sustained in the society, post-Holodomor. Offspring of survivors were then born into the sustained influences of the post-Holodomor society. As a result, they too were influenced by the behaviours, attitudes, and perceptions acquired by their parents during the Holodomor. Therefore, the combination of intra-familial learning and influences of the community-societal environment transmitted the impacts of the original trauma into the second and third generations. As such, the second and third generations reported the transmission of stockpiling, the continual need for survival, fear to take action, indifference toward others, hostility, among other impacts. 
In the same way that Bandura's cognitive social-learning theory might explain the second and third generation reports of intergenerational transmission of fears and behaviours, the strict-controlling and hostile parenting styles may have also been learned during the Holodomor and, henceforth, were transmitted through the generations. In terms of parenting styles, the family unit was probably the greatest influence in transmission.

In applying Bandura's (1991) tenets of morality (social cognitive theory of moral thought and action), reports of stealing were noted as an "erosion of societal morality," whereby an awareness of moral rules and regulations was prevalent (Bandura's moral competence); however, motivation was rewarded with the possibility of sustainment of life, and therefore, stealing emerged (Bandura's moral performance). In the new environment of Bandura's diminished moral performance, corruption also arose.

Ecological systems theory of the family. The tenets of Bronfenbrenner's (1979, $1986,1995)$ chronosystem dimension of the ecological systems theory of children and families may also be applied to help explain the current results of trauma transmission. In theory, the chronosystem dimension is always in a state of flux and, in turn, explains the flux in all other dimensions (micro, meso, exo, and macrosytems). However, the Holodomor seems to have represented more than a flux or alteration in the chronosystem as the participants did not report the impact of the Holodomor in terms of changing or altering the family structure, employment (microsystem), social settings, extended family (exosystem), and the culture, norms and beliefs (macrosytem). Instead, participants emphatically spoke of the destruction of all these systems. Specifically, first generation participants spoke of the death of family members creating permanent changes in the 
family units. Loss of homes and possessions of the microsystem were also noted. The first generation also spoke of the destruction of the extended family, parental workplaces (exosystem), and the cultural norms and values of independence and self-sufficiency (macrosystem). In this background of destruction, all of Bronfenbrenner's interactive systems responsible for psychological development and family life, unfolded.

Through the centuries, family structure evolved as a means to protect and nurture the development of children (Bjorklund, Yunger, \& Pellegrini, 2002). During the Holodomor, the stability of the family structure was destroyed as parents were deprived of the ability to even meet the basic survival needs of their children. In this context and based on the tenets of Bronfenbrenner, the chronosytem may have created the conditions whereby some children of the Holodomor (first generation) incorporated the reported strict and extremely controlling behaviours into their development in an attempt to survive the changes/flux (i.e., dangers) in the various systems (i.e., family, community, etc.). However, once incorporated into their personalities, the strict-controlling behaviours were maladaptive in their (first generation) adulthoods, post-Holodomor. Therefore, later as adults, these survivors of the Holodomor (first generation) were reported to raise their own offspring with what could be called the "authoritarian-power assertive" parenting style (Baumrind, 1975, 1991), characterized by: demandingness (Maccoby \& Martin, 1983), controlling (Kilgore, Snyder, \& Lentz, 2000) their children like "marionettes" (Kail \& Barnfield, 2009, p. 477), and lack of open communication (Gerrig, Zimbardo, Desmarais, \& Ivanco, 2009). As a result of the second generation participants being raised in and influenced by a microsystem of extremely authoritarian parents, the children of the survivors (second generation) learned these authoritartian 
parenting styles and used them in raising the third generation. In this context, trauma affected parenting styles, which in turn were transmitted through the generations. The research of Belsky, Jaffee, Sligo, Woodward and Silva (2005), indeed, suggests that both supportive and harsh parenting styles are transmitted intergenerationally.

The tenets of Bronfenbrenner suggest that the individual's immediate, familial environment and the societal environment influence each other and the development of the child. Since the large-scale nature of the Holodomor affected individual families and societal structures across Ukraine, the ecology theory suggests that the changes incorporated into society and the family would influence each other and the child's development. In the same way that the ecology systems theory might explain the second and third generation reports of the emergence and intergenerational transmission of parenting styles, new survival behaviours may also have been incorporated as learned strategies into the development of the children (as influenced by the microsystem and exosystem during the Holodomor) as a mechanism to protect the self against the destructive elements in the changing exosystem (genocide). Subsequently, fear to take action, stockpiling, indifference toward others, fear and mistrust of others, and other impacts of trauma developed as strategies for self-preservation and were transmitted through the generations in the family unit (microsystem) and in the greater community (exosystem). The results of this study do, indeed, suggest that the impact of trauma was transgenerationally transmitted via the microsystem and the exosystem. According to the ecological theory, the impacts of the Holodomor may have even also been embedded into the macrosystem of beliefs, culture and attitudes. The macrosystem, in turn, may have re- 
enforced the propagation of the impacts of trauma on society which, in turn affected the family. Hence, the original impacts of trauma were intergenerationally transmitted.

The second and third generations emphatically noted the loss and the impact of loss on par, with the first generation. In some instances, loss and the impacts of loss were more greatly reported by the second and third generations. In this context, loss and the impact of loss of the Holodomor was as evident in, and relevant to, the first generation survivors as it was as evident in, and relevant to, the second and third generations. Children and grandchildren of survivors reported that the destroyed traditional Ukrainian ways of life, culture, and family units were never restored or re-built. Instead, the Ukrainian traditional ways of life were forcibly replaced with a Soviet-Russian way of life resulting in poverty, dependency on state and corruption. As such, the sense of loss from the Holodomor that affected Ukrainians in the 1930's still seems to be felt by, and to impact, the second and third generations today. In this context, participants may actually be noting a sense of loss for the break or rupture in the microsystem (family losses), exosystem (societal-community losses) and macrosystems (loss of beliefs and attitudes) in Bronfenbrenner's theory of ecological systems.

Secondary traumatization. As mentioned in the introduction, research suggests that secondary traumatization may be prevalent in the helping "professional groups" (Vrklevski \& Franklin, 2008, p. 107) like social workers (Cornille \& Meyers, 1999) and clinicians (Elwood et al., 2011). Although to date the vast majority of the literature has focused on professional relationships (Feldman \& Kaal, 2007), secondary traumatization may also affect friends, family members and caregivers who play a significant role in the life of the trauma victim (Figley, 1995). Continual and daily exposure to disclosure of 
traumatic experiences is the proposed mechanism for transmission of secondary trauma (Elwood et al., 2011) and may result in the development of PTSD-like symptoms (Figley, 1995), sub-clinical depression and anxiety (Suozzia \& Motta, 2004), and newly acquired negative beliefs regarding personal safety, independence, esteem and intimacy (Pearlman \& Saakvitne, 1995) similar to those of the actual trauma survivors.

In the context of the current findings, exposure to disclosure as the mechanism of secondary trauma transmission (Elwood et al., 2011) may not readily lend itself to explaining the results of this study. Firstly, the participants of this study did not report the frequency or duration of exposure to disclosure as would be encountered by a clinician, social worker or other members of a helping profession. Secondly, although secondary traumatization may develop from cumulative exposure to disclosure of traumatic experiences (Pearlman \& Saakvitne, 1995), the participants in this study did not report the usual disrupted psychological well-being (Elwood et al., 2011) associated with secondary traumatization, such as intrusive thoughts, avoidance behaviours, and arousal (Figley, 1995). Instead, the majority of participants emphasized many benefits of exposure to disclosure and knowledge of their family histories and experiences of Holodomor-related trauma.

Attachment theory. Bar-On et al. (1998) proposed attachment theory as a model for intergenerational transmission when genocide survivors have an unwillingness to speak about their experiences with offspring. As mentioned in the introduction, when explicit reasons or overt causes for parental distress are unknown, children may develop disorganized attachment patterns. When children view their parents as a source of fear and a source of safety, they use neither a consistent insecure or secure attachment 
strategy. Hence, unresolved parental loss or trauma is often associated with disorganized attachment in their children. The underlying mechanism in this association may be the frightened parent and/or frightening parental behaviours that the child cannot understand or interpret.

Insecure attachment stemming from childhood can later result in difficulty in taking risks, venturing into new situations and accepting intimacy in adulthood (Gerrig et al., 2009). The multigenerational adult reports of the fear to take action and the fear and mistrust of others, in this study, are also compatible with the effects of insecure/disorganized infant-parent attachment, stemming from childhood.

Key to this interpretation of attachment theory is the parental unwillingness to speak about the traumatic event. Most participants, in this study however, spoke of a willingness to speak about the trauma in their families. Further, most of the second and third generation participants reported some in-depth conversation with antecedent family members. At this point, application of Bar-On et al.'s (1998) interpretation of attachment theory begins to break down, as the "open" intra-familial conversation should have prevented any intergenerational transmission of insecure attachment and, therefore, trauma in the families of this study. In addition, most participants in this study spoke of harmonious family relations and valuing parent-childhood relationships in their reports of intergenerational patterns of family communication. Such reports tend to be indicative of adults who had secure child-parent attachments (George et al., 1985) in their childhood. Conversely, a minority of third generation reports of their childhood experiences were often emotional, which can be indicative of insecure attachment (George et al., 1985). In this context, application of Bar-On et al.'s (1998) attachment theory also does not readily 
explain the current findings because the impacts of trauma, in terms of fear, indifference toward others, stockpiling, etc., were prevalent in families - independent of reports related to potential parent-child attachment, stemming from childhood. Moreover, the impacts of trauma were described as being learned intergenerationally via the family unit or through exposure at the societal level.

Shattered assumptions cognitive theory. Janoff-Bulman posited that the psychological impact of trauma in adults or children, stemming from secure parentchildhood attachments, breaks or "shatters" (p. 51) their fundamental assumption that the world is benevolent and the self is worthy. Arising from the broken trust associated with secure attachment, subsequent cognitive changes result in fear, anxiety, preoccupation with self-preservation, pessimism, and new views of the world as malevolent and an unworthy self. At first, plausible explanation might suggest that broken trust stemming from disruption of secure childhood attachment in the first generation precipitated their resultant fears and their perceived necessity for survival. In turn, insecure attachments were transmitted into the second and third generations. The literature also supports the notion of intergenerational transmission of insecure attachment (Armsworth, Mouton, DeWitt, Cooley, \& Hodwerks, 1993; Stronck \& Armsworth, 1994). According to the tenets of Janoff-Bulman, insecure attachment in the second and third generations would also account for their fear and mistrust of others, perceived necessity for survival and fear of another genocide - as all part of seeing the world as malevolent.

However, as previously noted regarding attachment, most participants in this study spoke of harmonious family relations and valuing parent-childhood relationships in their reports of intergenerational patterns of family communication. Such reports of 
family harmony tend to be indicative of secure child-parent attachments (George et al., 1985). At this point, application of Janoff-Bulman's theory does not readily explain the results of this study as many of the second and third generation participants appeared to have secure parent-child attachments and still spoke of a potential, malevolent world, in terms of their fears, need for self-preservation, stockpiling and indifference toward others. In addition, Janoff-Bulman's theory does not readily explain the second and third generations' ascribed characteristics of fear and preoccupation with self-preservation to social learning (taking place inside and outside of the family unit).

Emotions. According to Parrott (2001), fear may produce secondary feelings of horror and nervousness. In turn, nervousness may result in worry, dread, uneasiness and apprehension; horror may result in fright. The results of this study seem to support the tenets of Parrott (2001). For example, the reported fear of another genocide may have caused worry, uneasiness, dread, and apprehension about the future. In turn, this uneasiness and apprehension may have manifested into the need to stockpile and the inability to discard. Further, Maslow (1970) suggested that fear provides motivation to secure personal security and safety. In the context of this study, the reported fears may provide motivation for stockpiling, not taking action and indifference toward and mistrust of others - as all of these strategies seem to be related to the need for self-preservation. Plutchik's (1989) theory of emotions suggests that anger often motivates action. In this study, some of the participants reported anger, while most strongly emphasized the fear to take action. According to Plutchik (1989), anger and the fear to take action are incompatible. As a result, fear might be the overriding emotion that motivates to not take 
action. This explanation may help to clarify anger as the least reported emotion, especially in the third generation.

Plutchik's (1989) theory that sadness motivates individuals to isolate themselves from the world might help to explain the reports of indifference toward others. Since isolation may have placed emphasis on the self, an indifference to others might have emerged. In addition, isolation (stemming from participant reports of sadness) may be connected to the reports of self-preservation and the fear to take action - as taking action to effect socio-political change requires collective action, not isolation (Putnam, 1993).

The tenets of Plutchik (1989) also suggest that shame may motivate individuals to dissociate themselves from the original source of shame. Therefore, Holodomor-related shame may be an attempt to dissociate from the original shame of ethnic Ukrainians having been targeted for genocide (as ethnicity was the actual target of genocide). Hence, the reported shame of ethnic identity, associated with genocide, may have provided motivation to dissociate from ethnicity itself. This ethnic dissociation may have provided further motivation to disengage from ethnic language and ethnic culture. In turn, this disengagement may be responsible for the reported loss and inferiority of the Ukrainian language and culture.

Of the reported emotions, sadness, horror and anger seem to have been related to the individual participants' thoughts and perceptions only when they reflected on the Holodomor. As such, they may be state emotions. However, fear and shame were reported to be continually present in the participants' lives. Hence, they may be trait emotions that provide stronger motivations in the participants' and, overall, in Ukrainians' lives. The ever-present intergenerational fears (related to the fear to take 
action, the fear of another genocide, the perpetual state of survival, the stockpiling, etc.) and the long-term, intergenerational shame (related to the loss of Ukrainian language and culture) seem to support this notion.

\section{Limitations}

Firstly, the snowballing process risked sourcing participants that all shared similar views. Specifically, all colleagues, acquaintances and initial participants involved in the early phases of the snowballing technique possessed some connection to the researcher. As such, the original contacts may have shared similar views to that of the researcher and to each other. Therefore, the initial contacts may have attracted additional participants with similar views. However, the noted differing levels of family functioning and intergenerational patterns of communication demonstrated that variation in participants was expressed in the data. Secondly, most of the first generation participants were females. Lastly, although only one coder-analyst was utilized, consultation with the thesis supervisor helped to increase credibility during data analysis.

\section{Future Research}

Firstly, the themes of this study could inform a questionnaire to quantitatively determine the prevalence of intergenerational transmission of trauma in the Ukrainian population. Secondly, research on Ukrainian-Canadian families, comprised of Holodomor survivors (who immigrated to Canada after 1932-1933) and Canadian-born second and third generations, would provide insight on the influence of differing environmental settings and the role of social determinants on intergenerational trauma transmission. Thirdly, similar research could be applied to other populations, including Canadian Aboriginals. 


\section{Conclusions}

The multigenerational findings of this study, in terms of the reported impacts of the Holodomor, are consistent with the literature's reports of the intergenerationally transmitted constellation of perceptions, emotions, behaviours and family functioning (Harkness, 1993; Kalayjian et al., 1996; Kupelian, 1993; Lev-Wiesel, 2007; Major, 1996; Nagata, 1993; Rowland-Klein \& Dunlop, 1997), stemming from the impact of the original collective trauma. Therefore, the findings of this study strongly suggest that the impact of the trauma from the Holodomor is prevalent in, and has been intergenerationally transmitted into, the second and third generations of Ukrainian survivor families.

Research suggests that individuals, in an attempt to cope with the effects of trauma, are more likely to engage in risky health behaviours such as smoking (Nandi et al., 2005; Parslow \& Jorm, 2006), and alcohol (Vlahov et al., 2004) and drug use (Vetter et al., 2008). These attempts for attenuation, also supported by the finding of this study, may help to explain why: Ukraine is ranked first for the highest percentage of male adolescents who drink alcohol at least once a week (World Health Organization, 2008); Ukraine also is ranked first for the percentage of 11-year old boys who smoke at least once a week, and second for 13 and 15-year old boys who smoke at least once a week; excessive alcohol consumption and addiction are major public health concerns in Ukraine (Pavlychko \& Krawchenko, 2011); and, why Ukraine has the highest consumption of unrecorded (i.e., homemade) alcohol in eastern Europe (Popova, Rehm, Patra, \& Zatonksi, 2007). The findings of this study also suggest that trauma transmitted into the second and third generations has resulted in increased hostility and aggression. The 
literature also suggests that increased aggressive behaviours are an after-effect of trauma (Field et al., 2001). Therefore regarding aggression, the current findings together with the literature might explain why current international data rank Ukraine as second for the highest percentage of 15 -year old boys who had been involved in a physical fight at least three times in the last year (World Health Organization, 2008). The finding of this study regarding the rise of corruption in Ukraine, stemming from the impact of the Holodomor, may also explain international data that rank Ukraine as having high corruption in all levels of public administration, accompanied by a high tolerance for corruption in society (Toro Creative Union, 2011). For example, 43.5\% of Ukrainians believe that corruption is justified in certain circumstances (Kyiv International Institute of Sociology, 2009).

The findings of this study, suggesting that Ukrainians attributed the rise of corruption to loss of trust in the state, stemming from the Holodomor, also seem to be supported by international data (Berenson, 2008). For example, as a result of low trust in the state, Ukrainians are more likely to evade taxes as compared to their Polish and Russian neighbours (Berenson, 2008). Furthermore, Berenson (2008) reported greater trust in state structures and, hence, increased tax compliance in western Ukraine. These latter data also further help to substantiate the impact of the Holodomor, as reported by the participants of this study. Specifically, the Holodomor of 1932-1933 did not extend to western Ukraine because in 1932-1933 western Ukraine was not part of the Soviet Union.

Lastly, participant reports of emotions, behaviours, well-being and sense of loss, when triangulated with international data, suggest that the Holodomor is still exerting substantial effects on modern-day Ukraine. These intergenerational effects of the Holodomor may explain why Ukrainian citizens, overall, consistently rank themselves as 
having one of the lowest levels of life-satisfaction as compared with ninety-four other nations (Veenhoven, 2009). 


\section{References}

Adams, R. E., Boscarino, J. A., \& Galea, S. (2006). Social and psychological resources and health outcomes after the World Trade Center disaster. Social Science \& Medicine, 62(1), 176-188.

Ahmadzadeh, G., \& Malekian, A. (2004). Aggression, anxiety and social development in adolescent children of war veterans with PTSD versus those of non-veterans. Journal of Research in Medical Sciences, 9, 33-36.

American Psychiatric Association. (1994). Diagnostics and statistics manual of mental disorders: DSMIV (4th ed.). Washington, DC: American Psychiatric Association.

Armsworth, M., Mouton, S., DeWitt, J., Cooley, R., \& Hodwerks, K. (1993, October). Survivors as mothers: Intergenerational effects of incest on parenting abilities and attitudes. Paper presented at the $9^{\text {th }}$ annual meeting of the International Society for Traumatic Stress Studies, San Antonio, TX. In Y. Danieli (Ed.), International handbook of multigenerational legacies of trauma (pp. 37-38). New York:

Plenum Press.

Auerhahn, N., \& Laub, D. (1998). Intergenerational memory of the Holocaust. In Y. Danieli (Ed.), International handbook of multigenerational legacies of trauma (pp. 21-41). New York: Plenum Press.

Bandura, A. (1991). Social cognitive theory of moral thought and action. In W. M. Kurtines \& J. L. Gewirtz (Eds.), Handbook of moral behavior and development, Volume 1 (pp. 45-103). Hillsdale, NJ: Erlbaum.

Bandura, A. (1997). Self-efficacy: The exercise of control. New York: Freeman. 
Bandura, A. (2000). Social cognitive theory. In A. E. Kazdin (Ed.), Encyclopedia of psychology, Volume 7 (pp. 329-332). Washington, DC: American Psychological Association.

Barocas, H., \& Barocas, C. (1973). Manifestations of concentration camp effects on the second generation. American Journal of Psychiatry, 130(7), 820-821.

Barocas, H.A., \& Barocas, C.B. (1980). Separation-individuation conflicts in children of Holocaust survivors. Journal of Contemporary Psychotherapy, 11, 6-14.

Bar-On, D. (1989). Legacy of silence: Encounters with children of the Third Reich. Cambridge, MA: Harvard University Press.

Bar-On, D., Eland, J., Kleber R.J., Krell, R., Moore, Y., Sagi, A., Soriano, E., Suedfeld, P., van der Velden, P.G., \& van Ijzendoorn, M.H. (1998). Multigenerational perspectives on coping with the Holocaust experience: An attachment perspective for understanding the development sequelae of trauma across generations. International Journal of Behavioural Development, 22(2), 315-318.

Baumrind, D. (1975). Early socialization and the discipline controversy. Morristown, NJ: General Learning Press.

Baumrind, D. (1991). The influence of parenting style on adolescent competency and substance abuse. Journal of Early Adolescence, 11(1), 56-95.

Becker, D., \& Diaz, M. (1998). The social process and the transmission of trauma in Chile. In Y. Danieli (Ed.), International handbook of multigenerational legacies of trauma (pp. 435-445). New York: Plenum Press.

Belsky, J., Jaffee, S. R., Sligo, J., Woodward, L., \& Silva, P. A. (2005). Intergenerational transmission of warm-sensitive-stimulating parenting: A 
prospective study of mothers and fathers of 3-year olds. Child Development, 76, 384-396.

Berenson, M. P. (2008). Does political culture matter? Deciphering the ways of Ukrainian tax compliance, EUI working paper, MWP 2008/38. Italy: European University Institute.

Berg, B. L. (2004). Qualitative research methods for the social sciences, fifth edition. Boston: Pearson Education, Inc.

Bergman, M.S., \& Jucovy, M.E. (1982). Generations of Holocaust. New York: Basic Books.

Birck, A. (2001). Secondary traumatization and burnout in professionals working with torture survivors. Traumatology, 7(2), 85-90.

Bjorklund, D. F., Yunger, J. L., \& Pellegrini, A. D. (2002). The evolution of parenting and evolutionary approaches to childrearing. In M. H. Bornstein (Ed.), Handbook of parenting, Vol. 2: Biology and ecology of parenting (pp. 3-30). Mahwah, NJ: Erlbaum.

Braun, V., \& Clarke, V. (2006). Using thematic analysis in psychology. Qualitative Research in Psychology, 3:2, 77-101.

Bronfenbrenner, U. (1995). Developmental ecology through space and time: A future perspective. In P. Moen, G.H. Elder, Jr. \& K. Luscher (Eds.), Examining lives in context: Perspectives on the ecology of human development. Washington, D.C.: American Psychological Association.

Bronfenbrenner, U. (1986). Ecology of the family as a context for human development: Research perspectives. Developmental Psychology 22(6), 723-742. 
Bronfenbrenner, U. (1979). The ecology of human development: Experiments by nature and design. Cambridge, Massachusetts: Harvard University Press.

Bunce, S. C., Larsen, R. J., \& Peterson, C. (1995). Life after trauma: Personality and daily life experiences of traumatized people. Journal of Personality, 63(2), $165-$ 188.

Carmel, M. J. S., \& Friedlander, M. L. (2009). The relation of secondary traumatization to therapists' perceptions of the working alliance with clients who commit sexual abuse. Journal of Counseling Psychology, 56(3), 461-467.

Conquest, R. (1986). The harvest of sorrow: Soviet collectivization and the terror-famine. New York: Oxford University Press.

Cornille, T. A., \& Meyers, T. W. (1999). Secondary traumatic stress among child protective service workers: Prevalence, severity and predictive factors. Traumatology 5:1, Article 2.

Courtois, S., Werth, N., Panne, J., Paczkowski, L., Bartosek, K., \& Margolin, J. L. (1999). The black book of communism. Boston: Harvard University Press

Cross, W. (1998). Black psychological functioning and the legacy of slavery: Myths and realities. In Y. Danieli (Ed.), International handbook of multigenerational legacies of trauma (pp. 387-400). New York: Plenum Press.

Dansby, V. S., \& Marinelli, R. P. (1999). Adolescent children of Vietnam combat veteran fathers: A population at risk, Journal of Adolescence 22(3), 329-340.

Davidson, A. C., \& Mellor, D. (2001). The adjustment of children of Vietnam veterans: Is there evidence for the transgenerational transmission of the effects of warrelated trauma? Australian and New Zealand Journal of Psychiatry, 35, 345-351. 
de Graaf, T. (1975). Pathological patterns of identification in families of survivors of the Holocaust. Israel Annual Psychiatry and Related Disciplines, 13, 335-363.

Denzin, N. K., \& Lincoln, Y. S. (2011). The Sage handbook of qualitative research, $\left(4^{\text {th }}\right.$ ed.). Thousand Oaks, California: Safe Publications Inc.

Dutton, D. G. (2007). Genocides. In D. G. Dutton (Ed.) The psychology of genocide, massacres, and extreme violence: Why "normal" people come to commit atrocities (pp. 29-31). London: Prager Security International.

Dwyer, S. C., \& Buckle, J. L. (2009). The space between: On being an insider-outsider in qualitative research. International Journal of Qualitative Methods 8(1), 54-63.

Edelman, L., Kordon, D., \& Lagos, D. (1998). Transmission of trauma: The Argentine case. In Y. Danieli (Ed.), International handbook of multigenerational legacies of trauma (pp. 447-563). New York: Plenum Press.

Elwood, L. S., Mott, J., Lohr, J. M., \& Galovski, T. E. (2011). Secondary trauma symptoms in clinicians: A critical review of the construct, specificity, and implications for trama-focused treatment. Psychology Review 31, 25-36.

Epstein, H. (1979). Children of the Holocaust: Conversation with sons and daughters of survivors. New York: Putnam.

Felsen, I. (1998). Transgenerational transmission of effects of the Holocaust. In Y. Danieli (Ed.), International handbook of multigenerational legacies of trauma (pp. 43-68). New York: Plenum Press.

Field, C. A., Claassen, C. A., \& O'Keefe, G. (2001). Association of alcohol use and other high-risk behaviors among trauma patients. The Journal of Trauma, 50(1), 13-19. 
Figley, C. R. (1995). Compassion fatigue: Toward a new understanding of the costs of caring. In B. H. Stamm (Ed.), Secondary traumatic stress: Self care issues for clinicians, researchers, and educators (pp. 3-28). Baltimore, MD: The Sidran Press.

Freedom House (2011). Freedom in the World: 2011 Edition. Washington, D.C.

Retrieved from http://www.freedomhouse.org/template.cfm?page=363\&year=2011

Freyberg, J. T. (1980). Difficulties in separation-individuation as experienced by offspring of Nazi Holocaust survivors. American Journal of Orthopsychiatry, 50, $87-95$

Gagne, M.-A. (1998). Dependency, colonialism, and trauma. In Y. Danieli (Ed.), International handbook of multigenerational legacies of trauma (pp. 355-356). New York: Plenum Press.

Ganz, E. (2002). Intergenerational transmission of trauma: Grandchildren of Holocaust survivors. Dissertation Abstracts International: Section B. The Sciences and Engineering, 63(3-B), 1561.

George, C., Kaplan, M., \& Main, M. (1985). The adult attachment interview. Unpublished manuscript, University of California, Department of Psychology, Berkeley.

Gerrig, R., Zimbardo, P, Desmarais, S., \& Ivanco, T. (2009). Psychology and life (pp. 403-404). Toronto: Pearson Education Canada. 
Haley, S. (1985). Some of my best friends are dead: Treatment of the PTSD patient and his family. In W.E. Kelley (Ed.), Posttraumatic stress disorder and the war veteran patient (pp. 54-71). New York: Brunner/Mazel.

Harkness, L.L. (1993). Transgenerational transmission of war-related trauma. In J.P. Wilson \& B. Raphael (Eds.), International handbook of traumatic stress syndromes (pp. 635-643). New York: Plenum Press.

Health Canada (2003). A statistical profile on the health of First Nations in Canada. Ottawa, ON: Health Canada.

Iliceto, P., Candilera, G., Funaro, D., Pompilo, M., Kaplan, K. J., \& Markus-Kaplan, M. (2011). Hopelessness, temperament, anger and interpersonal relationships in Holocaust (Shoah) survivors' grandchildren. Journal of Religious Health 50, 321-329.

Indian and Northern Affairs Canada, 2001 Basic Departmental Data 2001, Catalogue no. $R 12-7 / 2000 E$. Retrieved from http:/www.hc-sc.gc.ca/fniah-spnia/diseasesmaladies/2005-01_health-sante_indicat-eng.php

International Centre for Policy Studies. (2008). Potential and performance of Ukraine. Kyiv, Ukraine: International Centre for Policy Studies. International Telecommunication Union. (2010). Measuring the information society. Geneva. Retrieved from http://www.itu.int/ITUD/ict/publications/idi/2010/index.html. Jackson, W., Gillis, A., \& Verberg, N. (1994). Methods: Doing social research. Scottsdale, Arizona: Pearson Education Imports. 
Jackson, W. (2003). Methods: Doing social research $\left(3^{\text {rd }}\right.$ ed.). Toronto, Ontario: Pearson Education International.

Janoff-Bulman, R. (1992). Shattered assumptions: Towards a new psychology of trauma. New York, New York: The Free Press.

Jordan, B., Marmar, C., Fairbank, J., Schlenger, W., Kulka, R., Hough, R., \& Weiss, D. (1992). Problems in families of male Vietnam veterans with posttraumatic stress disorder. Journal of Consulting and Clinical Psychology, 60(6), 916-926.

Kadambi, M., \& Truscott, D. (2003). Vicarious traumatisation and burnout among therapists working with sex offenders. Traumatology 9(4), 216-230.

Kail, R. V., \& Barnfield, A. (2009). Children and their development (Canadian ed.). Toronto, Ontario: Pearson Education Canada.

Kalayjian, K., Shahinian, S. P., Gergerian, E., \& Saraydarian, L. (1996). Coping with Ottoman Turkish Genocide: An exploration of the experience of Armenian survivors. Journal of Traumatic Stress, 9(1), 87-97.

Kalayjian, A., \& Weisberg, M. (2002). Generational impact of mass trauma: The postOttoman Turkish Genocide of the Armenians. In J. S. Piven, C. Boyd \& H. W. Lawton (Eds.), Jihad and sacred vengeance (pp. 254-279). New York: Writers Club Press.

Karenian, H., Livaditis, M., Karenian, S., Zafiriadis, K., Bochtsou, V., \& Xenitidis, K. (2010). Collective trauma transmission and traumatic reactions among descendants of Armenian refugees. International Journal of Social Psychiatry, $57(4), 327-337$. 
Kassabian, A. (1998). A three generational study of Armenian family structure as it correlates to Armenian ethnic identity within the context of traumatic loss. In Y. Danieli (Ed.), International handbook of multigenerational legacies of trauma (pp. 195-201). New York: Plenum Press.

Kav-Venaki, S., Nadler, A., \& Gershoni, H. (1983). Sharing past trauma: A comparison of communication behaviours in two groups of Holocaust survivors. International Journal of Psychiatry, 29, 49-59.

Kendall, C. (1994). The history: Present and future issues affecting Aboriginal adults who were removed as children. Aboriginal and Islander Health Worker Journal, $18,18-19$.

Kilgore, K., Snyder, J., \& Lentz, C. (2000). The contribution of parental discipline, parental monitoring, and school risk to early-onset conduct problems in African American boys and girls. Developmental Psychology, 36, 835-845.

Killian, K. (2008). Helping till it hurts? A multimethod study of compassion fatigue, burnout, and self-care in clinicians working with trauma survivors. Traumatology $14(2), 32-44$.

Klain, E. (1992). Psychology and psychiatry of a war (pp.77). Zagreb: Faculty of Medicine, University of Zagreb.

Kordan, B. (2008). A note on the political geography of the Great Famine of 1932-1933. In L. Y. Luciuk (Ed.), Holodomor: Reflections of the Great Famine of 1932-1933 in Soviet Ukraine. Kingston, Ontario: Kashtan Press. 
Krell, R. (1984). Holocaust survivors and their children: Comments on psychiatric consequences and psychiatric terminology. Comprehensive Psychiatry, 25(5), 521-528.

Kulchytsky, S. (2008). Defining the Holodomor as genocide. In L. Y. Luciuk (Ed.), Reflections on the Great Famine of 1932-33 in Soviet Ukraine (pp. 129-138). Kingston, Ontario: The Kashtan Press.

Kupelian, D. (1993). Armenian genocide survivors: Adaptation and adjustment eight decades after massive trauma. In Y. Danieli (Ed.), International handbook of multigenerational legacies of trauma (pp. 195-201). New York: Plenum Press.

Kyiv International Institute of Sociology. (2009). Corruption in Ukraine: The comparative analysis of the 2007-2009 national opinion polls (in Ukrainian), 21.

Lazarus, R. S. (1984). Puzzles in the study of daily hassles. Journal of Behavioral Medicine, 7, 375-389.

Lev-Wiesel, R. (2007). Intergenerational transmission of trauma across three generations: A preliminary study. Qualitative Social Work, 6(1), 75-94.

Levin, A. P., \& Greisberg, S. (2003). Vicarious trauma in attorneys. Pace Law Review, $24,245-252$.

Lincoln, Y. S., \& Guba, E. G. (1985). Naturalistic inquiry. Newbury Park, CA: Sage Publications.

Loos, C. M. (1993). An integrative-sequential treatment model for posttraumatic stress disorder: A case study of the Japanese-American internment and redress. Clinical Psychology Review 13, 89-117. 
Maccoby, E. E., \& Martin, J. A. 1983. Socialization in the context of the family: Parentchild interaction. In E. M. Hetherington (Ed.), Handbook of child psychology: Vol. 4. Socialization, personality, and social development (pp. 1-101). New York: Wiley.

Major, E. (1996). The impact of the Holocaust on the second generation: Norwegian Jewish Holocaust survivors and their children. Journal of Traumatic Stress, 9(3), 441-454.

Marochko, V. (2007). Henotsyd Ukraintsiv: Holodomor 1932-1933 [Genocide of Ukrainians: Holodomor 1932-1933]. Zhytomyr, Ukraine: Zhytomyr State Publishing.

Maslow, A. H. 1970. Motivation and personality (rev. ed.). New York: Harper \& Row. McCann, I. L., \& Pearlman, L. A. (1990). Vicarious traumatization: A framework for understanding the psychological effects of working with victims. Journal of Traumatic Stress, 3(1), 131-149.

Morozov, K. P., \& Garnett, S. W. (2001). Above and beyond: From Soviet general to Ukrainian state builder. Boston: Harvard University Press.

Motta, R. W., Kefer, J. M., Hertz, M. D., \& Hafeez, S. (1999). Initial evaluation of the secondary trauma questionnaire. Psychological Reports, 85, 997-1002.

Nagata, D. (1990). The Japanese American internment: Exploring the transgenerational consequences of traumatic stress. Journal of Traumatic Stress, 3, 47-69.

Nagata, D. (1993). Legacy of injustice: Exploring the cross-cultural impact of the Japanese-American internment. New York: Plenum Press. 
Nagata, D. K., \& Cheng, W. J. (2003). Intergenerational communication of race-related trauma by Japanese-American former internees. American Journal of Orthopsychiatry, 73(3), 266-278.

Nagata, D., Trierweiler, S., \& Talbot, R. (1999). Long-term effects of internment during early childhood on third-generation Japanese-Americans. American Journal of Orthopsychiatry, 69(1), 19-29.

Naimark, N. M. (2010). Stalin's Genocides. Princeton, New Jersey: Princeton University Press.

Nandi, A., Galea, S., Ahern, J., \& Vlahov, D. 2005. Probable cigarette dependence, PTSD, and depression after an urban disaster: Results from a population survey of New York City residents 4 months after September 11, 2001. Psychiatry, 68(4), 299-310.

National Native Addictions Partnership Foundation. (2000). NNADAP renewal framework for implementing the strategic recommendations of the 1998, General review of the national native alcohol and drug abuse program, Draft, Working paper prepared - for discussion purposes only. Muskoday, SK: National Native Addictions Partnership Foundation.

Nation Master. (2010). Economy statistics. Retrieved from http://www.nationmaster.com /graph/eco_gdp_rea_gro_rat-economy-gdp-real-growth-rate\&date $=2010$.

Odejide, A., Sanda, A., \& Odejide, A. (1998). Intergenerational aspects of ethnic conflict in Africa. In Y. Danieli (Ed.), International handbook of multigenerational legacies of trauma (pp. 373-385). New York: Plenum Press.

Parrott, W. G. (2001). Emotions in social psychology. Philadelphia: Psychology Press. 
Parslow, R., \& Jorm, A. (2006). Tobacco use after experiencing a major natural disaster: Analysis of a longitudinal study of 2063 young adults. Addiction, 101(7), 10441050.

Patton, M. (1990). Qualitative research and evaluation methods (2nd ed.). Newbury Park, CA: Sage Publications.

Patton, M. (2002). Qualitative research and evaluation methods (3rd ed.). Thousand Oaks: Sage Publications.

Pavlychko, B., \& Krawchenko, T. (2011). Alcohol abuse and dependency in Ukraine: The policy challenge of a "wicked" problem. The NISPAcee Journal of Public Administration and Policy, 4(1).

Pearlman, L. A., \& Saakvitne, K. W. (1995). Treating therapists with vicarious traumatization and secondary traumatic stress disorders. In C. R. Figley (Ed.), Compassion fatigue: Coping with secondary traumatic stress disorder in those who treat the traumatized (pp. 150-177). New York, NY: Brunner/Mazel.

Pennebaker, J., Barger, S., \& Tiebout, J. (1989). Disclosure of traumas and health among Holocaust survivors. Psychosomatic Medicine, 51, 577-589.

Plutchik, R. (1989). Measuring emotions and their derivatives. In R. Plutchik \& H. Kellerman (Eds.), The measurement of emotions (pp. 1-35). New York: Academic Press.

Popova, S., Rehm, J., Patra, J., \& Zatonski, W. (2007). Comparing alcohol consumption in central and eastern Europe to other European countries. Alcohol and Alcoholism 42, 465-473. 
Population Reference Bureau. (2007). 2007 World population data sheet. Retrieved from http://www.prb.org./pdf07/07WPDS_Eng.pdf.

Putnam, R. D. (1993). Making democracy work: Civil traditions in modern Italy. Princeton, New Jersey: Princeton University Press.

Rakoff, V., Sigal, J., \& Epstein, N. (1966). Children and families of concentration camp survivors. Canada's Mental Health, 14, 24-26.

Reid, A. (1999). Borderland: A journey through the history of Ukraine. Boulder, Colorado: Westview Press.

Rosenberger, L. (1973). Children of survivors. In E.J. Anthony \& C. Koupernik (Eds.), The child in his family: The impact of disease and death (pp. 375-377). New York: Wiley.

Rosenheck, R., \& Fontana, A. (1998). Transgenerational effects of abusive violence on the children of Vietnam combat veterans. Journal of Traumatic Stress, 11(4), 731742.

Rosenheck, R., \& Nathan, P. (1985). Secondary traumatisation in children of Vietnam veterans. Hospital and Community Psychiatry, 36(5), 538-539.

Rowland-Klein, D., \& Dunlop, R. (1997). The transmission of trauma across generations: Identification with parental trauma in children of Holocaust survivors. Australian and New Zealand Journal of Psychiatry, 31, 358-369.

Rubin, H. J., \& Rubin, I. S. (2005). Qualitative interviewing: The art of hearing data. Thousand Oaks, California: Sage Publications Inc.

Russell, A. (1974). Late psychosocial consequences in concentration camp survivor families. American Journal of Orthopsychiatry, 44, 611-619. 
Salston, M., \& Figley, C. R. (2003). Secondary traumatic stress effects of working with survivors of criminal victimization. Journal of Traumatic Stress, 16, 167-174.

Serbyn, R. (2008). The Holodomor: Genocide against the Ukrainians. In L.Y. Luciuk (Ed.), Holodomor: Reflections of the Great Famine of 1932-1933 in Soviet Ukraine. Kingston, Ontario: Kashtan Press.

Sigal, J.J., \& Weinfeld, M. (1989). Trauma and rebirth: Intergenerational effects of the Holocaust. New York: Praeger.

Simpson, M. (1998). The second bullet: Transgenerational impacts of conflict within a South African and world context. In Y. Danieli (Ed.), International handbook of multigenerational legacies of trauma (pp. 487-511). New York: Plenum Press.

Solkoff, N. (1992). Children of survivors of the Nazi Holocaust: A critical review of the literature. American Journal of Orthopsychiatry, 62(3), 342-358.

Solomon, Z. (1998). Transgenerational effects of the Holocaust: The Israeli research perspective. In Y. Danieli (Ed.), International handbook of multigenerational legacies of trauma (pp. 69-83). New York: Plenum Press.

Steinberg, A. (1989). Holocaust survivors and their children: A review of the clinical literature. In P. Marcus \& A. Rosenberg (Eds.), Healing their wounds: Psychotherapy with Holocaust survivors and their families (pp. 23-48). New York: Praeger.

Stronck, K., \& Armsworth, M. (1994, November). Intergenerational transposition of disturbances to the self and quality of attachment relationships between mothers with a history of trauma and their adult children. Paper presented at the $10^{\text {th }}$ annual meeting of the International Society for Traumatic Stress Studies, Chicago, 
IL. In Y. Danieli (Ed.), International handbook of multigenerational legacies of trauma (pp. 37-38). New York: Plenum Press.

Subtelny, O. (1994). Ukraine: A history, second edition. Toronto, Canada: University of Toronto Press.

Suozzia, J., \& Motta, R. (2004). The relationships between combat exposure and the transfer of trauma-like symptoms to offspring of veterans. Traumatology 10(1), $17-37$.

Terr, L. C. (1979). Children of Chowchilla: A study of psychic trauma. The Psychoanalytical Study of the Child, 34, 552-623.

Toro Creative Union, Transparency International National Contact in Ukraine. (2011). National integrity system assessment: Ukraine 2011. Kirovohrad, Ukraine: Toro Creative Union.

Trossman, B. (1968). Adolescent children of concentration camp survivors. Canadian Psychiatric Association Journal, 13, 121-123.

United Nations (2007). World population prospects: The 2006 revision, highlights. Working paper no. ESA/P/WP.202. Department of Economic and Social Affairs, Population Division, New York. Retrieved from http://www.un.org/esa/population/publications/wpp2006/WPP2006_Highlights_re v.pdf.

United Nations (2009a). Human development report 2009: Human mobility and development. New York: Palgrave Macmillan. Retrieved from http:/hdr.undp.org/en/media/HDR_2009_EN_Complete.pdf. 
United Nations (2009b). World population prospects 2008 database. Department of Economic and Social Affairs, Population Division. Retrieved from: http://esa.un.org/unpp/index.asp?panel=2.

United Nations Educational, Scientific and Cultural Organization (UNESCO) Institute for Statistics (2008). International literacy statistics: A review of concepts, methodology and current data. Montreal: ICAO Publishers. Retrieved from http://www.uis.unesco.org.

US Commission on the Ukraine Famine (1988). Investigation of the Ukrainian Famine 1932-1933: Report to Congress: United States Government Printing Office: Washington.

van der Kolk, B. A., Roth, S., Pelcovitz, D., Sunday, S. and Spinazzola, J. (2005). Disorders of extreme stress: The empirical foundation of a complex adaptation to trauma. Journal of Traumatic Stress 18(5), 389-399.

Van IJzendoorn, M.H., Bakermans-Kranenburg, M.J., \& Sagi-Schwartz, A. (2003). Are children of Holocaust survivors less well-adapted? A meta-analytic investigation of secondary traumatisation. International Society for Traumatic Stress Studies, $16(5), 459-469$.

Veenhoven, R. (2009). States of nation: World database of happiness. Erasmus University

Rotterdam. Retrieved from http://worlddatabaseofhappiness.eur.nl.

Vetter, S., Rossegger, A., Rossler, W., Bisson, J., \& Endrass, J. (2008). Exposure to the tsunami disaster, PTSD symptoms and increased substance use - An internet 
based survey of male and female residents of Switzerland. BMC Public Health, $8(1), 92$.

Vlahov, D., Galea, S., Ahern, J., Resnick, H., Boscarino, J. A., Gold, J., et al. (2004).

Consumption of cigarettes, alcohol and marijuana among New York City residents six months after the September 11 terrorist attacks. American Journal of Drug and Alcohol Abuse, 30(2), 385-407.

Vrklevski, L. P., \& Franklin, J. (2008). Vicarious trauma: The impact on solicitors of exposure to traumatic material. Traumatology, 14(1), 106-118.

Wagner, K. D., Brief, D. J., Vielhauer, M. J., Sussman, S., Keane, T. M., \& Malow, R. (2009). The potential for PTSD, substance use, and HIV risk behaviour among adolescents exposed to hurricane Katrina. Substance Use \& Misuse, 44(12), 17491767.

Westerink, J., \& Giarratano, L. (1999). The impact of posttraumatic stress disorder on partners and children of Australian Vietnam veterans. Australian and New Zealand Journal of Psychiatry, 33, 841-847.

Wiseman, H., Metzl, E., \& Barber, J. (2006). Anger, guilt and intergenerational communication of trauma in interpersonal narratives of second generation holocaust survivors. American Journal of Orthopsychiatry, 76(2), 176-184.

World Bank (2009). World development indicators database. Washington, D.C. Retrieved from: http://ddpext.worldbank.org/ext/ddpreports/ViewSharedReport?\&CF=1\&REPOR T_ID=9147\&REQUEST_TYPE=VIEWADVANCED\&HF=N\&WSP=N. 
World Health Organization. (2008). Inequalities in young people's health: Health behaviour in school-aged children, International report from the 2005/2006 survey. Retrieved from http://www.euro.who.int/Document/E91416.pdf.

World Health Organization. (2009). Global health observatory data repository. Retrieved from http://apps. who.int/ghodata/?vid=61740.

Zinkewych, O., \& Sorokowski, A. (1988). A thousand years of christianity in Ukraine. New York: Smoloskyp Publishers. 
Table 1

Summary of Reported Emotions for Families 1-10

\begin{tabular}{|c|c|c|c|c|c|c|c|c|}
\hline Family & Generation & Pseudonym & Fear & Horror & Sadness & $\begin{array}{c}\text { Indifference } \\
\text { to others }\end{array}$ & Shame & Anger \\
\hline \multirow[t]{3}{*}{1} & First & Tamara & $\mathrm{x}$ & $\mathrm{x}$ & $\mathrm{x}$ & $\mathrm{x}$ & & $\mathrm{x}$ \\
\hline & Second & Lesia & $\mathrm{X}$ & $\mathrm{x}$ & & $\mathrm{x}$ & & \\
\hline & Third & Halyna & $\mathrm{x}$ & & $\mathrm{x}$ & $\mathrm{x}$ & & \\
\hline \multirow[t]{3}{*}{2} & First & Vira & $\mathrm{x}$ & $\mathrm{x}$ & & $\mathrm{x}$ & $\mathrm{x}$ & \\
\hline & Second & Anton & & & & & $\mathrm{x}$ & \\
\hline & Third & Ruslana & $\mathrm{x}$ & $\mathrm{x}$ & $\mathrm{x}$ & & $\mathrm{x}$ & \\
\hline \multirow[t]{3}{*}{3} & First & Yulia & $\mathrm{x}$ & $\mathrm{x}$ & & $\mathrm{x}$ & & \\
\hline & Second & Mykhailo & & $\mathrm{x}$ & & & $\mathrm{x}$ & $\mathrm{x}$ \\
\hline & Third & Myroslava & $\mathrm{x}$ & $\mathrm{x}$ & & $\mathrm{x}$ & & $\mathrm{x}$ \\
\hline \multirow[t]{3}{*}{4} & First & Olena & $\mathrm{x}$ & $\mathrm{x}$ & $\mathrm{x}$ & $\mathrm{x}$ & $\mathrm{x}$ & \\
\hline & Second & Danylo & $\mathrm{x}$ & $\mathrm{x}$ & $\mathrm{x}$ & $\mathrm{x}$ & $\mathrm{x}$ & \\
\hline & Third & Ivan & & & & & & \\
\hline \multirow[t]{3}{*}{5} & First & Anastasia & $\mathrm{x}$ & $\mathrm{x}$ & $\mathrm{x}$ & & & $\mathrm{x}$ \\
\hline & Second & Oleksandra & $\mathrm{x}$ & $\mathrm{x}$ & & $\mathrm{x}$ & $\mathrm{x}$ & $\mathrm{x}$ \\
\hline & Third & Pavlo & & & $\mathrm{x}$ & $\mathrm{x}$ & & \\
\hline \multirow[t]{3}{*}{6} & First & Stephania & $\mathrm{x}$ & $\mathrm{x}$ & $\mathrm{x}$ & & $\mathrm{x}$ & $\mathrm{x}$ \\
\hline & Second & Pylyp & $\mathrm{x}$ & $\mathrm{x}$ & $\mathrm{x}$ & $\mathrm{x}$ & $\mathrm{x}$ & \\
\hline & Third & Mystyslav & $\mathrm{x}$ & & $\mathrm{x}$ & & & \\
\hline \multirow[t]{3}{*}{7} & First & Kalyna & $\mathrm{x}$ & $\mathrm{x}$ & $\mathrm{x}$ & $\mathrm{x}$ & $\mathrm{x}$ & $\mathrm{x}$ \\
\hline & Second & Volodymyr & $\mathrm{x}$ & & & & $\mathrm{x}$ & $\mathrm{x}$ \\
\hline & Third & Sofia & $\mathrm{x}$ & $\mathrm{x}$ & $\mathrm{x}$ & $\mathrm{x}$ & $\mathrm{x}$ & \\
\hline \multirow[t]{3}{*}{8} & First & Hafia & $\mathrm{x}$ & $\mathrm{x}$ & & & & $\mathrm{x}$ \\
\hline & Second & Bohdana & $\mathrm{x}$ & $\mathrm{x}$ & $\mathrm{x}$ & $\mathrm{x}$ & & $\mathrm{x}$ \\
\hline & Third & Vasylyna & $\mathrm{x}$ & & $\mathrm{x}$ & $\mathrm{x}$ & $\mathrm{x}$ & \\
\hline \multirow[t]{3}{*}{9} & First & Petrusia & $\mathrm{x}$ & $\mathrm{x}$ & & $\mathrm{x}$ & & $\mathrm{x}$ \\
\hline & Second & Nazar & $\mathrm{x}$ & $\mathrm{x}$ & & $\mathrm{x}$ & & \\
\hline & Third & Savelia & $\mathrm{x}$ & & $\mathrm{x}$ & $\mathrm{x}$ & & \\
\hline \multirow[t]{3}{*}{10} & First & Luba & & $\mathrm{x}$ & & $\mathrm{x}$ & $\mathrm{x}$ & $\mathrm{x}$ \\
\hline & Second & Roman & $\mathrm{x}$ & $\mathrm{x}$ & $\mathrm{x}$ & $\mathrm{x}$ & $\mathrm{x}$ & $\mathrm{x}$ \\
\hline & Third & Yaroslava & $\mathrm{x}$ & $\mathrm{x}$ & $\mathrm{x}$ & $\mathrm{x}$ & $\mathrm{x}$ & \\
\hline
\end{tabular}


Table 2

Summary of Reported Emotions for Families 10-15

\begin{tabular}{|c|c|c|c|c|c|c|c|c|}
\hline Family & Generation & Pseudonym & Fear & Horror & Sadness & $\begin{array}{c}\text { Indifference } \\
\text { to others }\end{array}$ & Shame & Anger \\
\hline \multirow[t]{3}{*}{11} & First & Lev & $\mathrm{x}$ & $\mathrm{x}$ & $\mathrm{x}$ & & & \\
\hline & Second & Liudmila & & $\mathrm{x}$ & $\mathrm{x}$ & & & \\
\hline & Third & Petro & $\mathrm{x}$ & $\mathrm{x}$ & $\mathrm{x}$ & & $\mathrm{x}$ & \\
\hline \multirow[t]{3}{*}{12} & First & Marianna & $\mathrm{x}$ & $\mathrm{x}$ & & $\mathrm{x}$ & $\mathrm{x}$ & $\mathrm{x}$ \\
\hline & Second & Mykola & $\mathrm{x}$ & $\mathrm{x}$ & $\mathrm{x}$ & $\mathrm{x}$ & $\mathrm{x}$ & $\mathrm{x}$ \\
\hline & Third & Tymofiy & $\mathrm{x}$ & & $\mathrm{x}$ & & & \\
\hline \multirow[t]{3}{*}{13} & First & Onysym & $\mathrm{x}$ & $\mathrm{x}$ & $\mathrm{x}$ & & $\mathrm{x}$ & $\mathrm{x}$ \\
\hline & Second & Svyatoslav & $\mathrm{x}$ & $\mathrm{x}$ & $\mathrm{x}$ & $\mathrm{x}$ & $\mathrm{x}$ & $\mathrm{x}$ \\
\hline & Third & Andrusia & $\mathrm{x}$ & $\mathrm{x}$ & & & $\mathrm{x}$ & \\
\hline \multirow[t]{3}{*}{14} & First & Roksolana & $\mathrm{x}$ & $\mathrm{x}$ & $\mathrm{x}$ & & $\mathrm{x}$ & $\mathrm{x}$ \\
\hline & Second & Orianna & $\mathrm{x}$ & & $\mathrm{x}$ & $\mathrm{x}$ & & \\
\hline & Third & Orysia & $\mathrm{x}$ & $\mathrm{x}$ & $\mathrm{x}$ & $\mathrm{x}$ & & \\
\hline \multirow[t]{3}{*}{15} & First & Irka & $\mathrm{x}$ & $\mathrm{x}$ & & & & \\
\hline & Second & Viktoria & & & & & $\mathrm{x}$ & $\mathrm{x}$ \\
\hline & Third & Liza & $\mathrm{x}$ & & & & & \\
\hline
\end{tabular}


Table 3

Summary of Reported Behaviours and Mental-Well Being for Families 1-10

\begin{tabular}{|c|c|c|c|c|c|c|}
\hline Family & Generation & Pseudonym & $\begin{array}{c}\text { Stockpiling } \\
\text { of food }\end{array}$ & $\begin{array}{c}\text { Inability } \\
\text { to } \\
\text { discard }\end{array}$ & $\begin{array}{l}\text { Reverence } \\
\text { for food }\end{array}$ & $\begin{array}{l}\text { Overeating } \\
\text { and food } \\
\text { emphasis }\end{array}$ \\
\hline \multirow[t]{3}{*}{1} & First & Tamara & & & & \\
\hline & Second & Lesia & & & & \\
\hline & Third & Halyna & $\mathrm{x}$ & $\mathrm{x}$ & & $\mathrm{x}$ \\
\hline \multirow[t]{3}{*}{2} & First & Vira & $\mathrm{x}$ & & $\mathrm{x}$ & $\mathrm{x}$ \\
\hline & Second & Anton & & & $\mathrm{x}$ & \\
\hline & Third & Ruslana & $\mathrm{x}$ & $\mathrm{x}$ & $\mathrm{x}$ & $\mathrm{x}$ \\
\hline \multirow[t]{3}{*}{3} & First & Yulia & & & & \\
\hline & Second & Mykhailo & $\mathrm{x}$ & & & \\
\hline & Third & Myroslava & $\mathrm{x}$ & & $\mathrm{x}$ & \\
\hline \multirow[t]{3}{*}{4} & First & Olena & $\mathrm{x}$ & & & \\
\hline & Second & Danylo & $\mathrm{x}$ & & & \\
\hline & Third & Ivan & & & & \\
\hline \multirow[t]{3}{*}{5} & First & Anastasia & & & & \\
\hline & Second & Oleksandra & & & & \\
\hline & Third & Pavlo & & & & \\
\hline \multirow[t]{3}{*}{6} & First & Stephania & & & & \\
\hline & Second & Pylyp & $\mathrm{x}$ & & $\mathrm{x}$ & \\
\hline & Third & Mystyslav & & & & \\
\hline \multirow[t]{3}{*}{7} & First & Kalyna & & & & \\
\hline & Second & Volodymyr & $\mathrm{x}$ & & $\mathrm{x}$ & \\
\hline & Third & Sofia & $\mathrm{x}$ & & & \\
\hline \multirow[t]{3}{*}{8} & First & Hafia & & & & \\
\hline & Second & Bohdana & $\mathrm{x}$ & & $\mathrm{x}$ & \\
\hline & Third & Vasylyna & $\mathrm{x}$ & & & \\
\hline \multirow[t]{3}{*}{9} & First & Petrusia & & & & \\
\hline & Second & Nazar & & & $\mathrm{x}$ & \\
\hline & Third & Savelia & & & $\mathrm{x}$ & \\
\hline \multirow[t]{3}{*}{10} & First & Luba & & & & \\
\hline & Second & Roman & & & & \\
\hline & Third & Yaroslava & & & & \\
\hline
\end{tabular}


Table 4

Summary of Reported Behaviours and Mental-Well Being for Families 11-15

\begin{tabular}{|c|c|c|c|c|c|c|}
\hline Family & Generation & Pseudonym & $\begin{array}{c}\text { Stockpiling } \\
\text { of food }\end{array}$ & $\begin{array}{l}\text { Inability } \\
\text { to } \\
\text { discard }\end{array}$ & $\begin{array}{l}\text { Reverence } \\
\text { for food }\end{array}$ & $\begin{array}{l}\text { Overeating } \\
\text { and food } \\
\text { emphasis }\end{array}$ \\
\hline \multirow[t]{3}{*}{11} & First & Lev & & & & \\
\hline & Second & Liudmila & & & $\mathrm{x}$ & \\
\hline & Third & Petro & $\mathrm{x}$ & & & \\
\hline \multirow[t]{3}{*}{12} & First & Marianna & & & & \\
\hline & Second & Mykola & & & & $\mathrm{x}$ \\
\hline & Third & Tymofiy & & & & \\
\hline \multirow[t]{3}{*}{13} & First & Onysym & & & $\mathrm{x}$ & \\
\hline & Second & Svyatoslav & & & $\mathrm{x}$ & \\
\hline & Third & Andrusia & & & $\mathrm{x}$ & $\mathrm{x}$ \\
\hline \multirow[t]{3}{*}{14} & First & Roksolana & & & & \\
\hline & Second & Orianna & & & $\mathrm{x}$ & \\
\hline & Third & Orysia & & & $\mathrm{x}$ & \\
\hline \multirow[t]{3}{*}{15} & First & Irka & & & & \\
\hline & Second & Viktoria & & & & \\
\hline & Third & Liza & & & & \\
\hline
\end{tabular}


Table 5

Summary of Reported Behaviours and Mental-Well Being for Families 1-10, continued

\begin{tabular}{|c|c|c|c|c|c|c|}
\hline Family & Generation & Pseudonym & $\begin{array}{c}\text { Survival } \\
\text { mode }\end{array}$ & $\begin{array}{c}\text { Stress, } \\
\text { anxiety, } \\
\text { self- } \\
\text { esteem }\end{array}$ & Hostility & $\begin{array}{c}\text { Alcohol } \\
\text { AIDS } \\
\text { drugs }\end{array}$ \\
\hline \multirow[t]{3}{*}{1} & First & Tamara & & & & \\
\hline & Second & Lesia & $\mathrm{x}$ & & & \\
\hline & Third & Halyna & $\mathrm{x}$ & & & \\
\hline \multirow[t]{3}{*}{2} & First & Vira & & & & \\
\hline & Second & Anton & $\mathrm{x}$ & & & \\
\hline & Third & Ruslana & $\mathrm{x}$ & $\mathrm{x}$ & & \\
\hline \multirow[t]{3}{*}{3} & First & Yulia & & & & \\
\hline & Second & Mykhailo & $\mathrm{x}$ & & & \\
\hline & Third & Myroslava & $\mathrm{x}$ & $\mathrm{x}$ & $\mathrm{x}$ & \\
\hline \multirow[t]{3}{*}{4} & First & Olena & & & & \\
\hline & Second & Danylo & & & & $\mathrm{x}$ \\
\hline & Third & Ivan & & & & \\
\hline \multirow[t]{3}{*}{5} & First & Anastasia & $\mathrm{x}$ & & & \\
\hline & Second & Oleksandra & $\mathrm{x}$ & & & \\
\hline & Third & Pavlo & $\mathrm{x}$ & & & \\
\hline \multirow[t]{3}{*}{6} & First & Stephania & & $\mathrm{x}$ & & \\
\hline & Second & Pylyp & $\mathrm{x}$ & & & \\
\hline & Third & Mystyslav & & & & \\
\hline \multirow[t]{3}{*}{7} & First & Kalyna & & & & \\
\hline & Second & Volodymyr & & & & \\
\hline & Third & Sofia & $\mathrm{x}$ & $\mathrm{x}$ & & $\mathrm{x}$ \\
\hline \multirow[t]{3}{*}{8} & First & Hafia & & & & \\
\hline & Second & Bohdana & $\mathrm{x}$ & & & \\
\hline & Third & Vasylyna & $\mathrm{x}$ & & & \\
\hline \multirow[t]{3}{*}{9} & First & Petrusia & $\mathrm{x}$ & & & \\
\hline & Second & Nazar & & & & \\
\hline & Third & Savelia & $\mathrm{x}$ & & & \\
\hline \multirow[t]{3}{*}{10} & First & Luba & & & & \\
\hline & Second & Roman & $\mathrm{x}$ & & & \\
\hline & Third & Yaroslava & & & $\mathrm{x}$ & \\
\hline
\end{tabular}


Table 6

Summary of Reported Behaviours and Mental-Well Being for Families 11-15, continued

\begin{tabular}{|c|c|c|c|c|c|c|}
\hline Family & Generation & Pseudonym & $\begin{array}{c}\text { Survival } \\
\text { mode }\end{array}$ & $\begin{array}{c}\text { Stress, } \\
\text { anxiety, } \\
\text { self- } \\
\text { esteem }\end{array}$ & Hostility & $\begin{array}{c}\text { Alcohol } \\
\text { AIDS } \\
\text { drugs }\end{array}$ \\
\hline \multirow[t]{3}{*}{11} & First & Lev & & & & \\
\hline & Second & Liudmila & $\mathrm{x}$ & & & \\
\hline & Third & Petro & & & & \\
\hline \multirow[t]{3}{*}{12} & First & Marianna & & & & \\
\hline & Second & Mykola & $\mathrm{x}$ & & & \\
\hline & Third & Tymofiy & $\mathrm{x}$ & & & \\
\hline \multirow[t]{3}{*}{13} & First & Onysym & & & & $\mathrm{x}$ \\
\hline & Second & Svyatoslav & & & & \\
\hline & Third & Andrusia & & & & \\
\hline \multirow[t]{3}{*}{14} & First & Roksolana & & $\mathrm{x}$ & & \\
\hline & Second & Orianna & $\mathrm{x}$ & & & $\mathrm{x}$ \\
\hline & Third & Orysia & & & & \\
\hline \multirow[t]{3}{*}{15} & First & Irka & & & & \\
\hline & Second & Viktoria & & & & \\
\hline & Third & Liza & $\mathrm{x}$ & & & \\
\hline
\end{tabular}


Table 7

Summary of Reported Loss for Families 1-10

\begin{tabular}{|c|c|c|c|c|c|c|c|}
\hline Family & Generation & Pseudonym & $\begin{array}{c}\text { Mass of } \\
\text { Ukrainians }\end{array}$ & $\begin{array}{c}\text { Family } \\
\text { members }\end{array}$ & $\begin{array}{l}\text { Traditional } \\
\text { way of life }\end{array}$ & $\begin{array}{l}\text { Culture- } \\
\text { ethnicity }\end{array}$ & Men \\
\hline \multirow[t]{3}{*}{1} & First & Tamara & $\bar{x}$ & $\mathrm{x}$ & $\mathrm{x}$ & $\mathrm{x}$ & $\mathrm{x}$ \\
\hline & Second & Lesia & $\mathrm{x}$ & $\mathrm{x}$ & $\mathrm{x}$ & $\mathrm{x}$ & \\
\hline & Third & Halyna & $\mathrm{x}$ & $\mathrm{x}$ & $\mathrm{x}$ & $\mathrm{x}$ & \\
\hline \multirow[t]{3}{*}{2} & First & Vira & $\mathrm{x}$ & $\mathrm{x}$ & $\mathrm{x}$ & & $\mathrm{x}$ \\
\hline & Second & Anton & $\mathrm{x}$ & $\mathrm{x}$ & $\mathrm{x}$ & & $\mathrm{x}$ \\
\hline & Third & Ruslana & $\mathrm{x}$ & $\mathrm{x}$ & $\mathrm{x}$ & $\mathrm{x}$ & $\mathrm{x}$ \\
\hline \multirow[t]{3}{*}{3} & First & Yulia & $\mathrm{x}$ & & $\mathrm{x}$ & $\mathrm{x}$ & \\
\hline & Second & Mykhailo & & & $\mathrm{x}$ & & \\
\hline & Third & Myroslava & $\mathrm{x}$ & $\mathrm{x}$ & $\mathrm{x}$ & $\mathrm{x}$ & \\
\hline \multirow[t]{3}{*}{4} & First & Olena & $\mathrm{x}$ & $\mathrm{x}$ & $\mathrm{x}$ & & \\
\hline & Second & Danylo & $\mathrm{x}$ & & $\mathrm{x}$ & $\mathrm{x}$ & \\
\hline & Third & Ivan & $\mathrm{x}$ & & & & \\
\hline \multirow[t]{3}{*}{5} & First & Anastasia & $\mathrm{x}$ & $\mathrm{x}$ & $\mathrm{x}$ & $\mathrm{x}$ & $\mathrm{x}$ \\
\hline & Second & Oleksandra & $\mathrm{x}$ & $\mathrm{x}$ & $\mathrm{x}$ & & \\
\hline & Third & Pavlo & $\mathrm{x}$ & & & & \\
\hline \multirow[t]{3}{*}{6} & First & Stephania & $\mathrm{x}$ & $\mathrm{x}$ & $\mathrm{x}$ & & $\mathrm{x}$ \\
\hline & Second & Pylyp & $\mathrm{x}$ & $\mathrm{x}$ & $\mathrm{x}$ & $\mathrm{x}$ & $\mathrm{x}$ \\
\hline & Third & Mystyslav & $\mathrm{x}$ & & $\mathrm{x}$ & $\mathrm{x}$ & \\
\hline \multirow[t]{3}{*}{7} & First & Kalyna & $\mathrm{x}$ & $\mathrm{x}$ & $\mathrm{x}$ & & \\
\hline & Second & Volodymyr & $\mathrm{x}$ & $\mathrm{x}$ & $\mathrm{x}$ & $\mathrm{x}$ & $\mathrm{x}$ \\
\hline & Third & Sofia & $\mathrm{x}$ & $\mathrm{x}$ & $\mathrm{x}$ & $\mathrm{x}$ & $\mathrm{x}$ \\
\hline \multirow[t]{3}{*}{8} & First & Hafia & $\mathrm{x}$ & $\mathrm{x}$ & $\mathrm{x}$ & & $\mathrm{x}$ \\
\hline & Second & Bohdana & $\mathrm{x}$ & $\mathrm{x}$ & $\mathrm{x}$ & & \\
\hline & Third & Vasylyna & & & $\mathrm{x}$ & & \\
\hline \multirow[t]{3}{*}{9} & First & Petrusia & $\mathrm{x}$ & $\mathrm{x}$ & $\mathrm{x}$ & & \\
\hline & Second & Nazar & $\mathrm{x}$ & $\mathrm{x}$ & $\mathrm{x}$ & $\mathrm{x}$ & \\
\hline & Third & Savelia & $\mathrm{x}$ & $\mathrm{x}$ & $\mathrm{x}$ & & \\
\hline \multirow[t]{3}{*}{10} & First & Luba & $\mathrm{x}$ & $\mathrm{x}$ & $\mathrm{x}$ & & $\mathrm{x}$ \\
\hline & Second & Roman & $\mathrm{x}$ & & $\mathrm{x}$ & & \\
\hline & Third & Yaroslava & $\mathrm{x}$ & & $\mathrm{x}$ & & \\
\hline
\end{tabular}


Table 8

Summary of Reported Loss for Families 11-15

\begin{tabular}{|c|c|c|c|c|c|c|c|}
\hline Family & Generation & Pseudonym & $\begin{array}{c}\text { Mass of } \\
\text { Ukrainians }\end{array}$ & $\begin{array}{c}\text { Family } \\
\text { members }\end{array}$ & $\begin{array}{l}\text { Traditional } \\
\text { way of life }\end{array}$ & $\begin{array}{l}\text { Culture- } \\
\text { ethnicity }\end{array}$ & Men \\
\hline \multirow[t]{3}{*}{11} & First & Lev & $\mathrm{x}$ & $\mathrm{x}$ & $\mathrm{x}$ & & \\
\hline & Second & Liudmila & $\mathrm{x}$ & $\mathrm{x}$ & $\mathrm{x}$ & & \\
\hline & Third & Petro & $\mathrm{x}$ & $\mathrm{x}$ & $\mathrm{x}$ & & \\
\hline \multirow[t]{3}{*}{12} & First & Marianna & $\mathrm{x}$ & $\mathrm{x}$ & $\mathrm{x}$ & & $\mathrm{x}$ \\
\hline & Second & Mykola & $\mathrm{x}$ & $\mathrm{x}$ & $\mathrm{x}$ & & $\mathrm{x}$ \\
\hline & Third & Tymofiy & $\mathrm{x}$ & $\mathrm{x}$ & & $\mathrm{x}$ & \\
\hline \multirow[t]{3}{*}{13} & First & Onysym & $\mathrm{x}$ & $\mathrm{x}$ & $\mathrm{x}$ & $\mathrm{x}$ & $\mathrm{x}$ \\
\hline & Second & Svyatoslav & $\mathrm{x}$ & & $\mathrm{x}$ & $\mathrm{x}$ & \\
\hline & Third & Andrusia & $\mathrm{x}$ & & $\mathrm{x}$ & $\mathrm{x}$ & \\
\hline \multirow[t]{3}{*}{14} & First & Roksolana & $\mathrm{x}$ & $\mathrm{x}$ & $\mathrm{x}$ & $\mathrm{x}$ & \\
\hline & Second & Orianna & $\mathrm{x}$ & $\mathrm{x}$ & $\mathrm{x}$ & $\mathrm{x}$ & \\
\hline & Third & Orysia & $\mathrm{x}$ & $\mathrm{x}$ & $\mathrm{x}$ & & \\
\hline \multirow[t]{3}{*}{15} & First & Irka & $\mathrm{x}$ & & $\mathrm{x}$ & & $\mathrm{x}$ \\
\hline & Second & Viktoria & $\mathrm{x}$ & & $\mathrm{x}$ & & \\
\hline & Third & Liza & $\mathrm{x}$ & & $\mathrm{x}$ & & \\
\hline
\end{tabular}


Table 9

Summary of Reported Family Relations for Families 1-10

Strict-

controlling Fixation

Adjusted Maladjusted parenting on

Family Generation Pseudonym family family styles parents

\begin{tabular}{|c|c|c|c|c|c|c|}
\hline \multirow[t]{3}{*}{1} & First & Tamara & & $\mathrm{x}$ & & \\
\hline & Second & Lesia & & $\mathrm{x}$ & & \\
\hline & Third & Halyna & & $\mathrm{x}$ & $\mathrm{x}$ & $\mathrm{x}$ \\
\hline \multirow[t]{3}{*}{2} & First & Vira & & $\mathrm{x}$ & & \\
\hline & Second & Anton & & $\mathrm{x}$ & & \\
\hline & Third & Ruslana & & $\mathrm{x}$ & $\mathrm{x}$ & $\mathrm{x}$ \\
\hline \multirow[t]{3}{*}{3} & First & Yulia & $\mathrm{x}$ & & & \\
\hline & Second & Mykhailo & $\mathrm{x}$ & & & \\
\hline & Third & Myroslava & $\mathrm{x}$ & & & \\
\hline \multirow[t]{3}{*}{4} & First & Olena & $\mathrm{x}$ & & & \\
\hline & Second & Danylo & $\mathrm{x}$ & & & \\
\hline & Third & Ivan & $\mathrm{x}$ & & & \\
\hline \multirow[t]{3}{*}{5} & First & Anastasia & $\mathrm{x}$ & & & \\
\hline & Second & Oleksandra & $\mathrm{x}$ & & & \\
\hline & Third & Pavlo & $\mathrm{x}$ & & & \\
\hline \multirow[t]{3}{*}{6} & First & Stephania & $\mathrm{x}$ & & & \\
\hline & Second & Pylyp & $\mathrm{x}$ & & & \\
\hline & Third & Mystyslav & $\mathrm{x}$ & & & \\
\hline \multirow[t]{3}{*}{7} & First & Kalyna & & $\mathrm{x}$ & & \\
\hline & Second & Volodymyr & & $\mathrm{x}$ & & \\
\hline & Third & Sofia & & $\mathrm{x}$ & $\mathrm{x}$ & $\mathrm{x}$ \\
\hline \multirow[t]{3}{*}{8} & First & Hafia & $\mathrm{x}$ & & & \\
\hline & Second & Bohdana & $\mathrm{x}$ & & & \\
\hline & Third & Vasylyna & $\mathrm{x}$ & & & \\
\hline \multirow[t]{3}{*}{9} & First & Petrusia & $\mathrm{x}$ & & & \\
\hline & Second & Nazar & $\mathrm{x}$ & & & \\
\hline & Third & Savelia & $\mathrm{x}$ & & & \\
\hline \multirow[t]{3}{*}{10} & First & Luba & $\mathrm{x}$ & & & \\
\hline & Second & Roman & $\mathrm{x}$ & & & \\
\hline & Third & Yaroslava & $\mathrm{x}$ & & & \\
\hline
\end{tabular}


Table 10

Summary of Reported Family Relations for Families 11-15

\begin{tabular}{|c|c|c|c|c|c|c|}
\hline Family & Generation & Pseudonym & $\begin{array}{l}\text { Adjusted } \\
\text { family }\end{array}$ & $\begin{array}{l}\text { Maladjusted } \\
\text { family }\end{array}$ & $\begin{array}{c}\text { Strict- } \\
\text { controlling } \\
\text { parenting } \\
\text { styles }\end{array}$ & $\begin{array}{c}\text { Fixation } \\
\text { on } \\
\text { parents }\end{array}$ \\
\hline \multirow[t]{3}{*}{11} & First & Lev & $\mathrm{x}$ & & & \\
\hline & Second & Liudmila & $\mathrm{x}$ & & & \\
\hline & Third & Petro & $\mathrm{x}$ & & & \\
\hline \multirow[t]{3}{*}{12} & First & Marianna & $\mathrm{x}$ & & & \\
\hline & Second & Mykola & $\mathrm{x}$ & & & \\
\hline & Third & Tymofiy & $\mathrm{x}$ & & & \\
\hline \multirow[t]{3}{*}{13} & First & Onysym & $\mathrm{x}$ & & & \\
\hline & Second & Svyatoslav & $\mathrm{x}$ & & & \\
\hline & Third & Andrusia & $\mathrm{x}$ & & & \\
\hline \multirow[t]{3}{*}{14} & First & Roksolana & $\mathrm{x}$ & & & \\
\hline & Second & Orianna & $\mathrm{x}$ & & & \\
\hline & Third & Orysia & $\mathrm{x}$ & & & \\
\hline \multirow[t]{3}{*}{15} & First & Irka & $\mathrm{x}$ & & & \\
\hline & Second & Viktoria & $\mathrm{x}$ & & & \\
\hline & Third & Liza & $\mathrm{x}$ & & & \\
\hline
\end{tabular}


Table 11

Summary of Reported Intra-Familial Communication Strategies for Families 1-10

\begin{tabular}{|c|c|c|c|c|c|c|}
\hline \multirow[b]{3}{*}{ Family } & \multirow[b]{3}{*}{ Generation } & \multirow[b]{3}{*}{ Pseudonym } & \multicolumn{3}{|c|}{$\begin{array}{c}\text { Style of intra-familial } \\
\text { communication }\end{array}$} & \multirow{3}{*}{$\begin{array}{l}\text { Importance } \\
\text { of family } \\
\text { discussion }\end{array}$} \\
\hline & & & & Grandparent & & \\
\hline & & & Open & conveyor & $\begin{array}{l}\text { Limited- } \\
\text { none }\end{array}$ & \\
\hline \multirow[t]{3}{*}{1} & First & Tamara & & & $\mathrm{x}$ & \\
\hline & Second & Lesia & & & $\mathrm{x}$ & \\
\hline & Third & Halyna & & & $\mathrm{x}$ & \\
\hline \multirow[t]{3}{*}{2} & First & Vira & & & $\mathrm{x}$ & \\
\hline & Second & Anton & & & $\mathrm{x}$ & \\
\hline & Third & Ruslana & & & $\mathrm{x}$ & \\
\hline \multirow[t]{3}{*}{3} & First & Yulia & $\mathrm{x}$ & & & \\
\hline & Second & Mykhailo & $\mathrm{x}$ & & & \\
\hline & Third & Myroslava & $\mathrm{x}$ & & & $\mathrm{x}$ \\
\hline \multirow[t]{3}{*}{4} & First & Olena & $\mathrm{x}$ & & & \\
\hline & Second & Danylo & $\mathrm{x}$ & & & \\
\hline & Third & Ivan & $\mathrm{x}$ & & & $\mathrm{x}$ \\
\hline \multirow[t]{3}{*}{5} & First & Anastasia & & $\mathrm{x}$ & & \\
\hline & Second & Oleksandra & & $\mathrm{x}$ & & \\
\hline & Third & Pavlo & & $\mathrm{x}$ & & \\
\hline \multirow[t]{3}{*}{6} & First & Stephania & $\mathrm{x}$ & & & $\mathrm{x}$ \\
\hline & Second & Pylyp & $\mathrm{x}$ & & & $\mathrm{x}$ \\
\hline & Third & Mystyslav & $\mathrm{x}$ & & & $\mathrm{x}$ \\
\hline \multirow[t]{3}{*}{7} & First & Kalyna & $\mathrm{x}$ & & & \\
\hline & Second & Volodymyr & $\mathrm{x}$ & & & $\mathrm{x}$ \\
\hline & Third & Sofia & $\mathrm{x}$ & & & \\
\hline \multirow[t]{3}{*}{8} & First & Hafia & & $\mathrm{x}$ & & \\
\hline & Second & Bohdana & & $\mathrm{x}$ & & \\
\hline & Third & Vasylyna & & $\mathrm{x}$ & & \\
\hline \multirow[t]{3}{*}{9} & First & Petrusia & $\mathrm{x}$ & & & \\
\hline & Second & Nazar & $\mathrm{x}$ & & & $\mathrm{x}$ \\
\hline & Third & Savelia & $\mathrm{x}$ & & & $\mathrm{x}$ \\
\hline \multirow[t]{3}{*}{10} & First & Luba & & $\mathrm{x}$ & & \\
\hline & Second & Roman & & $\mathrm{x}$ & & \\
\hline & Third & Yaroslava & & $\mathrm{x}$ & & \\
\hline
\end{tabular}


Table 12

Summary of Reported Intra-Familial Communication Strategies for Families 11-15

\begin{tabular}{|c|c|c|c|c|c|c|}
\hline \multirow[b]{3}{*}{ Family } & \multirow[b]{3}{*}{ Generation } & \multirow[b]{3}{*}{ Pseudonym } & \multicolumn{3}{|c|}{$\begin{array}{c}\text { Style of intra-familial } \\
\text { communication }\end{array}$} & \multirow{3}{*}{$\begin{array}{l}\text { Importance } \\
\text { of family } \\
\text { discussion }\end{array}$} \\
\hline & & & & Grandparent & & \\
\hline & & & Open & conveyor & $\begin{array}{c}\text { Limited- } \\
\text { none }\end{array}$ & \\
\hline \multirow[t]{3}{*}{11} & First & Lev & $\mathrm{x}$ & & & $\mathrm{x}$ \\
\hline & Second & Liudmila & $\mathrm{x}$ & & & \\
\hline & Third & Petro & $\mathrm{x}$ & & & $\mathrm{x}$ \\
\hline \multirow[t]{3}{*}{12} & First & Marianna & $\mathrm{x}$ & & & \\
\hline & Second & Mykola & $\mathrm{x}$ & & & $\mathrm{x}$ \\
\hline & Third & Tymofiy & $\mathrm{x}$ & & & $\mathrm{x}$ \\
\hline \multirow[t]{3}{*}{13} & First & Onysym & $\mathrm{x}$ & & & \\
\hline & Second & Svyatoslav & $\mathrm{x}$ & & & $\mathrm{x}$ \\
\hline & Third & Andrusia & $\mathrm{x}$ & & & $\mathrm{x}$ \\
\hline \multirow[t]{3}{*}{14} & First & Roksolana & $\mathrm{x}$ & & & \\
\hline & Second & Orianna & $\mathrm{x}$ & & & \\
\hline & Third & Orysia & $\mathrm{x}$ & & & $\mathrm{x}$ \\
\hline \multirow[t]{3}{*}{15} & First & Irka & & $\mathrm{x}$ & & \\
\hline & Second & Viktoria & & $\mathrm{x}$ & & \\
\hline & Third & Liza & & $\mathrm{x}$ & & \\
\hline
\end{tabular}


Table 13

Summary of Reported Extra-Familial Communication Strategies for Families 1-10

\begin{tabular}{|c|c|c|c|c|c|c|}
\hline \multirow[b]{2}{*}{ Family } & \multirow[b]{2}{*}{ Generation } & \multirow[b]{2}{*}{ Pseudonym } & \multicolumn{3}{|c|}{ Extra-familial communication } & \multirow{2}{*}{$\begin{array}{c}\text { Importance of } \\
\text { extra-familial } \\
\text { discussion }\end{array}$} \\
\hline & & & In-depth & Limited & None & \\
\hline \multirow[t]{3}{*}{1} & First & Tamara & & & $\mathrm{x}$ & \\
\hline & Second & Lesia & & & $\mathrm{x}$ & \\
\hline & Third & Halyna & & & $\mathrm{x}$ & \\
\hline \multirow[t]{3}{*}{2} & First & Vira & & & $\mathrm{x}$ & \\
\hline & Second & Anton & & & $\mathrm{x}$ & \\
\hline & Third & Ruslana & & & $\mathrm{x}$ & \\
\hline \multirow[t]{3}{*}{3} & First & Yulia & & $\mathrm{x}$ & & \\
\hline & Second & Mykhailo & $\mathrm{x}$ & & & \\
\hline & Third & Myroslava & $\mathrm{x}$ & & & $\mathrm{x}$ \\
\hline \multirow[t]{3}{*}{4} & First & Olena & $\mathrm{x}$ & & & $\mathrm{x}$ \\
\hline & Second & Danylo & $\mathrm{x}$ & & & $\mathrm{x}$ \\
\hline & Third & Ivan & $\mathrm{x}$ & & & $\mathrm{x}$ \\
\hline \multirow[t]{3}{*}{5} & First & Anastasia & & & $\mathrm{x}$ & \\
\hline & Second & Oleksandra & & & $\mathrm{x}$ & \\
\hline & Third & Pavlo & & & $\mathrm{x}$ & \\
\hline \multirow[t]{3}{*}{6} & First & Stephania & & & $\mathrm{x}$ & \\
\hline & Second & Pylyp & & & $\mathrm{x}$ & \\
\hline & Third & Mystyslav & & & $\mathrm{x}$ & \\
\hline \multirow[t]{3}{*}{7} & First & Kalyna & & & $\mathrm{x}$ & \\
\hline & Second & Volodymyr & & $\mathrm{x}$ & & $\mathrm{x}$ \\
\hline & Third & Sofia & $\mathrm{x}$ & & & \\
\hline \multirow[t]{3}{*}{8} & First & Hafia & & & $\mathrm{x}$ & \\
\hline & Second & Bohdana & & $\mathrm{x}$ & & \\
\hline & Third & Vasylyna & $\mathrm{x}$ & & & $\mathrm{x}$ \\
\hline \multirow[t]{3}{*}{9} & First & Petrusia & & $\mathrm{x}$ & & \\
\hline & Second & Nazar & & & $\mathrm{x}$ & \\
\hline & Third & Savelia & & $\mathrm{x}$ & & \\
\hline \multirow[t]{3}{*}{10} & First & Luba & & $\mathrm{x}$ & & \\
\hline & Second & Roman & & $\mathrm{x}$ & & \\
\hline & Third & Yaroslava & & & $\mathrm{x}$ & \\
\hline
\end{tabular}


Table 14

Summary of Reported Extra-Familial Communication Strategies for Families 11-15

\begin{tabular}{|c|c|c|c|c|c|c|}
\hline \multirow[b]{2}{*}{ Family } & \multirow[b]{2}{*}{ Generation } & \multirow[b]{2}{*}{ Pseudonym } & \multicolumn{3}{|c|}{ Extra-familial communication } & \multirow{2}{*}{$\begin{array}{l}\text { Importance of } \\
\text { extra-familial } \\
\text { discussion }\end{array}$} \\
\hline & & & In-depth & Limited & None & \\
\hline \multirow[t]{3}{*}{11} & First & Lev & & $\mathrm{x}$ & & \\
\hline & Second & Liudmila & & $\mathrm{x}$ & & \\
\hline & Third & Petro & $\mathrm{x}$ & & & $\mathrm{x}$ \\
\hline \multirow[t]{3}{*}{12} & First & Marianna & $\mathrm{x}$ & & & $\mathrm{x}$ \\
\hline & Second & Mykola & $\mathrm{x}$ & & & $\mathrm{x}$ \\
\hline & Third & Tymofiy & $\mathrm{x}$ & & & $\mathrm{x}$ \\
\hline \multirow[t]{3}{*}{13} & First & Onysym & & $\mathrm{x}$ & & \\
\hline & Second & Svyatoslav & $\mathrm{x}$ & & & $\mathrm{x}$ \\
\hline & Third & Andrusia & & $\mathrm{x}$ & & \\
\hline \multirow[t]{3}{*}{14} & First & Roksolana & $\mathrm{x}$ & & & \\
\hline & Second & Orianna & $\mathrm{x}$ & & & $\mathrm{x}$ \\
\hline & Third & Orysia & $\mathrm{x}$ & & & $\mathrm{x}$ \\
\hline \multirow[t]{3}{*}{15} & First & Irka & & & $\mathrm{x}$ & \\
\hline & Second & Viktoria & & & $\mathrm{x}$ & \\
\hline & Third & Liza & $\mathrm{x}$ & & & \\
\hline
\end{tabular}




\section{Appendix}

\section{Interview Guide}

1. What does being Ukrainian mean to you?

2. What does the Holodomor mean to you?

3. Has the Holodomor ever come up as a topic of discussion in your family?

4. Have you had discussion about the Holodomor outside of the family?

5. How has the Holodomor impacted your life and that of your family? Or, How might your life be different had the Holodomor not occurred?

6. How do you think that the Holodomor has affected Ukrainians?

7. How do you think that the Holodomor has affected Ukraine?

8. How would Ukrainians/Ukraine be different had the Holodomor not occurred?

9. What emotion(s) comes to mind regarding the Holodomor?

10. What do you want future generations to know about the Holodomor?

11. Is there anything else you would like to add?

\section{Extra questions for the first generation}

1. Can you tell me about you at the time when the Holodomor occurred?

2. Do you remember what you were thinking at the time?

3. How did you survive the Holodomor? 